Universidad de Lima

Facultad de Comunicación

Carrera de Comunicación

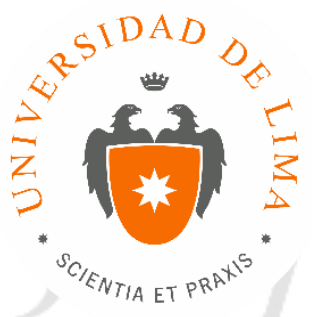

\title{
ANÁLISIS DE LA OFERTA EXPERIENCIAL DEL RECORRIDO NOCTURNO DEL MUSEO FORTALEZA REAL FELIPE EN RELACIÓN \\ CON SU VISIBILIDAD, IMPACTO Y ACEPTACIÓN ENTRE LOS PÚBLICOS VISITANTES
}

Tesis para optar el Título Profesional de Licenciado en Comunicación

\section{Olga María Magdalena Talledo Alvarado}

Código 20121256

Asesor

Manuel Santillán Vásquez

$$
\text { Lima - Perú }
$$

Agosto de 2018 


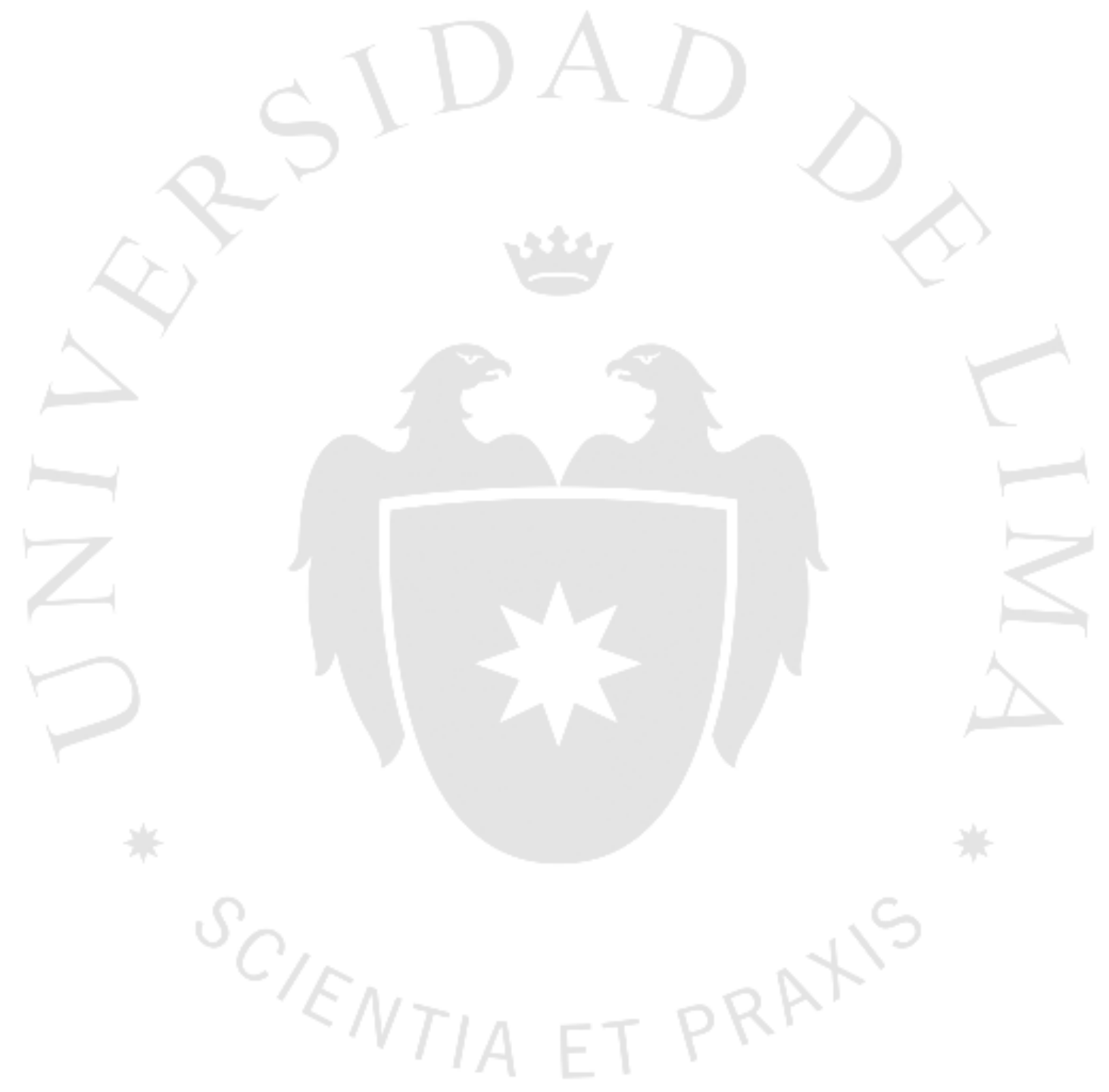




\section{ANÁLISIS DE LA OFERTA EXPERIENCIAL DEL RECORRIDO NOCTURNO DEL MUSEO FORTALEZA REAL FELIPE EN RELACIÓN CON SU VISIBILIDAD, IMPACTO Y ACEPTACIÓN ENTRE LOS PÚBLICOS VISITANTES}




\section{TABLA DE CONTENIDO}

\section{INTRODUCCIÓN..............................................................99}

II.MARKETING APLICADO A LA CULTURA ...................... 13

2.1.Marketing cultural ................................................................ 13

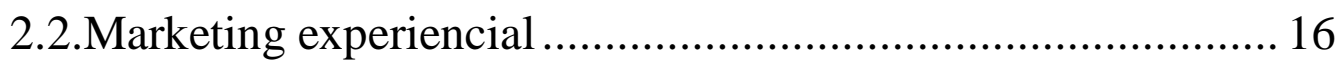

2.2.1Factores envolventes en la experiencia ................................ 18

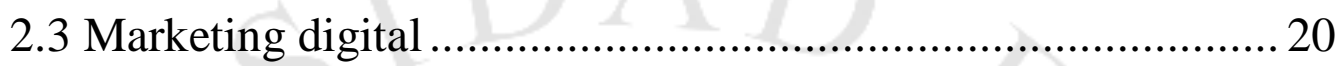

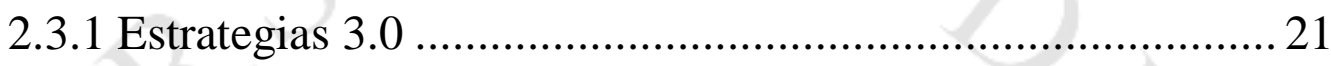

2.3.2 Ventajas del marketing digital .......................................... 21

2.4 Perfil de visitantes a museos.................................................. 24

2.4.1Perfil del público digital seguidores de museos ................... 27

III.ACCIONES ESTRATÉGICAS PARA LA PROMOCIÓN DE EXPERIENCIAS DE LAS PRINCIPALES INSTITUCIONES

CULTURALES EN EL MUNDO........................................30

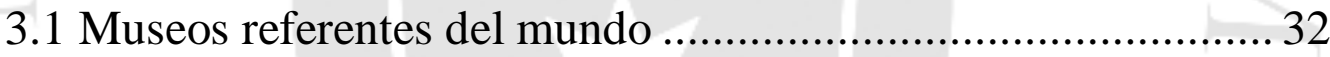

3.1.1Museo MoMA - Estados Unidos ................................................. 33

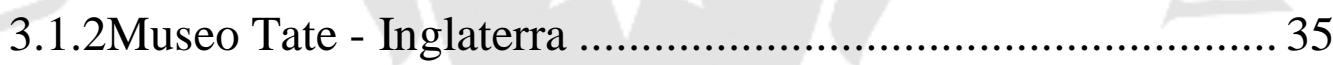

3.1.3Museo Louvre - Francia.......................................................... 37

3.1.4Museo de Historia Natural - Estados Unidos ......................... 39

IV.MUSEOS EN EL PERÚ ....................................................... 42

4.1 El museo Fortaleza Real Felipe .............................................4 44

V.METODOLOGÍA ............................................................ 48

5.1 El problema de la investigación ............................................... 48

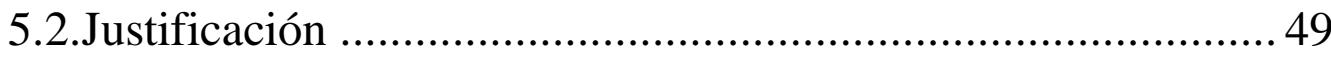

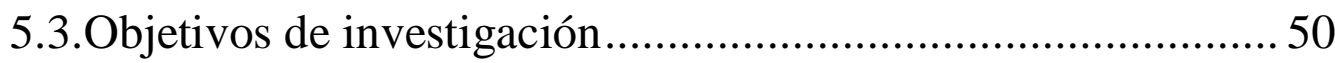

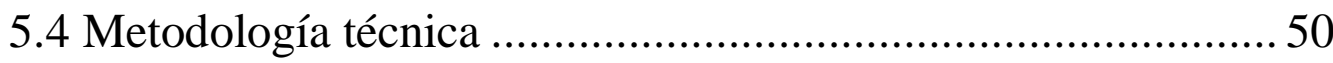

5.5 Técnica de recolección y aplicación .........................................52

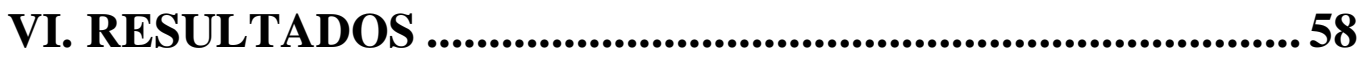


6.1 El museo en los ojos del público 58

6.2 La visibilidad del museo Fortaleza Real Felipe como consecuencia de las acciones de comunicación en Facebook.......................... 60

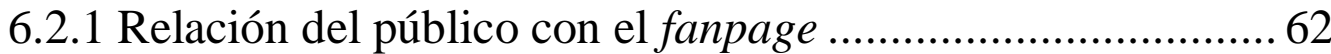

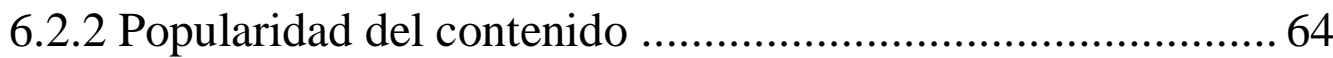

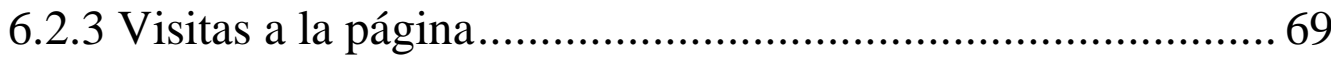

6.2.4 Estrategias a futuro y beneficios del tour de noche ............. 70

6.3 Afluencia al recorrido nocturno desde la publicación de contenido

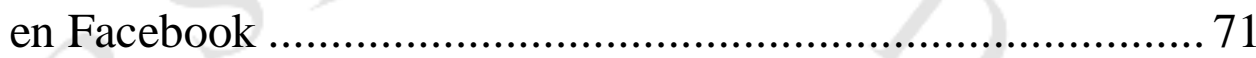

6.4 Aceptación y la experiencia del tour nocturno ......................... 72

VII. DISCUSIÓN..........................................................................8 80

VIII. CONCLUSIONES..............................................................91

IX. RECOMENDACIONES.............................................96

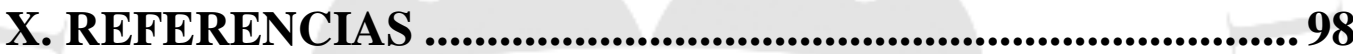




\section{ÍNDICE DE TABLAS}

Tabla 2. 1 Comparación en medios digitales de museos limeños ................................. 28

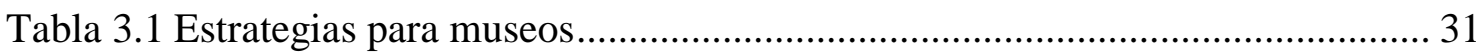

Tabla 3.2 Resumen de actividad en medios digitales MoMA ....................................... 34

Tabla 3.3 Resumen de acciones y actividades que realizan en el MoMA..................... 35

Tabla 3.4 Resumen de actividad en medios digitales Tate .......................................... 36

Tabla 3.5 Resumen de acciones experienciales Tate ..................................................... 36

Tabla 3.6 Resumen de actividad en medios digitales Louvre ..................................... 38

Tabla 3.7 Resumen de acciones y actividades que realiza Louvre ............................... 38

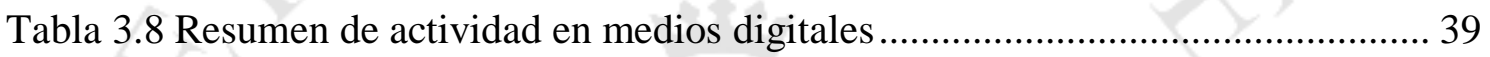

Tabla 3.9 Resumen de actividades y acciones que realiza ......................................... 41

Tabla 4.1 Resumen de Museo Fortaleza Real Felipe .................................................. 47

Tabla 5.1 Detalle de la muestra 1era encuesta en Real Felipe ...................................... 55

Tabla 5.2 Detalle de la muestra 2da encuesta en Real Felipe ....................................... 56

Tabla 6.3 Detalle de las fuentes de conocimiento del tour en la 1era y 2 da muestra..... 62

Tabla 6.4 Detalle de la información que le interesa a los visitantes en la fanpage ........ 63

Tabla 6.5 Detalle de comentarios más resaltantes de las publicaciones relacionadas al

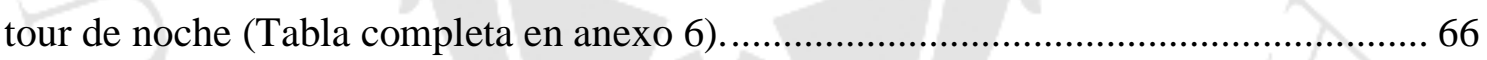

Tabla 6.6 Aspectos del tour evaluados en la primera muestra .................................... 75

Tabla 6.7 Número de respuestas de emociones seleccionadas en la muestra.................. 76

Tabla 6.8 Detalle de las partes favoritas de los visitantes del tour ................................ 78

Tabla 6.9 Detalle de la experiencia vivida por los visitantes en la 1era y 2 da muestra. 78 


\section{ÍNDICE DE FIGURAS}

Figura 6.1 Detalle de edad y sexo de fans del Facebook del Real Felipe 58

Figura 6.2 Detalle de los museos en Lima que siguen en Facebook los visitantes 60

Figura 6.3 Publicación "dato curioso" 30 de octubre 2016 63

Figura 6.4 Publicación 27 de octubre 2017 del tour nocturno... 68

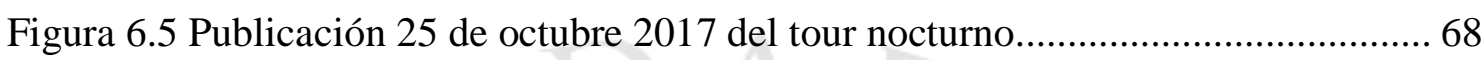

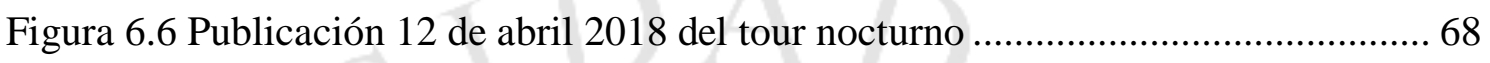

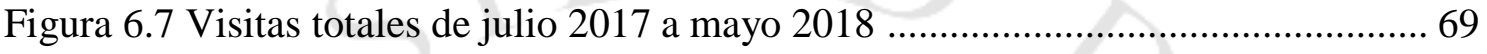

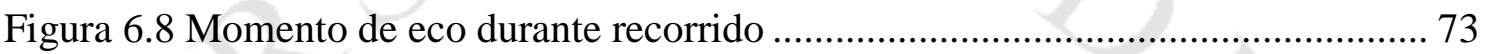

Figura 6.9 Visitantes en el Torreón de la Reina ....................................................... 74

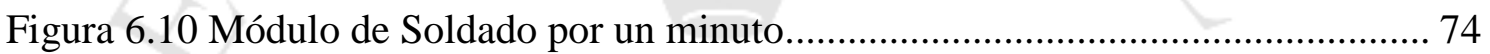

Figura 6.11 Sentidos que involucró el tour de noche según la experiencia sensorial de visitantes. 


\section{ÍNDICE DE ANEXOS}

Anexo 1: Guía de preguntas al coordinador de marketing ........................................ 104

Anexo 2: Transcripción de entrevista al coordinador de marketing ............................. 105

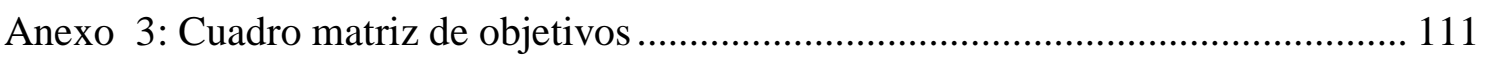

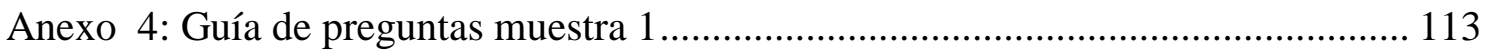

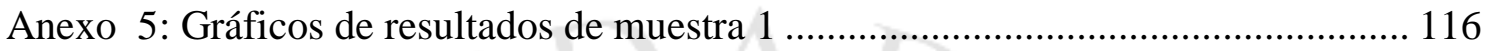

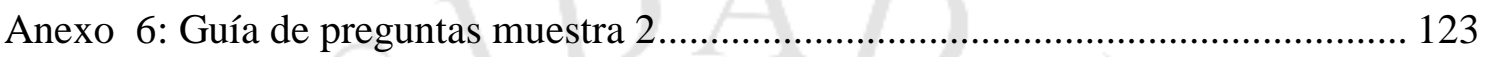

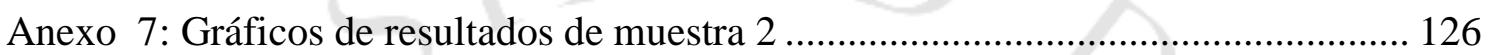

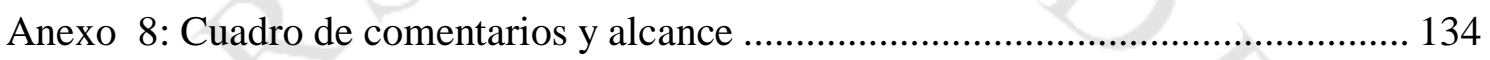

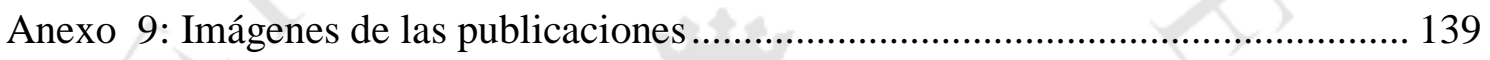




\section{INTRODUCCIÓN}

El Museo Fortaleza Real Felipe está ubicado en la Provincia Constitucional del Callao y pertenece a la red de museos del Ejército del Perú. Actualmente ofrece un recorrido nocturno en fechas específicas de cada mes, el cual es comunicado por medio de su fanpage. El recorrido o tour ha adquirido mayor popularidad desde que el museo es promovido vía medios digitales, generando un mayor número de asistentes en cada fecha. En esta investigación se determinará la visibilidad que ha obtenido el recorrido nocturno del museo mediante su promoción en Facebook, así como el impacto y la aceptación de la oferta experiencial entre los públicos visitantes.

Muchos cuestionamientos surgen a raíz de este tema, por lo cual se desea hallar, en primer lugar, los posibles factores que influyen de manera positiva o negativa en las iniciativas de promoción del museo en Facebook para obtener visibilidad y aceptación entre los públicos visitantes. Finalmente, para continuar con las interrogantes relacionadas con la red social donde está presente la institución, se busca hallar las variables que determinan el aumento de visitantes a un museo mediante el contenido publicado en Facebook, con el fin de conocer por qué el número de asistentes a un tour se incrementa al implementar dichas acciones. Por el lado experiencial nos es importante identificar aquellos aspectos que llevan a la aceptación del tour y aquello que podría significar puntos de mejora de la oferta.

Hoy en día, los visitantes a museos e instituciones culturales desean vivir una experiencia particular y ser partícipes de un evento único. Los consumidores de cultura han cambiado y buscan realizar actividades que no hayan hecho anteriormente, vivir experiencias nunca imaginadas y disfrutar de un buen momento con amigos o familia. Sobre la base de esta realidad, surgió la curiosidad por conocer más sobre las nuevas exigencias que se vienen dando tanto desde los públicos como desde las instituciones culturales, y en la forma que buscan obtener la aceptación de sus productos y comunicarlos mediante redes sociales para sobresalir en el mercado museístico. Se toma como caso de estudio el recorrido o tour nocturno del Museo Fortaleza Real Felipe, ya que es uno de los pocos museos en Lima que está aplicando el marketing experiencial, junto con otras estrategias, para promover el evento que ofrece. Además, es interesante analizar este museo ya que sus limitaciones presupuestales no le permiten realizar 
acciones más penetrantes y agresivas en temas comunicacionales, como sí lo hacen otras instituciones; sin embargo, ha podido hacerse notar a pesar de estas barreras.

Para poder resolver el problema de la investigación se tomará como base varios conceptos relacionados con el marketing. En primer lugar figura el marketing cultural. Este es un aspecto importante en la investigación, ya que se trata de un museo que desarrolla diversas acciones relacionadas con este concepto, con el fin de facilitar el intercambio de los productos culturales que posee la institución con los diversos públicos. Tal como menciona Jiménez (2011), esto debe darse con la finalidad de que sea satisfactorio para ambas partes mediante el desarrollo, la valoración y la promoción que el sector cultural realiza por medio de sus tours, eventos y exhibiciones. De esta manera, se busca democratizar los servicios y generar interés entre las audiencias para que puedan asistir de manera más concurrida a instituciones que promueven la cultura y la historia del país.

El marketing experiencial involucra sentidos y emociones; este se tomará en cuenta debido a que es una de las más importantes herramientas ligadas al marketing que se relacionan con esta investigación, puesto que es enfatizado en la experiencia que brinda el tour nocturno a todos los visitantes y todos los aspectos que este abarca. Se tomará como referencia los factores experienciales de Schmitt (1999), que permiten crear ventajas competitivas entre un museo y otro mediante los Módulos Experienciales Estratégicos (MEE) —en los cuales se propone lineamientos para gestionar las experiencias de los asistentes-; Schmitt menciona el Módulo de sensaciones, el cual involucra los sentidos; el Módulo de sentimientos, desde el que se evalúa qué emociones se han sentido; el Módulo de pensamientos, el cual se relaciona con las experiencias cognitivas e intelectuales recibidas; el Módulo de actuaciones, en que se muestran otras formas de desarrollar actividades diarias; y el Módulo de relaciones, el cual permite crear conexión entre el visitante, su yo interior, la cultura y otras personas.

Además de los Módulos de Schmitt para evaluar la experiencia del recorrido, se consideran los diez componentes de Lindstrom (2005), que permitirán ahondar en la propuesta del tour de forma más profunda, para hallar los aspectos que están permitiendo construir la experiencia en sí. Estos componentes giran alrededor de crear sentidos, establecer lazos con la institución y fortalecer la relación visitante-experiencia. De esta manera, se busca generar una experiencia sólida y estable. Considerar al público como seres emocionales con el fin de ofrecerles más que un producto cultural, también 
experiencias sensoriales, es uno de los puntos que se enfatizan en el tema del marketing experiencial, ya que los asistentes están en la búsqueda de un elemento diferencial para poder seleccionar la institución a visitar.

Sumado a ello, al tratarse de una investigación que involucra Facebook, se aplican conceptos de marketing digital y net sentiment, especialmente como métrica usada para evaluar la percepción positiva o negativa sobre el Real Felipe en redes sociales, mediante las interacciones y comentarios. Este análisis es un aporte para evaluar la oferta experiencial junto con la promoción en Facebook que se realiza sobre la misma, con el fin de obtener visibilidad entre los usuarios. Estos son quienes se convierten en potenciales visitantes y por medio de ellos se pueden conocer nuevos aspectos de mejora para los recorridos del museo, por lo que conocer su comportamiento resulta beneficioso para la aplicación de distintas estrategias por parte de la organización. Adicionalmente, en la investigación se ahondará en las cuatro motivaciones que tienen los visitantes por asistir a un evento, las cuales Soydanbay (2017) menciona en su artículo Undertourism: How to Make Archaeological Sites and Museums More Attractive as Destinations, las cuales son: motivación social, motivación intelectual, motivación emocional y motivación espiritual. Se complementará también con el proceso de decisión para escoger el lugar a visitar basado en el Momento Cero de la Verdad.

Esta investigación está relacionada con un museo en el Callao, aunque actualmente existen otros casos de museos que están promoviendo sus productos culturales de diversas formas. Al respecto, también se consideró relevante indagar referentes museísticos en el mundo, para conocer las estrategias que aplican con respecto de la experiencia y acciones que toman para atraer al público y generar la revisita. Mediante ello, se obtiene un panorama más amplio de lo que otras instituciones vienen realizando con el fin de evaluar qué resulta efectivo y adaptable a las condiciones locales.

La selección de la oferta experiencial del recorrido nocturno como caso de análisis junto con la promoción en Facebook en relación con su visibilidad y aceptación entre los públicos visitantes se debió al importante aporte académico que la investigación brindaría para futuros estudios de publicidad y marketing experiencial, ya que se muestra la necesidad de hacer converger varios aspectos comunicacionales y de marketing para implementar nuevas acciones que permitan ofrecer tours y eventos 
culturales integrales. Sumado a ello, la investigación toma un caso práctico local que permitirá conocer más a fondo la realidad de la institución con respecto a la valoración que tienen los visitantes acerca del recorrido nocturno, para brindar un aporte al sector museístico del país, puesto que poseer mayor información del sector cultural nacional trae beneficios tales como el turismo local y extranjero, la democratización de la educación y el incremento de puestos de trabajo.

El objetivo general de la investigación es determinar el grado de visibilidad que ha obtenido el recorrido nocturno del Museo Fortaleza Real Felipe mediante el contenido publicado en Facebook, así como el impacto y la aceptación de la oferta experiencial entre los públicos visitantes. Para resolver el objetivo general, se plantean tres objetivos específicos: el primero es determinar si las acciones en Facebook y la gestión han favorecido la visibilidad del Museo Fortaleza Real Felipe; el segundo objetivo es identificar el nivel de afluencia medido en el número de visitantes al recorrido nocturno desde que se iniciaron las actividades en Facebook; y el último objetivo es identificar la aceptación y la experiencia obtenida con la oferta del recorrido nocturno.

Para finalizar, se resalta la visibilidad lograda por el museo en nuevas audiencias mediante el fanpage y la aceptación de la oferta experiencial por parte de los visitantes. Sin embargo, aún existen aspectos a reforzar para lograr que la experiencia cumpla con todos los componentes de la rueda experiencial que Lindstrom (2005) menciona para la construcción de una experiencia sólida. En cuanto a los temas comunicacionales, las acciones en Facebook han logrado penetrar en nuevos visitantes, aunque la forma en que llega al público es monótona y no motiva a los usuarios a interactuar con el contenido de forma constante. Pese a ello, el museo continúa realizando las acciones ya pauteadas, para mantener el incremento constante de visitantes mes a mes. 


\section{MARKETING APLICADO A LA CULTURA}

\subsection{Marketing cultural}

El marketing busca atraer nuevos consumidores, prometiéndoles un valor superior, reteniendo a los consumidores actuales e identificando las necesidades de las personas, y buscando soluciones que sean rentables (Armstrong, 2015).

Sin embargo, Colbert (2003) sostiene que el concepto tradicional del marketing no puede aplicarse para el arte, ya que el producto artístico no existe para satisfacer una necesidad del mercado sino que se buscan consumidores atraídos por el producto cultural o artístico, por lo cual el marketing cultural se vuelve retador. Anteriormente, otros autores también ratificaban lo dicho por Colbert, ya que cayeron en cuenta que no se podía adaptar para esto el marketing tradicional en su totalidad.

Una de las primeras menciones acerca del marketing cultural fue realizada por Kotler a finales de la década de 1960, con la publicación de su Manual de marketing, en el cual ratifica que las organizaciones culturales producen bienes culturales, las cuales tienen como necesidad atraer a públicos y que esto se puede ver solucionado mediante un plan de marketing que sea adaptado a sus circunstancias y tipo de organización (Monistrol, 2009). Desde esa época se viene forjando el marketing cultural y se le define como el arte de alcanzar aquellos segmentos de mercado interesados en el producto, con el objetivo de poner en contacto al producto con un número suficiente de consumidores y alcanzar así los objetivos de acuerdo con la misión de la organización cultural (Colbert \& Cuadrado, 2003).

Pese a que el marketing cultural es aplicado para el arte y la cultura, cada producto es distintivo ya que promover una obra de teatro es distinto a vender un álbum de música, por mencionar solo un ejemplo. Gómez-Tarragona (2010) sostiene que el marketing cultural es aplicado por instituciones culturales tales como museos, ya que facilita el intercambio de relaciones colaborativas entre estos y los visitantes, es decir, permite ser un nexo entre la herencia cultural y la comunidad. Esto resulta sumamente útil para las organizaciones ya que el turismo es una fuente importante de ingresos para los países culturalmente atractivos. Jiménez \& Quero (2011) avalan lo dicho por Goméz-Tarragona y agrega que se facilita el intercambio con la finalidad de que sea 
satisfactorio para ambas partes mediante el desarrollo, la valoración y la promoción que el sector cultural realiza mediante sus productos culturales.

Los museos a su vez buscan generar difusión cultural, la cual es una actividad de transferencia de conocimiento y cuyo objetivo es permitir la accesibilidad del conjunto de la sociedad al uso y disfrute del patrimonio cultural en el ámbito nacional (Guglielmino, 2007). Por medio de esa accesibilidad, la comunicación de ideas alrededor del patrimonio que incluye obras de arte, documentos o restos arqueológicos se expande y llega a un mayor público, democratizando la cultura del país (Rusillo, 2013). En esta democratización, el marketing cultural se relaciona con la gestión cultural que realiza una institución para administrar los productos culturales — bien o servicio cultural- que posee con el objetivo de promover y realizar proyectos culturales para llegar a un mayor público.

En los museos, el número de visitantes que asiste a la institución puede incrementarse cada año mediante el plan de acción que se decida tomar. François (2016) enlista ciertos puntos que deberían poseer los museos para atraer a turistas nacionales y extranjeros. Como primer punto, François hace hincapié en la fuerte presencia de marca que debería tener el museo; con esta presencia se define la relevancia que tendría en el mercado museístico para crear conciencia de la importancia de la institución. Todo ello se construye mediante las actividades de marketing, tales como publicidad en paneles de calles concurridas o la publicidad en línea, las cuales permitirán alcanzar los propósitos de cada institución. Si se da de manera exitosa, los visitantes no recurrentes desarrollan un sentido de familiaridad con la institución y consideran al museo como una de las primeras opciones a visitar. Para lograr esto, François resalta la necesidad de tener una definida propuesta de valor para el mercado turístico y diferenciarse del resto de instituciones culturales para atraer a los visitantes, ya que se convierten en una de las prioridades dentro de la estrategia de marketing cultural.

En algunas ocasiones, la institución puede volcar todos sus esfuerzos en promover los programas públicos y centrarse en ellos, dejando de lado el valor de la institución, es decir la experiencia única que pueden encontrar visitando el lugar, lo cual se convierte en un error que podría afectar a la institución en sí. Se deben aprovechar las oportunidades que ofrece el mercado museístico y visualizar todo el panorama. François afirma que el turismo es un mercado heterogéneo, en el cual cada persona tiene gustos e intereses distintos, por lo que considerar diferentes canales de marketing para asegurar 
el mejor alcance a cada segmento es vital. Por medio de distintas herramientas, los museos pueden satisfacer a todos sus públicos aprovechando las opciones que poseen en cada medio.

Sin embargo, Malde (2013) difiere con François en el punto que menciona al museo como marca, ya que sostiene que el museo debe comprometer a los visitantes dando mayor énfasis al contenido que ofrece que a la presencia de marca. Malde lo argumenta con una aproximación de contenido ordenada, la cual se basa en evaluar los lugares y espacios en que su audiencia consume contenido, para poder lograr un compromiso entre ellos y el museo. Por ejemplo, el contenido digital está cambiando hábitos y patrones entre los públicos, lo cual genera que la institución cultural se centre en ofrecer la información e interactuar con ellos mediante esos espacios. El museo debe aprender a aplicar el marketing cultural en todos los canales que sean posibles, para tener mayores oportunidades de atracción a posibles visitantes.

Los diferentes aspectos que mencionan los autores son relevantes para que las instituciones culturales puedan ofrecer a los visitantes lo que ellos necesiten y estén así interesados por conocer sus servicios, continuando a su vez con su misión de educar de manera accesible y democratizada.

El marketing cultural orientado a los museos está obteniendo mayor protagonismo y se está convirtiendo en una herramienta estratégica y de planificación para aquellos, con la finalidad de generar mayor atracción, visitas y visibilidad. Mediante el marketing cultural también se desea innovar en estrategias que les permitan incrementar sus ingresos y exponerse frente a otros museos mediante canales pensados para cada público. El marketing cultural permite a los coordinadores y gestores culturales adaptar sus productos y servicios en experiencias y actividades que ningún otro lugar les pueda ofrecer, haciendo sinergia con otras plataformas y canales donde pueden alcanzar a más públicos, atrayendo así la atención de más visitantes y turistas.

Sin embargo, para poder cumplir de forma más eficiente y satisfactoria lo que se propongan como institución, los museos deben considerar añadir en sus acciones estrategias que involucren el marketing experiencial, ya que esto le da un valor agregado al impacto que genera sobre los visitantes y permite formar lazos más fuertes con ellos. 


\subsection{Marketing experiencial}

El marketing experiencial es una herramienta ligada al marketing convencional; actualmente se entiende como la forma en que conectamos con el público, y envuelve tanto los sentidos como las emociones (Schmitt, 1999). Esta es la relevancia de este concepto y la relación que genera con las audiencias para poder añadirle valor al museo.

Clairbone (2004) y Schmitt (1999) coinciden en ratificar que la experiencia total es esencial a la hora de crear valor para los consumidores, en la cual los elementos racionales y emocionales permiten la transformación de productos y servicios en algo memorable.

Las estrategias usadas por los museos hoy en día ya no se centran en audiencias meramente racionales, sino que han evolucionado para tocar la fibra emocional de los visitantes. Schmitt (2010) menciona que el valor no reside en el objeto o servicio de consumo, sino en el proceso de información sobre esos objetos, y que su valor se apoya en la experiencia del consumo.

Tomando en consideración lo dicho por Schmitt, resulta relevante que la experiencia incluya características dinámicas antes, durante y despúes de la experiencia, para así aceptar no solo bienes durables y no durables sino servicios más intangibles, ideas y eventos (Barrios, 2012; Holbrook \& Hirschman, 1982).

Las características en las estrategias a aplicar deben ir más allá de tratar de vender productos en sí; deben vender experiencias y sensaciones vinculadas a los productos, así lo detallan Muñoz \& Martí (2008). Los museos deben enfocar esfuerzos en vender de manera emocional y experiencial, yendo en sinergia con sus propósitos y objetivos, y manteniendo su rentabilidad.

El producto cultural que se desee ofrecer deber coincidir con las expectativas del visitante, y que este último pueda tener el control de la experiencia; de esta forma se espera que la relación que el visitante construya con el museo sea duradera, y se genere la revisita (Benediktsson, 2014). Para lograr eso, los gestores y directores de museos deben repensar la manera en que la marca debe conectarse con su audiencia y desarrollar los productos en torno a la relación que deseen tener con los clientes, en lugar de quedarse solo en la fase racional y no enfocarse en lo que ellos deseen vivir, sentir y apreciar en su visita a la institución. Para añadir a lo dicho por los autores 
anteriores, Linsdtrom (2006) engloba estas ideas afirmando que ahora tanto marcas como instituciones deben poseer la Proposición de venta holística (HSP, Holistic selling proposition), la cual implica no solo quedarse en términos tradicionales de lo que se es como institución, sino también adoptar características de la experiencia sensorial para elevar el producto que ofrecen. Aquí, la experiencia sensorial se refiere a comprometer los sentidos de la persona con el espacio en que se encuentra; así el visitante se ve inmerso en el escenario que visualiza y disfruta en un nivel más profundo y crítico la experiencia.

Tomemos los ejemplos de lugares como Bagan en Myanmar, ${ }^{1}$ Cappadocia en Turquía $^{2}$ o Teotihuacán en México, ${ }^{3}$ sitios que ofrecen una experiencia única mediante paseos en globos aerostáticos. La Torre de David en Jerusalén ${ }^{4}$ también utiliza la táctica de ofrecer tours nocturnos, en los cuales las luces nocturnas hacen resaltar el lugar y generan misterio cuando la luz del sol se oculta, y todo esto hace que los visitantes se sumerjan en la historia y le den mayor importancia a los detalles (Soydanbay, 2017).

Otra estrategia que permite que el visitante obtenga una experiencia mejor es crear una narrativa, una historia que enlace toda la información de forma memorable. Museos en Edinburgh contratan a actores para que sean los guías; lo mismo sucede en el Museo Tenement en Nueva York, donde los actores interactúan con los visitantes pretendiendo ser personajes históricos y que solo pueden responder preguntas relacionadas con el pasado.

Estas estrategias involucran a las emociones las cuales, basadas en la teoría de Eckman (2003), se segregan en seis básicas: alegría, tristeza, ira, sorpresa, miedo y aversión. Estas brotan en la persona dependiendo de la situación, siempre se evalúa lo que sucede en el contexto para generar concordancia con la emoción sentida. Las emociones cambian la manera en que vemos el mundo y cómo interpretamos las

\footnotetext{
${ }^{1}$ Bagan es una ciudad muy popular en Myanmar, por el recorrido que se hace en globos aerostáticos, lo cual se ha convertido en un símbolo regional. En los paseos se puede apreciar los horizontes y el atardecer por 45 minutos. Los precios varían entre US\$300 y US\$400.

${ }^{2}$ La ciudad de Cappadocia en Turquía ofrece tours en globos aerostáticos todo el año. La vista desde tierra firma hacia el cielo es impresionante durante el día por haber decenas de globos volando.

${ }^{3}$ Las pirámides de Teotihuacán en México pueden ser apreciadas mediante un tour en globo aerostático, una experiencia fuera de lo común y que se ofrece todo el año para los visitantes que quieran realizar el recorrido de una manera diferente.

${ }^{4}$ Las paredes de la Torre de David, en Jerusalén, por cuatro noches a la semana se convierten en un show nocturno en el que personas de todo el mundo celebran la historia de la ciudad con luces, música y vistas espectaculares.
} 
acciones de otros. Además de las seis emociones básicas, Barrios (2012) enumera sentimientos que envuelven a las estrategias de marketing con experiencias: enfado, miedo, romanticismo, optimismo, descontento, vergüenza, amor, alegría, preocupación, envidia, tranquilidad, entusiasmo, tristeza, soledad, satisfacción. Todo esto no se integra necesariamente en todas las actividades realizadas por el museo pero pueden coincidir en más de una.

Las experiencias que ofrecen las distintas instituciones varían dependiendo del espacio físico y de las actividades que poseen; sin embargo, todas tienen aspectos en común basados en factores que envuelven la experiencia. En el caso específico de los museos, estos ofrecen eventos que generan una experiencia para el visitante, cada museo la ofrece a su manera y con su propia estructura. Basado en eso, se debe considerar tomar como referencia todos los posibles factores que permitan mejorar el evento y, a través de ello, hallar acciones de implementación y analizar la calidad de la experiencia y del recorrido que se está ofreciendo a los visitantes. Por medio de esto, es posible aplicar soluciones innovadoras con el fin de que la experiencia vivida por los asistentes sea aún más completa y genere una conexión especial con la institución.

\subsubsection{Factores envolventes en la experiencia}

A continuación se mencionan los factores más relevantes, los cuales serán contrastados más adelante con el caso de investigación del presente trabajo.

Schmitt (1999) ratifica que los factores permiten crear ventajas competitivas entre un museo y otro por medio de los MEE, Módulos Experienciales Estratégicos, en los cuales propone directrices para gestionar las experiencias de los clientes.

- Módulo de sensaciones: los sentidos cobran protagonismo con el fin de crear experiencias sensoriales mediante el oído, la vista, el tacto, el gusto y el olfato (Schmitt, 1999, p.61).

- Módulo de sentimientos: los sentimientos y emociones de las personas son los principales componentes para crear las experiencias afectivas en relación con la marca. Schmitt menciona que esto se produce durante el consumo, por lo que el tiempo real en el cual la persona está en contacto con el evento es crucial (Schmitt, 1999, p. 61). 
- Módulo de pensamientos: relacionados con experiencias cognitivas y de intelecto que creen atracción en un nivel creativo (Schmitt, 1999, p. 61).

- Módulo de actuaciones: buscan intervenir ampliando las experiencias físicas de las personas e influyendo en su estilo de vida, mostrándole otras formas de desarrollar actividades rutinarias (Schmitt, 1999, p. 62).

- Módulo de relaciones: amplían las experiencias y fomentan la conexión del individuo con su yo interior, otras personas y culturas (Schmitt, 1999, p. 62).

Gracias a los módulos mencionados se puede lograr la experiencia holística desde el inicio, gradualmente y hasta el término de lo que Schmitt denomina rueda experiencial. Esta rueda se refiere a cada fase vivida por la persona desde que ingresa a sentir el primer módulo hasta el último de forma aleatoria.

Adicionalmente, Barrios (2012) afirma que las claves para el éxito de una experiencia son: el servicio memorable, la integración del modelo y la consideración de los pensamientos, relaciones, actuaciones, sensaciones y sentimientos de los visitantes. Mediante estos aspectos, Frow y Payne (2007) afirman que se apunta a crear clientes o visitantes que sean los "defensores" de la empresa, de tal manera que sean ellos mismos quienes den a conocer a la institución de manera natural y orgánica, basados en su experiencia en los módulos y considerando los aspectos claves. Todo ello converge para ofrecer el mejor servicio. Sin embargo, un cuestionamiento a responder es si el camino a seguir es el correcto o las acciones que se están tomando tendrán efectos positivos en la experiencia del visitante.

Lindstrom (2005) plantea la forma de medir los sentidos mediante tres dimensiones:

- ¿La experiencia sensorial hizo sentir de forma positiva o negativa en las personas con respecto a la institución o marca?

- ¿Qué tan distintiva ha sido la impresión?

- ¿Qué emociones fueron captadas por la experiencia sensorial?

Seguido de ello, mediante la gran experiencia de la marca — si a las personas les parece mejor una marca que otras —, la claridad — identidad distintiva - y el liderazgo — marca más auténtica y popular - se puede identificar si el producto experiencial que se ofrece está teniendo éxito; es así como complementa Lindstrom (2005) las dimensiones. 
Existen además, ciertos componentes de construcción a lo largo de la experiencia. A continuación, se enumeran diez reglas con las cuales se construye una sólida experiencia para las personas (Lindstrom, 2005, p. 10):

- Crear un sentido único de pertenencia.

- Crear un sentido de propósito.

- Toma poder de los competidores.

- Crear un sentido de autenticidad.

- Establecer consistencia.

- Sumergir a las personas en un mundo perfecto.

- Crear atractivo sensorial.

- Endurece poderes ritualistas.

- Crea símbolos representativos para la marca.

- Desarrolla sentido de misterio.

Las diez reglas permiten construir una experiencia sólida pero no significa que todas se deban aplicar en todas las instituciones; cada punto se desarrolla de manera independiente. Dependerá de la situación, espacio físico y productos culturales que ofrezcan y que mejor se adapten a cada regla. Sin embargo, se debe dar énfasis en poder integrar la experiencia de forma holística con los aspectos necesarios para que la persona que sea parte de la experiencia quede satisfecha con la institución o marca.

Los factores mencionados son sumamente importantes para que el visitante pueda tener una experiencia plena. Sumado a ello, para que el producto cultural pueda hacerse notar se toma como soporte el marketing digital, el cual permite obtener el alcance de una mayor audiencia. Por medio de las técnicas que forman parte del marketing digital se pueden visualizar las valoraciones y opiniones de los visitantes con respecto a la institución y al evento del que fueron partícipes, además de las acciones que los museos pueden desarrollar mediante ellas.

\subsection{Marketing digital}

La revolución digital está cambiando radicalmente el consumo cultural y los patrones de producción, obligando a los museos a repensar sus estrategias de manera virtual y 
mejorar sus formas de interactuar con las audiencias para satisfacer las necesidades de los usuarios (Bertacchini, 2013; Ballard, 2011).

Debido a ello, los museos deberían notar la relevancia de aplicar estrategias de marketing digital, lo cual se define como la promoción de las marcas y productos mediante canales digitales. Dicha promoción se desarrolla bajo tres pilares que se complementan entre sí: el espacio propio en red, la publicidad en línea y las redes sociales. Todo ello con el objetivo de que los usuarios interactúen con la marca en los medios digitales (Yasmin, Fatema \& Tasmeen , 2015).

\subsubsection{Estrategias 3.0}

Dentro del marketing digital, Kotler (2012) menciona una serie de estrategias 3.0 que se enfocan en el comportamiento del usuario y favorecen los cambios de información que este necesita, combinándolas con la intervención de colaboración y producción de contenido. De esta manera, es el usuario detrás de la pantalla quien interviene generando su propio contenido de forma colaborativa con la institución.

En 2013, Villaespesa ratificó lo dicho por Kotler, mencionando que la presencia del museo no proviene solo de su contenido en línea, sino que también se le retribuye la visibilidad de su imagen al contenido que los visitantes comparten acerca del museo, expresando sus opiniones, experiencias y fotos mediante Instagram, Facebook o Twitter. Por ello, las estrategias que se usan deben ir acorde a lo que los usuarios desean, para que la interacción sea recíproca y puedan difundir su experiencia con sus más allegados. De esta manera, el objetivo de los museos al hacer uso de redes sociales debe apuntar a extraer información valiosa de los usuarios para el beneficio de estos y de la institución (Crespo, 2012; Malavé, 2016).

\subsubsection{Ventajas del marketing digital}

El uso de medios digitales por parte de los museos ha logrado varios aportes, entre los cuales se destacan: el acceso a infinidad de nuevos canales de comunicación con los que se puede ganar visibilidad, el conocimiento del museo frente a potenciales visitantes y el conocimiento de los públicos que lo visitan o que podrían hacerlo. La obtención de 
estos u otros beneficios están relacionados con la gestión estratégica y la manera en la que se aplique en la comunicación dentro de la plataforma virtual, en la cual la planificación y la generación de contenido valioso para el público serán clave (Martínez-Sanz; Berrocal-Gonzalo, 2017). El marketing digital ofrece distintas ventajas, como la reducción de costos; mantener una red social tiene un costo usualmente menor a la aplicación de otras acciones de marketing. Otra ventaja es el alcance que posee; esto se refiere al número de personas que verán determinado anuncio, publicación o información relacionado al museo. Uno de los aspectos positivos también es la comunicación inmediata que se puede tener con los usuarios que pese a la distancia o limitaciones temporales son personas contactables (Yasmin, Fatema \& Tasneem, 2015).

Gracias a las ventajas ofrecidas y a una técnica importante llamada social media marketing, las compañías pueden hacer uso de las redes sociales para distribuir mensajes a sus audiencias objetivo o target (Yasmin, Fatema \& Tasneem, 2015). Todo se realiza de forma directa contactando a los públicos específicos que quieran llegar con la comunicación. Otro aspecto a favor del uso del social media marketing es que permite a los museos comprometerse con las audiencias, creando con ellas experiencias culturales (Dudareva, 2014). Ambas partes interactúan en el desarrollo de la experiencia, ya sea antes, durante o después del evento, mediante la información transmitida. De esta manera, se descentraliza la información para coincidir con las necesidades de cada individuo en las redes (Carter, 2008). Cada persona tiene diferentes intereses informativos relacionados con la institución, por lo que coincidir en el momento oportuno con respecto a lo que estén averiguando es relevante para poder captar un visitante más. El primer contacto en internet es el más importante y debe ser lo suficientemente impactante para capturar su atención. Esto se asocia directamente con el Momento Zero de la Verdad, que se define como el momento en que la persona coge su laptop, celular o dispositivo móvil y empieza a indagar y averiguar sobre un producto o servicio que le interese adquirir. Esta es la manera en que ahora los consumidores viven y toman decisiones, desde opiniones en páginas web hasta recomendaciones de amigos sobre videos de internet (Lecinski, 2011).

El marketing digital democratiza la información al tener un alcance mucho mayor en comparación con estrategias en medios tradicionales, el cual permite que los usuarios sean más críticos y seleccionen la información relevante para ellos. Las herramientas de marketing digital posibilitan la opción de mapear los resultados de los 
anuncios pagados contantemente; es decir, cuando una organización decide invertir en publicidad en línea, posee formas de medición adecuadas para que sus publicaciones sean exitosas en las redes que decidan estar presentes, y pueden así visualizar la información que está teniendo mayor interacción y que funciona mejor. También existe el alcance orgánico por publicación en redes sociales, cuando no hay inversión económica de por medio; esto se refiere, por ejemplo, al número de fans y no fans en Facebook que han visto la publicación, lo cual se puede visualizar en el interfaz de dicha red social. Estas métricas son importantes ya que se puede ver de forma certera la calidad del contenido y de qué manera está llegando a usuarios.

Las redes sociales en el sector cultural, además, sirven para crear, financiar, impulsar y dar futuro a la cultura, todo con ayuda de estrategias y objetivos claros, además de la medición constante (Peña, 2014). Esta medición se realiza por medio de distintas vías y herramientas; existen por ejemplo los leads de conversión. Estos pueden ser: número de membrecías, clics al link del museo en Facebook, inscripción a algún evento, etcétera. Dependerá de la institución medir resultados de la manera como mejor le beneficie. Las posibilidades de usar herramientas cualitativas y cuantitativas para poder realizar mediciones u obtener datos son variadas. Una de las cualitativas es el net sentiment, el cual permite evaluar percepciones y ver opiniones de los usuarios sobre su experiencia en la institución, todo ello mediante los canales digitales que usen. De esta manera, se puede evaluar nuevas acciones a aplicar en las distintas plataformas virtuales con que cuenta la institución, abriendo el paso para poder segmentar mejor los públicos en las redes y en la publicidad en línea que se ofrece.

\subsubsection{Net sentiment}

El net sentiment es una métrica usada para evaluar la percepción positiva o negativa sobre la marca en redes sociales, mediante las interacciones y comentarios en la red donde se encuentre la marca o institución. Esta forma de evaluar el desempeño en las redes sociales se centra en el uso del lenguaje natural y de las logísticas computacionales para identificar y extraer información subjetiva en material textual, tales como los comentarios dejados en una fanpage o los tweets. Así, se puede inferir si los textos son positivos, neutrales o negativos. En esta investigación, las logisticas computacionales no serán necesarias al tratarse de un fanpage que no cuenta con 
muchos años de presencia, por lo que las métricas se realizan de forma manual, considerando palabras claves del lenguaje que representen la experiencia del visitante, mediante comentarios positivos o negativos, las cuales se explicarán más adelante en la metodología.

Para ejemplificar la aplicación de la métrica, se detalla uno de los primeros estudios realizados usando el net sentiment como base para definir variables positivas, negativas o neutrales. Este se realizó en la red social Twitter y se trató de una investigación de polaridad de tweets guiada por Huang (2009), quien condujo un análisis de clasificación de tweets usando solo emoticones para representar las distintas emociones y luego segregándolas en la variable a la cual pertenezca. Aquí, el lenguaje se transformó en imágenes visuales para representar de manera más grafica las emociones y las variables.

De esta manera, el net sentiment se vuelve relevante para observar la aceptación que está teniendo la marca en las redes sociales y poder tomar acciones de mejora en cuanto interacción y contenido.

Esta métrica es importante para la investigación ya que permitirá segregar los comentarios e interacciones que poseen las publicaciones en Facebook del museo, y determinar si están teniendo reacciones positivas o negativas con respecto al recorrido nocturno. De esta manera, se podrá conocer más la experiencia vivida basada en la realidad de las percepciones de los visitantes y responder a las preguntas de la investigación que se detallarán más adelante.

\subsection{Perfil de visitantes a museos}

El público que asiste a los museos alrededor del mundo lo hace por diversas razones y tiene distintas motivaciones para hacerlo. Puede que le guste conocer nuevas culturas, tener interés por el arte o estar pendiente de nuevas exhibiciones. Existen diversos perfiles y es necesario poder conocer todos para saber cómo adaptar los productos y servicios a sus gustos.

Ford W. Bell (Are museums still relevant?: 12 de julio de 2017) sostiene que los museos son aún relevantes para las audiencias, desde niños a adultos, ya que los considera como la extensión del colegio e instituciones educacionales, por lo cual la 
inversión que hacen los gobiernos de varios países para remodelaciones y continuos avances permiten que estos espacios públicos sean esenciales para las comunidades. El autor también hace referencia a estudios realizados, los cuales mencionan que los turistas culturales gastan y se quedan más tiempo que otro tipo de turistas en un museo. La actividad económica que generan en la ciudad es sobresaliente, sea el país que sea, por ejemplo en el caso puntual del MoMA, ${ }^{5}$ que en las exhibiciones del año 2016 obtuvo ganancias de US\$700 millones, siendo un incremento abismal frente a años anteriores.

Por otro lado, Soydanbay (2017), en su artículo Undertourism: How to Make Archaeological Sites and Museums More Attractive as Destinations, ${ }^{6}$ menciona estudios que demuestran la existencia de cuatro razones por las cuales los visitantes deciden asistir a los museos:

- Motivación social: los visitantes ven a los museos como atracciones llamativas.

- Motivación intelectual: los visitantes esperan obtener una relación con un nivel crítico, profundo y centrado.

- Motivación emocional: los visitantes esperan obtener un sentido de descubrimiento y asombro, además de un contacto sensorial e intelectual.

- Motivación espiritual: debe existir alimento para el alma, sustancia espiritual y ambiente correcto.

Además de las cuatro razones mencionadas, Soydanbay hace énfasis en el drástico cambio de las motivaciones que tienen los visitantes antes y después de ser impactados por la visita al museo. Por regla estándar, la mitad de visitantes posee una motivación social y la tercera parte son intelectualmente motivados. Sin embargo, en investigaciones realizadas por Andrew McIntyre’s citadas en el artículo de Soydanbay (2017), demuestran que antes de la visita, el $49 \%$ de visitantes poseen motivaciones sociales, siendo este el más alto porcentaje frente al de otras motivaciones. Después de la visita, el porcentaje de motivación emocional es el más alto con el $41 \%$. De esta manera, los museos que son exitosos son los que ofrecen una experiencia transformadora a sus visitantes, los mantienen inmersos dentro del recinto tornando su recorrido en una experiencia profunda. McIntyre’s en el artículo de Soydanbay (2017)

\footnotetext{
${ }^{5}$ Museo de arte moderno ubicado en Nueva York. Uno de los museos más reconocidos a nivel mundial, la página web con toda la información referente a esta institución es: https://www.moma.org/

${ }^{6}$ Recuperado de: https://placebrandobserver.com/how-to-make-museums-attractive-destinations/
} 
explica que existen tres principales problemas por lo que algunos museos no logran una conexión emocional con el público: el primero es que el museo se percibe como un establecimiento aburrido y sin vida, lo cual es todo lo contrario a ser cautivador y atractivo; el segundo problema es el tema de relevancia, pues el tiempo se considera lineal y solo se mira al futuro, dejando de lado el pasado y no se le considera importante en los tiempos actuales, lo cual se visualiza más en sitios arqueológicos donde solo se pueden visualizar ruinas, monumentos u otras piezas que no se pueden tocar; el tercer problema es la barrera comunicacional entre los visitantes y el museo: el lenguaje usado muchas veces puede ser aburrido, haciéndolo nada tentador de visitar.

Para superar esos problemas se debe poder encontrar la motivación emocional que conduce a los visitantes a tener acercamientos con los museos.

Ford W. Bell concuerda con Soydanbay con respecto a la motivación emocional, ya que en tiempos difíciles, las personas retornan a sus museos para valorar y reconectarse con su historia. Tal como sucedió; por ejemplo, con los eventos suscitados el 9/11 en Nueva York. Por este atentado histórico, construyeron un museo que genera millones de dólares en venta de tickets al año y rinde homenaje a todas las vidas perdidas. Aquí, los públicos obtienen una reacción frente a un determinado contexto social que los atrae a visitar alguna institución que les brinde cultura, educación y los concientice sobre un hecho histórico.

Los eventos que se produzcan en la sociedad pueden marcar tanto de forma positiva como negativa la percepción de los visitantes a instituciones culturales. En el mencionado Museo del 9/11 convergen tanto sucesos positivos como negativos, relacionados con su historia y cultura, que generan lazos casi inmediatos por el simple hecho de vivir en esa ciudad. Sin embargo, hechos suscitados que marcan en la sociedad también pueden afectar la visita de los públicos a las instituciones, tal como sucedió en Londres el año 2017, en que la afluencia de asistentes a diversos museos populares cayó terriblemente en más de una década debido al miedo suscitado por actos terroristas y de inseguridad. Pese a las novedosas exhibiciones y actividades, los púbicos se ven afectados por el contexto social de diversas maneras, en este caso negativamente.

Los museos deben considerar las diferentes motivaciones y contextos a los cuales se enfrentan en la actualidad para poder brindarles una mejor experiencia a las audiencias, además de contrastarlos con acciones que puedan impactar positivamente en sus vidas, acercándolos más a la historia. Se deben considerar tanto sus motivaciones y 
comportamientos antes, durante y después de su visita, como sus formas de actuar en redes, todo ello con la finalidad de conocer también a su público digital para poder impactarlos de forma más efectiva.

\subsubsection{Perfil del público digital seguidores de museos}

Las instituciones culturales están presentes en medios digitales para comunicar a su audiencia lo que ofrecen y los eventos que realizan. También están por otros motivos, tales como generar branding, posicionamiento, obtener visibilidad o lo que sea que se propongan. Se torna importante conocer los distintos públicos a los que se quiere penetrar sobre la base de su estilo de vida, nivel socioeconómico y educación, ya que la tecnología puede traer beneficios a las galerías y museos si se conoce más a profundidad lo que desean los visitantes.

Actualmente, una persona puede enviarle vía correo electrónico o mensaje de texto una imagen a un amigo, o publicarla en redes en tiempo real, colocar su ubicación y mencionar el lugar desde donde se encuentra. La tecnología en internet presenta formas de entretenimiento pero también ofrece nuevas formas de conectar con las audiencias jóvenes en el arte, ciencia e historia (Cannell, 2015).

En el contexto local, los peruanos son activos a las redes sociales y cada año se incrementa el número de usuarios. Según el Perfil del usuario de redes sociales de Ipsos (2016), el 33\% de peruanos pertenece a una red social, ya sea Facebook, Twitter, YouTube o Instagram, tiene en promedio 26 años y pertenece al NSE C en su gran mayoría.

Además, en el último año se estimó que 19 millones de peruanos se conectan a Facebook mes a mes, de los cuales el $80 \%$ son usuarios activos y lo hacen mediante un celular. Otro dato relevante, es que en el Black Friday de noviembre de 2016, la red social registró un incremento del 29\% de interacciones. Estas interacciones fueron lideradas por jóvenes (36\% de las personas, de 18 a 24 años) y mujeres (52\% del total). Las compras en línea cobran gran protagonismo entre las acciones que realizan los usuarios, siendo un gran porcentaje de estas relacionadas con entretenimiento, tecnología, productos y servicios turísticos (Villalobos, 2017). 
Tomando estos datos en consideración, se realizó una comparación de algunos museos en el Perú que hacen uso de las redes de manera notoria y que cuentan con un mayor número de usuarios seguidores de estos. Se considera relevante mencionarlos debido a que se han convertido en referentes en el sector museístico, ya que publican contenido interesante y atractivo para los usuarios.

Tabla 2.1 Comparación en medios digitales de museos limeños

\begin{tabular}{|l|l|l|}
\hline Museo & $\begin{array}{l}\text { Número de seguidores en redes } \\
\text { Sociales }\end{array}$ & Página web \\
\hline Museo de Arte de Lima & $\begin{array}{l}\text { Facebook: } 324,112 \\
\text { Instagram: } 18,100 \\
\text { Twitter: } 38,300\end{array}$ & $\begin{array}{l}\text { Actualizada } \\
\text { Información de exposiciones y } \\
\text { cursos. }\end{array}$ \\
\hline Museo de Arte Contemporáneo & $\begin{array}{l}\text { Facebook: } 200,788 \\
\text { Twitter: } 17,100\end{array}$ & $\begin{array}{l}\text { Actualizada } \\
\text { Información de exposiciones. }\end{array}$ \\
\hline Museo MATE & $\begin{array}{l}\text { Facebook: } 99,018 \\
\text { Instagram: } 51,600\end{array}$ & $\begin{array}{l}\text { Actualizada } \\
\text { Información de exposiciones. }\end{array}$ \\
\hline Museo Larco & $\begin{array}{l}\text { Facebook: } 24,373 \\
\text { Instagram: } 1,583\end{array}$ & $\begin{array}{l}\text { Actualizada } \\
\text { Información de exposiciones. }\end{array}$ \\
\hline Museo de la Memoria & $\begin{array}{l}\text { Facebook: } 81,705 \\
\text { Twitter: } 2,516\end{array}$ & $\begin{array}{l}\text { Actualizada } \\
\text { Información de actividades. }\end{array}$ \\
\hline
\end{tabular}

Fuente: Elaboración propia

Cada museo posee su propio lenguaje, genera su propio contenido e interactúa con los usuarios a su manera; publica nueva información de manera constante y mantienen informada a su audiencia sobre lo que vienen desarrollando y las nuevas actividades que vendrán. Por el lado del público, en cada museo las preguntas que estos realizan son más que todo informativas, además de comentarios de opinión.

Las redes más usadas tanto por los públicos como por los museos son Facebook e Instagram, esto sobre la base de las investigaciones y la realidad actual de los distintos museos mencionados; coinciden con los medios que usan las instituciones culturales para poder alcanzar a nuevos visitantes, tal como se visualiza en el cuadro comparativo. La información en redes de esos museos se complementa mediante una página web actualizada y con las últimas novedades relevantes. 
El informe Estadísticas de las tecnologías de información y comunicación en los hogares del INEI de 2017 indica que el 88,8\% de la población navega para obtener información relevante a sus intereses, el $87 \%$ lo utiliza para comunicarse por medio de correo y redes sociales, y el $79 \%$ recurre a internet para realizar actividades de entretenimiento como jugar videojuegos u obtener películas o música (Día del Internet: Este es el perfil del internauta peruano: 17 de mayo de 2017). Además, es la población joven la que ocupa el mayor porcentaje en las cifras, siendo el $80 \%$ de la población de 19 a 24 años los mayores usuarios de enternet y quienes gastan mayor tiempo navegando en la web.

Ahora que se tiene un contexto más amplio de los perfiles de los visitantes y del público digital, se procederá a explicar estrategias que se han realizado en museos alrededor del mundo y las acciones que han tomado para poder ser instituciones referentes y conectar con el público de manera satisfactoria. 


\section{ACCIONES ESTRATÉGICAS PARA LA PROMOCIÓN DE EXPERIENCIAS DE LAS PRINCIPALES INSTITUCIONES CULTURALES EN EL MUNDO}

French \& Runyard (2011) mencionan que para sobrevivir y luchar en el siglo XXI, los museos, galerías y atracciones sin fines de lucro tendrán que aplicar técnicas sofisticadas de marketing para atraer a visitantes en un ambiente muchas veces competitivo.

La declaración de French \& Runyard resultó ser un precedente para que las instituciones y gestores tomen conciencia de los cambios. Alrededor del mundo, los museos han optado por hacer uso de distintas estrategias para comunicar lo que ofrecen y poseer mayor visibilidad frente a otras instituciones culturales, además de generar valor y diferenciarse del resto.

Para ejemplificar lo dicho, se tomará como referencia lo realizado por el Museo de Londres. Con el objetivo de reposicionarse en la mente de los londinenses, aprovechó la inauguración de las Galerías de Londres Moderno dentro del establecimiento para lanzar la aplicación móvil Streetmuseum Londiniu (Rusillo, 2013). La aplicación permitía a los visitantes superponer imágenes originales dentro del contexto de las exposiciones actuales, de esta manera se sumergían en la historia mediante la realidad aumentada ofrecida por la aplicación. Solo debían descargar la aplicación del museo, buscar el lugar donde se encuentren dentro de esta, señalar con la pantalla del Smartphone y poco a poco las imágenes iban apareciendo para complementar la obra de arte que se estaba visualizando o el lugar donde se encontrasen, ya que también funcionaba con los espacios de las galerías. Esto fue considerado un caso de éxito en 2011, cuando se aplicó esta estrategia de content marketing $^{7}$ ya que la prensa londinense rebotó la noticia de forma orgánica y atrajo a más visitantes.

Acciones como esas revolucionan la manera de ver nuestro pasado. Jiménez y Quero (2011), en su Manual de Marketing y Comunicación Cultural, proponen estrategias que tienen relación con los públicos consumidores de cultura:

\footnotetext{
${ }^{7}$ Marketing de contenido que envuelve la creación y despliegue de material digital como videos, publicaciones en redes, fotos, etcétera.
} 
- Estrategia de creación de valor: mediante estos se busca incrementar la rentabilidad de la institución por medio del desarrollo de contenido en redes sociales, las cuales permiten intensificar su visibilidad.

- Estrategia de captación: se introduce al cliente en una actividad cultural específica para lograr que asista al evento, primero se debe seleccionar al target para luego dirigir su proceso en la decisión de compra o la asistencia al evento.

Alrededor del público y del producto cultural debe girar el plan estratégico que se proponga realizar; de esta manera se consigue atraer la atención de los visitantes y generar una conexión con la organización, por lo que conocer a los públicos se torna un factor positivo para poder llegar a ellos.

Para recalcar la importancia de tomar acciones que sirvan a los museos y galerías, Pešić (2014) y Porter (2006) mencionan otras posibles estrategias para el desarrollo cultural, tal como vemos en la tabla 3.1.

Tabla 3.1 Estrategias para museos

\begin{tabular}{|c|c|c|}
\hline 8 & Estrategia & Definición \\
\hline \multirow{4}{*}{ Pešić (} & Internacionalización & $\begin{array}{l}\text { Estrategia a nivel global, regional o en el } \\
\text { continente donde se encuentre. Se refiere a } \\
\text { alcanzar visibilidad fuera de la ciudad donde se } \\
\text { encuentre el museo. }\end{array}$ \\
\hline & $\begin{array}{l}\text { Elevación de la calidad de } \\
\text { la audiencia mediante el } \\
\text { engagement }\end{array}$ & $\begin{array}{l}\text { Fidelizar a la audiencia, generar conexión } \\
\text { duradera a los años. }\end{array}$ \\
\hline & $\begin{array}{l}\text { Descentralización de } \\
\text { programas y actividades }\end{array}$ & $\begin{array}{l}\text { Poder llevar las actividades a otras ciudades o } \\
\text { lugares, fuera del recinto museístico si es posible. } \\
\text { Actividades o presencia del museo. }\end{array}$ \\
\hline & $\begin{array}{l}\text { Alineación con estándares } \\
\text { profesionales }\end{array}$ & $\begin{array}{l}\text { Alinearse con los estándares básicos que deben ser } \\
\text { ofrecidos cuando un visitante adquiere el ticket } \\
\text { para ingresar al museo. Estándares como: } \\
\text { visualizar alguna exposición o evento, espacio } \\
\text { físico, servicios básicos como luz, agua e internet. }\end{array}$ \\
\hline \multirow{3}{*}{ Porter (2006) } & Aspiración & $\begin{array}{l}\text { Tener cierto número de visitantes, duplicar } \\
\text { financiamiento, incrementar los ingresos. }\end{array}$ \\
\hline & Acción & $\begin{array}{l}\text { Expandir colecciones, construcción de nueva } \\
\text { infraestructura. }\end{array}$ \\
\hline & Visión/misión & Servir a la comunidad, avanzar en ciencia. \\
\hline
\end{tabular}

Fuente: Elaboración propia

El plan de desarrollo cultural debe optar por estrategias básicas que contribuyan con la realización de los objetivos más próximos de la institución. Tomando esto en consideración, Porter plantea además, que el propósito fundamental de un museo u otra 
organización es la creación de valor, el cual equivale a los beneficios sociales entre los recursos gastados. De esta manera, las bases de las estrategias a aplicar por cada institución deben estar en sinergia con su situación actual.

Para cumplir con los objetivos propuestos y dependiendo de la institución, se debe considerar los medios más ad hoc para poder conectar con el público. El estudio realizado por Walker (2015), en el cual se encuesta a más a de cien community managers de museos en Estados Unidos, arrojó como resultado que la plataforma de red social más usada por ellos es Facebook, seguida de Twitter, YouTube y Google+. Sumado a ello, la razón por la que expresaron hacer uso de redes sociales fue por "marketing o promoción de eventos", ya que buscan atraer tráfico a la página web del museo por diversas razones (eventos, venta de tickets, venta de productos, etcétera).

Los gestores culturales y personas a cargo de poner en marcha las acciones estratégicas en las instituciones culturales deben tener en mente lo que se desea conseguir, por lo que considerar la primera experiencia de consumo en la persona es importante, ya que si no es exitosa no se realizará la repetición. La colaboración con otras organizaciones también favorece la visibilidad de la institución y genera lazos externos. Otro punto importante es generar una base de datos de clientes desde su primera visita, la cual permita trazar estrategias sobre la gestión de relaciones con la organización desde el principio; esto permite también aplicar estrategias de marketing directo (Jiménez \& Quero, 2011).

Las estrategias mencionadas solo son algunas de las utilizadas por ciertos museos. Alrededor del mundo se desarrollan distintas acciones que permiten innovar y destacar en el mercado cultural, por lo que se desarrollará un análisis puntual y sistemático de cuatro museos en el mundo que actualmente son referentes por la gran afluencia de público que los visitan cada año y por las distintas actividades que realizan.

\subsection{Museos referentes del mundo}

Alrededor del mundo existen museos que se destacan por sus colecciones, exposiciones y por la buena administración de sus gestores. 
En la investigación realizada por la Rotterdam School of Management en 2018, titulada "Why people love art museums", 8 se hallaron razones por las que ciertos museos alrededor del mundo obtienen los primeros puestos en el ranking de preferencia entre visitantes internacionales y nacionales de cada país. Entre las razones se consideran el atractivo y la diferenciación de la colección, el impacto positivo en la ciudadanía y la sociedad en general, además de la buena gestión de sus fondos para que el museo pueda sobresalir entre la vasta variedad de la oferta. Otro aspecto importante mencionado por Blas (2018) es el tamaño del museo, el cual está muy relacionado con el número de visitantes, por lo que en la gran mayoría pierde atractivo para el visitante. Los grandes museos sufren habitualmente por un exceso de afluencia de público, lo que empobrece la experiencia del visitante. Los museos pequeños o que se centran en un solo artista o tema, son los que atraen mayor atención por la experiencia vivida por el visitante en un nivel más personal (Blas, 2018).

Sobre esta base, se seleccionó cuatro museos referentes en el ámbito mundial, considerando el gran número de fans en redes sociales que poseen y por las experiencias que brindan a sus visitantes, las cuales están alineadas con su contenido digital demostrando que están en constante innovación y que llegan a su público de manera sobresaliente.

\subsubsection{Museo MoMA - Estados Unidos}

El Museo de Arte Moderno (MoMA) de Nueva York es un referente en el ámbito museístico alrededor del mundo, por ofrecer distintas exhibiciones de arte y actividades innovadoras que involucran arte, aprendizaje, cultura y desarrollo. El museo se concentra en su público local e internacional, los que se encuentran en el mismo espacio virtual, ya sea por medio de su página web, redes sociales o programación pública.

El MoMA es uno de los museos con mayor número de seguidores en el mundo y la buena reputación que ha ido adquiriendo a lo largo de los años como una de las instituciones de arte líderes, permite que el interés de lo que sucede en el espacio físico del museo tenga implicancia mundial e integre tanto experiencias físicas como virtuales.

\footnotetext{
${ }^{8}$ What businesses can learn from the high reputations of museums https://discovery.rsm.nl/articles/detail/297-what-businesses-can-learn-from-the-high-reputations-ofmuseums/
} 
Tabla 3.2 Resumen de actividad en medios digitales MoMA

\begin{tabular}{|l|l|l|l|}
\hline & \multicolumn{1}{|c|}{ Seguidores en redes } & \multicolumn{1}{c|}{ Información en redes } & \multicolumn{1}{c|}{ Interacciones } \\
\hline & Facebook: 2.031 .164 & - Exhibiciones presentes & - Promedio 500 \\
& Instagram: 3.400 .000 & - Fotos de piezas del & - Comentarios y \\
MoMA & Twitter: 5.510 .000 & museo & reacciones positivos \\
& $\begin{array}{l}\text { Página web: activa y } \\
\text { actualizada }\end{array}$ & - Videos de exposiciones & \\
\hline
\end{tabular}

Fuente: Elaboración propia

El MoMA ofrece precios altos de admisión ya que busca que los visitantes adquieran un paquete de membrecía; de esta manera generan una comunidad sólida y fiel a la institución, motivando a otros museos a innovar en estrategias de atracción y retención de visitantes. Esto, sin dejar de lado los beneficios en línea, pues el museo logra conjugar sus actividades a través de la aplicación de museo MoMA Books ${ }^{9}$ y cursos en línea.

En 2011, lanzaron la versión 2.0 de "I went to MoMA and..." (Yo fui al MoMA y...) como un experimento social, tal como se describe en la tabla 3.3. La estrategia tuvo tanta acogida que, al poco tiempo, las notas cubrían todo el lobby y la web, y se convirtió en una popular campaña de publicidad en The New York Times, revistas y posters alrededor de la ciudad. Esta estrategia permitió además obtener el feedback de los visitantes y mejoras a desarrollar basadas en sus comentarios.

Otra actividad que realizaron fue en 2017, cuando el museo presentó la exhibición "Robert Rauschenberg: Among Friends", la cual incluía una serie de colaboraciones con otros artistas, bailarines y músicos, recolectadas en el transcurso de varios años. Esta exhibición mezcló la tecnología con el arte tradicional, y a cada visitante al ingresar a la exhibición se le daba la opción de tener un audiotour autodirigido. Gracias a esta estrategia, el museo podía recolectar información personal del visitante y conocer más sus intereses.

\footnotetext{
${ }^{9}$ Aplicación del MoMA donde los usuarios pueden visualizar de forma digital todas las publicaciones de historia y arte realizadas por el museos.
} 
Tabla 3.3 Resumen de acciones y actividades que realizan en el MoMA

\begin{tabular}{|c|c|c|}
\hline & $\begin{array}{l}\text { "I went to MoMA and..." (Yo fui al } \\
\text { МoМА у...") }\end{array}$ & $\begin{array}{l}\text { "Robert Rauschenberg: Among } \\
\text { Friends" }\end{array}$ \\
\hline $\begin{array}{l}\text { Acciones } \\
\text { experienciales } \\
\text { MoMA }\end{array}$ & $\begin{array}{l}\text { La versión } 2.0 \text { de "I went to MoMA } \\
\text { and..." ("Yo fui al MoMA y...") } \\
\text { permitió conocer qué sucede cuando se } \\
\text { les da la oportunidad a los visitantes de } \\
\text { compartir sus experiencias en el museo, } \\
\text { con solo lápiz y notas de papel colocados } \\
\text { en el lobby, promovieron respuestas } \\
\text { conmovedoras, profundas y que } \\
\text { reflejaban sentimientos positivos y su } \\
\text { buena experiencia vivida en el museo. }\end{array}$ & $\begin{array}{l}\text { Aquí en lugar de dar los clásicos } C D \\
\text { player, el museo entregaba un MoMA } \\
\text { audio + guía móvil en un iPod. Durante } \\
\text { el recorrido, el dispositivo iba más allá } \\
\text { de lo funcional, ofreciendo toda una } \\
\text { experiencia de principio a fin. Permitía } \\
\text { enviar links en tiempo real con } \\
\text { información de la pieza de arte que el } \\
\text { visitante presenciaba en ese momento } \\
\text { para luego poder recordar la información } \\
\text { brindada en su propio teléfono }\end{array}$ \\
\hline \multirow[t]{2}{*}{ Actividades } & \multicolumn{2}{|c|}{$\begin{array}{l}\text { El MoMA.org sirve a su comunidad online con admisión gratuita } 24 / 7 \text {. En la web } \\
\text { mencionada los visitantes pueden encontrar objetos y experiencias disponibles } \\
\text { virtualmente que no podrían ser comparadas con el museo físico, es "lo mismo pero } \\
\text { diferente" (Bautista, 2014) }\end{array}$} \\
\hline & \multicolumn{2}{|c|}{ App de museo MoMA Books y cursos en línea. } \\
\hline
\end{tabular}

Fuente: Elaboración propia

Durante la navegación en la página web del MoMA (www.moma.org/) se pudo apreciar que está organizada de forma que facilite al usuario su recorrido y planee su visita de acuerdo a sus intereses. Posee una sección del calendario de actividades con detalle de los eventos y exhibiciones, que permite visualizar los horarios y las salas para que la organización del itinerario del visitante sea aún más completa. También se puede visualizar las exhibiciones por artista y corriente artística.

El MoMA está dedicado a crear un diálogo entre lo establecido y lo experimental, en un ambiente que responde a los problemas del arte contemporáneo y moderno, pero que a la vez permite ser accesible para todos los públicos, desde los profesionales adultos a los niños y niñas más pequeños. Las obras de arte presentes se orientan a tener un propósito educacional brindando además, una experiencia redonda del movimiento visual y artístico que engloba el museo (Porter, 2006).

El museo ha logrado conectar el espacio físico de las salas con el espacio virtual que poseen mediante tours virtuales, audios y guías en la web, videos en vivo y fotografías en las redes sociales.

\subsubsection{Museo Tate - Inglaterra}


El museo Tate es uno de los más populares en arte moderno y contemporáneo del mundo; atrae un poco más de cinco millones de visitantes por año. Ubicado en Londres, es considerado como la galería nacional de arte moderno internacional y del Grupo Tate (Tate Britain, Tate Modern Liverpool, Tate Modern St Ives). Posee una diversidad de eventos y exhibiciones a lo largo del año, las cuales son comunicadas mediante sus redes y página web.

Tabla 3.4 Resumen de actividad en medios digitales Tate

\begin{tabular}{|l|l|l|l|}
\hline \multirow{4}{*}{ Tate } & \multicolumn{1}{|c|}{ Seguidores en redes } & \multicolumn{1}{c|}{ Información en redes } & \multicolumn{1}{c|}{ Interacciones } \\
\cline { 2 - 4 } & Facebook: 1.158 .093 & - Información de horarios & - Promedio 1.200 \\
& Instagram: 2.000 .000 & - Muestras y exposiciones & - Comentarios y \\
& Twitter: 4.920 .000 & actuales & reacciones positivos \\
Página web: activa y & - Datos históricos & \\
actualizada & & \\
\hline
\end{tabular}

Fuente: Elaboración propia

Una de las exhibiciones más resaltantes de 2017 es Modigliani, la cual estuvo en exposición hasta abril del 2018 y presentó las obras de arte creadas por el pintor en el siglo XX. Además de pinturas y piezas originales del artista que figuran en la exhibición, los visitantes pudieron vivir una experiencia de realidad virtual que los envolvió en un nivel más cercano a la producción de las piezas de arte. Uno de los desafíos fue la recreación de los espacios con los objetos y detalles originales que poseía el estudio, ya que en esa época no había fotografías que reflejen el ambiente de la manera más adecuada. Mediante investigación histórica y técnica se pudo lograr una semejanza muy alta, por lo que cada pieza que visualiza el visitante en la experiencia ha sido pensada meticulosamente (Tate, 2017). La estrategia de Modigliani persiguió la innovación mediante el desarrollo de la experiencia digital por medio de la realidad virtual, y con ello celebraron el nuevo espacio virtual que pudieron consolidar con el objetivo de generar compromiso entre los visitantes y los miembros del museo.

Tabla 3.5 Resumen de acciones experienciales Tate

\begin{tabular}{|c|c|c|}
\hline & Actividades & Alianzas \\
\hline $\begin{array}{l}\text { Acciones } \\
\text { experienciales } \\
\text { Tate }\end{array}$ & $\begin{array}{l}\text { D.I.Y Machine el cual consiste en } \\
\text { permitir a los visitantes que colaboren } \\
\text { con los diversos artistas que se } \\
\text { encuentren en el museo, interactuar con } \\
\text { comunidades locales y usar la máquina }\end{array}$ & $\begin{array}{l}\text { Tate tiene como aliado a la marca } \\
\text { BMW, la cual colabora con la } \\
\text { realización de estos junto con } \\
\text { reconocidos artistas. En la gran mayoría } \\
\text { tratan de unir música, proyección de }\end{array}$ \\
\hline
\end{tabular}




\begin{tabular}{|l|l|l|}
\hline $\begin{array}{l}\text { D.I.Y para contribuir con nuevas piezas } \\
\text { de arte. }\end{array}$ & $\begin{array}{l}\text { videos y acciones de improvisación } \\
\text { donde tratan de incluir a la audiencia } \\
\text { presente para que sea parte del } \\
\text { espectáculo y desaten su curiosidad a } \\
\text { través de performances en vivo } \\
\text { revolucionarias e innovadoras. }\end{array}$ \\
\hline
\end{tabular}

Fuente: Elaboración propia

El museo Tate combina sus plataformas digitales con el espacio físico que posee, y en este último también busca generar experiencias de toda índole para sus miembros y visitantes. Durante el año realiza gran cantidad de workshops gratuitos, eventos especiales y perfomances que combinan arte, cultura y vivencias. Las actividades que realiza están enfocadas para cada público específico; así permite al visitante escoger los talleres de su interés y organizarse. Un workshop que realizan junto con la escuela Thomas Tallis es muy popular: en una de las salas del museo recrean un estudio de fotografía donde los visitantes que se inscriben tienen la oportunidad de participar en un debate con profesionales de la fotografía sobre la importancia de este arte, pueden apreciar el espíritu de experimentación y colaborar en la producción de nuevas ideas donde las perspectivas de fotógrafos reconocidos con los visitantes amantes de la fotografía se unen.

Mediante las diversas actividades, tareas y exhibiciones, el museo Tate se consagra a nivel mundial como uno de los mejores museos de arte que ha logrado la sinergia de brindar experiencia y educación a los visitantes de toda edad. Además, de aportar a la cultura y promover la creación de nuevas producciones artísticas.

\subsubsection{Museo Louvre - Francia}

El museo Louvre, ubicado en París, ha cumplido a lo largo de los años con exponer y enriquecer el conjunto de las colecciones y obras que pertenecen a la historia del arte en Europa y que constituyen exhibiciones de expresión artística valoradas alrededor del mundo. El museo es reconocido además, por ser sede de eventos relevantes relacionados con el arte y la moda, que cobran relevancia en todo el mundo y son comunicadas vía redes. 
Tabla 3. 6 Resumen de actividad en medios digitales Louvre

\begin{tabular}{|l|l|l|l|}
\hline & \multicolumn{1}{|c|}{ Seguidores en redes } & \multicolumn{1}{c|}{ Información en redes } & \multicolumn{1}{c|}{ Interacciones } \\
\hline \multirow{4}{*}{ Louvre } & Facebook: 2.418 .838 & - Exhibiciones presentes & - Promedio 4.000 \\
& Instagram: 1.500 .000 & - Fotos de piezas del & - Comentarios y \\
& Twitter:1.390.000 & museo & reacciones positivas \\
& $\begin{array}{l}\text { Página web: activa y } \\
\text { actualizada }\end{array}$ & - Datos y textos curiosos & \\
\hline
\end{tabular}

Fuente: Elaboración propia

Una de las actividades realizadas en 2014 y que causó gran expectación fue el "Sculpting your body" touch tour, el cual consistía en ofrecer una experiencia de exploración táctil a las personas ciegas o con problemas de visión, tal como se detalla en el cuadro en la parte inferior. Las piezas contaban con descripción braille para agregarle mayor información. La exposición contaba también con un mapa táctil a la entrada, con el motivo de darles a los visitantes una idea del espacio del área y la posición en que se encontraban los objetos. Los pisos también eran táctiles y guiaban a los visitantes mediante luces, de esta manera cada persona podía hacer el recorrido de manera independiente y planear su visita de acuerdo a sus intereses. Sumado a ello, los visitantes contaban con un audio tour adaptado por personas con discapacidad visual. El equipo de audio era totalmente y sencillo de usar mediante colores. El museo aquí brindó una experiencia que innovó la forma de adaptar actividades realizadas por instituciones culturales a segmentos de públicos específicos.

Tabla 3.7 Resumen de acciones y actividades que realiza Louvre

\begin{tabular}{|c|c|}
\hline \multirow[b]{2}{*}{$\begin{array}{l}\text { Acciones } \\
\text { experienciales } \\
\text { Louvre }\end{array}$} & "Sculpting your body" touch tour \\
\hline & $\begin{array}{l}\text { Los niños y adultos tenían la oportunidad de tocar réplicas de reconocidas piezas } \\
\text { del museo, que en un ambiente de recorrido natural no estaría permitido. Un dato } \\
\text { interesante es que dentro de las piezas habían dos originales junto a sus réplicas, allí } \\
\text { las personas podían hacer un contraste de las diferencias. }\end{array}$ \\
\hline \multirow[b]{2}{*}{ Actividades } & Museum Lab - Masterpieces of Spanish paintings. \\
\hline & $\begin{array}{l}\text { Los visitantes que deciden asistir al laboratorio, descubren la colección de arte } \\
\text { español que posee el Louvre mediante un despliegue multimedia. Este } \\
\text { acercamiento interactivo se realiza de manera didáctica y divertida para públicos de } \\
\text { todas las edades y permite a los visitantes entender de manera más profunda las } \\
\text { piezas de Zurbarán, Murillo y Goya. }\end{array}$ \\
\hline
\end{tabular}

Fuente: Elaboración propia 
El museo posee varias salas separadas por corriente artística y país, lo que permite que la visita esté mejor estructurada. El Louvre también tiene laboratorios, en los cuales realiza actividades que combinan lo digital con la interactividad de los visitantes y las piezas de arte. Un evento resaltante que realiza todos los días desde hace un par de años es el Museum Lab - Masterpieces of spanish paintings. Alrededor del laboratorio se encuentran instaladas dos pantallas producidas con el objetivo de ser mediadores de innovación digital entre el visitante y las piezas de arte. Las pantallas permiten entender el desarrollo de las pinturas de manera más exhaustiva y el proceso que se siguió durante todo el armado de las instalaciones donde se encuentran las colecciones. Los equipos multimedia muestran el panorama de la evolución desde el siglo XVII al presente, de manera que los visitantes tienen un mejor entendimiento de cómo una colección es puesta en escena satisfactoriamente. Al igual que la colección de pinturas españolas, también cuentan con un laboratorio con piezas egipcias y con la misma dinámica interactiva.

Los eventos y actividades que otros museos no ofrecen, permiten que el Louvre continúe resaltando entre las opciones de los visitantes a nivel mundial, ya que todos buscan vivir una experiencia que vaya más allá de la apreciación de las pinturas o piezas de arte, sino que buscan agregarle valor a su recorrido.

\subsubsection{Museo de Historia Natural - Estados Unidos}

The American Museum of Natural History, ubicado en Nueva York, es una institución científica y cultural reconocida en el mundo por sus aportes relevantes a la ciencia. Tiene como misión descubrir, interpretar y analizar información sobre el ser humano, el mundo natural y el universo mediante programas de investigación, educación y exhibición. El museo tiene fuerte presencia en redes sociales.

Tabla 3.8 Resumen de actividad en medios digitales

\begin{tabular}{|l|l|l|l|}
\hline & \multicolumn{1}{|c|}{ Seguidores en redes } & \multicolumn{1}{c|}{ Información en redes } & \multicolumn{1}{c|}{ Interacciones } \\
\hline \multirow{4}{*}{ Louvre } & Facebook: 1.009 .925 & - Información de horarios & - Promedio 700 \\
& Instagram: 192.000 & - Muestras y exposiciones & - Comentarios y \\
& $\begin{array}{l}\text { Twitter: } 2.280 .000 \\
\text { Página web: activa y } \\
\text { actualizada }\end{array}$ & $\begin{array}{l}\text { actuales } \\
\text { - Datos históricos de } \\
\text { piezas }\end{array}$ & \\
\hline
\end{tabular}

Fuente: Elaboración propia 
El museo cuenta con instalaciones y piezas atractivas para todos los públicos por lo que es usado para realizar películas, eventos de moda y corporativos. Una de las películas que se realizó en los espacios del museo y generó mayor exposición para la institución fue "Una noche en el museo" (2006), la cual narra la historia de un guardián del museo que descubre que varias piezas y personajes de las exhibiciones cobran vida por la noche. La película ocasionó mayor afluencia de público internacional en el año 2006, el de su estreno, ya que generó mayor interés entre los públicos y a los miembros del museo en ese momento. A pesar de los años, las piezas exhibidas en el museo siguen siendo reconocidas por los visitantes gracias a la película. Debido a ello, el museo creó el evento "Una noche en el museo pijamada para adultos", el cual es organizado cada cierto tiempo para pocos afortunados mayores de 21 años.

El precio es de US\$350 por persona, y miembros solo pagan US\$300. El pago incluye:

- Cena buffet con vino, cerveza y piqueos ligeros.

- Música en vivo.

- Acceso a exhibiciones especiales.

- Tour de fósiles con linterna.

Además de los recorridos a todas las salas disponibles en ese momento. Cada vez que se realiza el evento, los visitantes tienen la oportunidad de vivir una íntima aventura de descubrimiento que es diferente a otra visita a un museo que hayan realizado anteriormente.

Ese es solo uno de los eventos que genera gran aceptación u ofrece a los visitantes una actividad que no podría vivir en ningún otro lugar, ya que también está la exhibición especial llamada "Nuestros sentidos: Una experiencia inmersa", en la cual los asistentes pueden descubrir el porqué de los sentidos y qué es único en la percepción humana, mediante una sesión interactiva con un presentador que conduce el conversatorio.

Cabe resaltar que todas las actividades realizadas en el museo son comunicadas mediante sus canales digitales, y que se promueve la participación del público para generar su propio contenido mediante etiquetas y publicaciones que llamen la atención de estos y sean de su interés. 
Tabla 3.9 Resumen de actividades y acciones que realiza

\begin{tabular}{|c|c|}
\hline \multirow[t]{2}{*}{ Acción } & Una noche en el museo - pijamada para adultos \\
\hline & $\begin{array}{l}\text { El evento es organizado cada cierto tiempo para pocos afortunados mayores de } 21 \\
\text { años. En esta actividad, los inscritos ingresan al museo a las } 6: 30 \mathrm{pm} \text { y salen a las } 9 \\
\text { am viviendo una experiencia única. La noche comienza con una recepción de } \\
\text { champagne y música jazz de una banda popular neoyorquina, mientras los que } \\
\text { buscan explorar el lugar lo realizan de manera calmada por no toparse con una gran } \\
\text { cantidad de turistas. }\end{array}$ \\
\hline \multirow{2}{*}{ Actividad } & Nuestros sentidos: Una experiencia inmersa \\
\hline & $\begin{array}{l}\text { La exhibición tiene como finalidad retar a los visitantes a hacer uso de todos sus } \\
\text { sentidos en ambientes que obligan a confiar en ellos y la percepción que se tiene de } \\
\text { cada uno de ellos no es solo resultado del cerebro sino más allá de eso. }\end{array}$ \\
\hline
\end{tabular}

Fuente: Elaboración propia

Los cuatro museos mencionados realizan actividades que son agradables y entretenidas para los visitantes, llaman la atención y generan que estos transmitan su experiencia a sus amistades y conocidos. Las acciones que los museos toman se basan en lo que le gusta al público, y considerando la realidad y el contexto en que se encuentra la institución, están en concordancia además con lo que transmiten en sus redes sociales y página web. Estos museos son referentes a nivel mundial y, sobre la base del análisis realizado se puede identificar varios factores en común:

- Ofrecen actividades y experiencias que les permiten sobresalir mediante acciones diferenciadas.

- Conocen a su público y adecúan las acciones que realizan basándose en sus preferencias.

- La tecnología e información que comunican en sus plataformas digitales van de la mano con su propuesta de valor.

Si bien, estos museos no pertenecen al territorio peruano y poseen otra realidad económica y afluencia de público, coinciden en ciertos aspectos que podrían ser adaptados por instituciones culturales nacionales. En el siguiente capítulo se explicará más a detalle los museos en el Perú. 


\section{MUSEOS EN EL PERÚ}

Alrededor del país hay museos públicos y privados, con diversas piezas de arte, que ofrecen exhibiciones, siendo Lima la ciudad donde se concentra la mayor cantidad de estos, seguida de Cusco y Arequipa.

Los museos públicos contienen herencia nacional y están a cargo y disposición del Estado; allí se encuentran piezas que son consideradas reliquias y necesitan de cuidado especial por entes reguladores de la cultura. Los recintos son establecidos con apoyo estatal y de los diversos organismos que lo componen; el Museo de Arqueología, Museo de la Nación y el Museo de Pachacamac son claros ejemplos del apoyo que han tenido y continúan teniendo por parte del Estado para poder sostenerse a lo largo del tiempo.

En el caso de los museos privados, se han establecido en menor cantidad y cuentan con apoyo de donaciones de empresas privadas para su mantenimiento, también se respaldan en personas independientes, quienes ofrecen su apoyo y donaciones. Por ejemplo, en el caso del museo MATE, fue Mario Testino quien lo fundó, estableció y registró para poder mostrar sus trabajos y piezas. En su caso no requirió de ningún apoyo estatal y cuenta con cientos de visitas al mes.

Sin embargo, los museos cuentan con un ente regulador, la Dirección General de Museos, el cual es el órgano de línea que tiene a su cargo la formulación de políticas y normas en materia de museos, así como la gestión de museos y la protección, conservación, difusión de los bienes muebles integrantes del Patrimonio Cultural de la Nación descrito por el Ministerio de Cultura en su página web oficial.

La Dirección General de Museos cumple las siguientes funciones mencionadas en la página web del Ministerio de Cultura del Perú: ${ }^{10}$

- Elaborar, promover y proponer cuando corresponda, normas, lineamientos y directivas para la gestión de museos.

- Normar, conducir, implementar, supervisar y gestionar el Sistema Nacional de Museos del Estado (SNME).

\footnotetext{
${ }^{10} \mathrm{http} / / /$ www.cultura.gob.pe/patrimonio/museos/ - Información extraída en abril del 2018.
} 
- Planear, organizar, aprobar dirigir, coordinar y supervisar todas las actividades y programas académicos, técnicos, administrativos y financieros vinculados al quehacer museológico a nivel nacional.

- Planificar y ejecutar las actividades destinadas a fortalecer la identidad local, regional y nacional, a través de programas y actividades de museos, salas de exposición, galerías y centros de interpretación.

- Investigar, conservar, restaurar, exponer y difundir los bienes culturales de los museos.

- Fomentar la creación, implementación y difusión de museos de sitio, o centros de interpretación en monumentos arqueológicos, históricos y lugares relacionados a eventos relevantes para la memoria colectiva del país en coordinación con las áreas pertinentes del Ministerio de Cultura.

Además, la entidad busca mantener nuestra identidad y realiza todos los esfuerzos posibles con el fin de garantizar la defensa, conservación, investigación y exhibición del patrimonio cultural de la nación tal como se menciona en la página web del Ministerio de Cultura. De esta manera, el Estado designa una parte del presupuesto anual para actividades que cumplan con el fin propuesto por la Dirección General de Museos, válido solo para museos pertenecientes al Estado y con limitaciones en museos privados.

Sin embargo, en varios casos, los museos que reciben sustento económico por parte de la nación, cuentan con un grado de comodidad por ser respaldados de esta manera; lo que conlleva a una falta de iniciativa de modernización, y las instituciones culturales que aún no han notado la importancia de utilizar redes sociales como una de las iniciativas básicas para estar expuestas frente a otras instituciones, se han quedado varios pasos atrás (Tugbay, 2012; Liu, 2016). Los fines que posee la Dirección de Museos no abarcan promoción digital u otros medios que no sean los del Estado, por lo que el alcance al público nacional es aún bajo.

Los museos deberían poder readaptar sus programas tratando de integrar aspectos más innovadores mediante análisis previos de instituciones museísticas, y las acciones que han tomado para reflejar el estado de la situación actual que poseen en el sector museístico (Yáñez, 2013); es el caso de los museos del Estado, los cuales no cuentan muchas veces con presupuesto que les permitan realizar otro tipo de actividades 
y la integración de nuevos aspectos para brindar un mejor servicio tiene un proceso más lento.

Retomando lo mencionada por Blas (2018) en el capítulo anterior con respecto a los museos que se centran en un solo artista o tema, y que atraen mayor la atención por la experiencia vivida por el visitante en un nivel más personal, se desea contrastar esta información con la realidad nacional. En el caso de los museos en el país, en general, estos no tienen espacios tan grandes y no abarcan una gran variedad de artistas, sino que se centran más en algún tema específico, como por ejemplo la cultura Chavín o el arte contemporáneo limeño. Mediante esta investigación se podrá validar si lo mencionado por Blas se cumple o es un aspecto que no impacta mucho en los visitantes.

Los museos en el país reflejan nuestra historia y realidad, y nos recuerdan el pasado vivido por nuestros ancestros; otros nos brindan modernidad y una visión más amplia de otras culturas del mundo; sin embargo, aún falta explotar el potencial de muchos de estos para que sean entidades que generen mayor atracción.

En esta investigación, se tomará un museo perteneciente al Ejército como caso de estudio: Museo Fortaleza Real Felipe. El museo se centra en el período de protección de piratas y corsarios y toda la temática gira alrededor de ese tema. Al pertenecer a una entidad del Estado, este se convierte en un museo público y por ende, cuenta con apoyo del gobierno de la región y apoyo estatal.

\subsection{El museo Fortaleza Real Felipe}

El Museo Fortaleza Real Felipe está ubicado en el distrito del Callao y tiene más de 250 años de fundación. Se considera una de las más grandes e impresionantes fortalezas de Europa y Sudamérica.

A comienzos del siglo XVII, Lima era el centro económico para las colonias españolas en Sudamérica; la ciudad floreció gracias al oro y la plata que se obtenía, así como a las riquezas que debían ser exportadas desde el puerto del Callao. Todos esos objetos de valor atrajeron a piratas y corsarios, por lo que a fines de ese siglo se inició la construcción de la fortaleza con el motivo de proteger al puerto de los constantes ataques de piratas y corsarios. 
El museo fue construido de forma pentagonal y los materiales que se utilizaron fueron piedras traídas desde la isla de San Lorenzo y el calicanto, que es una mezcla de cal, arena y clara de huevo de aves guaneras, las cuales abundaban en esa época. Esta reseña histórica se confirma en la página oficial ${ }^{11}$ del Museo Fortaleza Real Felipe.

En 1984, la fortaleza se convirtió en el museo tal como lo conocemos ahora, donde se guardan las piezas de guerra consideradas reliquias historias y que nos brindan remembranzas de una parte de nuestra historia. Además de las piezas, sobresalen también la Casa del Gobernador, estatuas de diversos soldados, el Torreón del Rey y la Reina y variedad de cañones usados durante los ataques.

El museo actualmente forma parte de la red de museos del Ejército del Perú junto con el Museo Andrés A. Cáceres, Museo Chavín de Huántar y Museo Combatientes del Morro de Arica. El Real Felipe es una dependencia del Ejército, el cual se encarga de resguardar y conservar los objetos que fueron parte de los conflictos de la independencia del Perú en defensa de la patria y su soberanía. Las funciones mencionadas se validan en la página oficial del Museo Fortaleza Real Felipe.

Desde que el museo abrió sus puertas al público, ha ido cambiando y renovándose a lo largo de los años gracias al apoyo de las instituciones nacionales. Se ofrecen recorridos diurnos como los demás museos pertenecientes al Ejército, pero también recorridos nocturnos que lo convierten en el museo más atractivo dentro de ese grupo, y en general dentro del mercado museístico.

Los tours nocturnos se iniciaron en 2015, debido a los constantes reportajes que se le realizaban ante la creencia de actividades paranormales en el museo. Sus gestores culturales vieron la oportunidad de ofrecer un tour nocturno para poder brindar a los visitantes una experiencia de suspenso y terror. En un inicio se realizaban solo uno o dos recorridos cada dos meses, ya que se debía llegar a una cuota de público mínima para poder abrir las puertas en la noche. Sin embargo, cuando el museo se insertó en redes sociales, los recorridos nocturnos aumentaron su periodicidad llegando a realizarse cuatro al mes. En fechas especiales como Semana Santa, Halloween u otros feriados, el número de tours se incrementa, debido a que no solo el museo los organiza sino que mantiene relaciones con agencias de turismo que se encargan de coordinar con

\footnotetext{
${ }^{11}$ Reseña histórica extraída de http://www.realfelipe.com/museos-relacionados/museo-fortaleza-realfelipe
} 
el museo días de tours no previstos. La información de los recorridos, fechas y días es comunicada por medio del fanpage oficial del Museo Fortaleza Real Felipe (www.facebook.com/fortalezarealfelipe). En términos comunicacionales, este es el medio más directo que posee para llegar a su público. Allí resuelven dudas de los usuarios y brindan información adicional mediante los comentarios y mensajes privados (inbox). La página web está actualizada con información del museo, pero no pueden responder a las dudas tan rápidamente como se realiza mediante Facebook, ya que toda la comunicación externa llega mediante correo.

El tour nocturno ha creado su propio flujo comunicacional con los usuarios y con las agencias de turismo, y para especificar un poco más el atractivo del recorrido nocturno que ofrece el museo, se brinda el detalle: un guía acompaña al grupo en todo el recorrido, que dura aproximadamente dos horas y media. Se visitan todos los espacios que posee el museo. El recorrido se realiza a oscuras, sin luces ni linternas de por medio. A la mitad del mismo se realiza un descanso para que los visitantes vayan a los servicios o puedan comer algo.

El número de asistentes es, en promedio, de 50 a 70 personas por noche de tour, en que solo se permite el ingreso a mayores de 18 años. Los públicos son variados pero en su mayoría son jóvenes. Cuando se inició el recorrido, los asistentes eran 20 en promedio, número que se incrementó al estar presentes en Facebook, llegando a alcanzar 100 personas por noche en fechas como Halloween.

El precio de los recorridos diurnos es inferior a los nocturnos por temas de logística. En ambos tours se ofrece la misma información histórica pero relatada de diferente manera, adaptándose al público asistente y el ambiente que se viva en el momento.

Todos los aspectos que están envueltos en el tour nocturno se explicarán más a detalle en la sección Resultados, yendo desde el ingreso de los visitantes al museo a las primeras fases del recorrido, describiendo las actividades que realizan dentro y cerrando con la manera en que finaliza el recorrido.

En la tabla 4.1 se presenta un resumen de los activos digitales del museo, del contenido y de las actividades que se realizan. 
Tabla 4.1 Resumen de los activos digitales del museo, del contenido y de las actividades que se realizan en el Museo Fortaleza Real Felipe

\begin{tabular}{|l|l|}
\hline Medios digitales & $\begin{array}{l}\text { Facebook: } 4.177 \text { seguidores } \\
\text { Página web: activa y actualizada con información de los tours, horarios y números de } \\
\text { contacto. }\end{array}$ \\
\hline $\begin{array}{l}\text { Información en } \\
\text { redes sociales }\end{array}$ & $\begin{array}{l}\text { - Eventos de tour de noche. } \\
\text { - Fotos de visitantes a museos. } \\
\text { - Videos del tour de noche y de programas donde han tenido alguna participación televisiva. } \\
\text { - Datos y textos curiosos sobre el museo. }\end{array}$ \\
\hline Interacciones & $\begin{array}{l}\text { - Promedio 30. } \\
\text { - Comentarios y reacciones positivos. }\end{array}$ \\
\hline $\begin{array}{l}\text { Acciones } \\
\text { experienciales }\end{array}$ & $\begin{array}{l}\text { - Durante el tour nocturno, los visitantes recorren el museo de forma diferente. } \\
\text { - Durante el tour diurno, los visitantes aprecian un show relacionado con la historia del } \\
\text { museo. Un hombre disfrazado de pirata les cuenta parte de lo vivido en la en la fortaleza de } \\
\text { forma didáctica y envolvente. }\end{array}$ \\
\hline Actividades & $\begin{array}{l}\text { - Realiza representaciones para conmemorar alguna fecha histórica importante relacionada } \\
\text { con alguna batalla o guerra. Actores se visten de los personajes y ofrecen un show que los } \\
\text { asistentes disfrutan. La mayoría de veces es de ingreso gratuito. }\end{array}$ \\
\hline
\end{tabular}

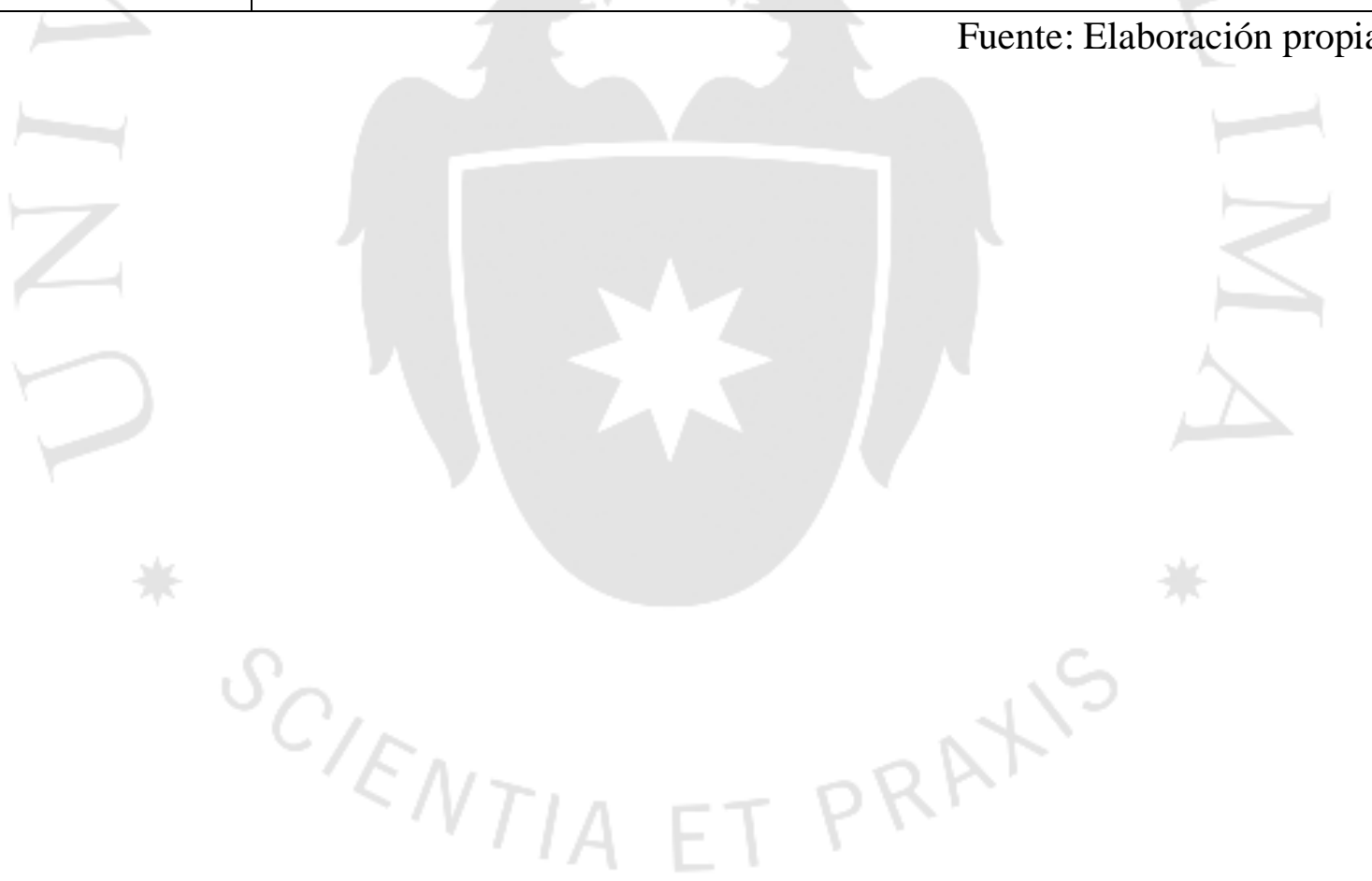




\section{v. METODOLOGÍA}

\subsection{El problema de la investigación}

Varios museos de Lima han dado un salto a los medios digitales, debido a la forma en la cual ahora las personas reciben las noticias e información. Dentro de este mercado cultural cambiante, se encuentra el Museo Fortaleza Real Felipe, que en 2016 realizó su inserción a los medios digitales mediante la creación de su página web y una página en Facebook. Esta inserción ha sido lenta ya que al trabajar con fondos públicos, hace uso de estos para remodelaciones y estas no incluyen la inversión en estrategias de marketing más elaboradas para la difusión del museo. Pese a ello, el museo ha logrado comunicar en sus redes uno de los servicios más llamativos que ofrece: el recorrido nocturno, el cual es una experiencia única, por lo que se desea investigar el grado de visibilidad que ha obtenido mediante el contenido publicado en Facebook, así como el impacto y la aceptación de la oferta experiencial entre los públicos visitantes.

Actualmente, varios museos y organizaciones cuentan con productos culturales que son dados a conocer vía redes sociales, las cuales se han convertido en herramientas accesibles y económicas para lograr mayor reconocimiento entre los potenciales visitantes. El presente estudio incluirá el análisis de la promoción que tiene el recorrido nocturno en Facebook, enfatizando en la oportunidad de vivir una experiencia única, sobre la base del marketing experiencial y continuando con las respuestas de las muestras del público obtenidas al término del recorrido. El público será un objeto clave, ya que es quien selecciona el lugar a visitar basado en sus intereses. Partiendo de eso, se desea hallar respuesta a los distintos cuestionamientos y tener una aproximación más certera para determinar la visibilidad del tour nocturno mediante la estrategia aplicada.

Las interrogantes a resolver que se plantean en esta investigación son:

1. ¿Qué tipo de experiencia y aspectos son los que llevan a la aceptación del recorrido nocturno por parte de los visitantes?

2. ¿Qué componentes envuelven la experiencia del recorrido nocturno?

3. ¿Qué aspectos sugieren mejoras dentro del tour para darles mayor satisfacción a los visitantes? 
4. ¿Cuáles son los posibles factores que influyen de manera positiva o negativa en las acciones en Facebook que realiza el museo para obtener visibilidad y aceptación entre los públicos visitantes?

5. ¿Cuáles son las variables que determinan el aumento de visitantes a un museo mediante el contenido en Facebook?

6. ¿Cuáles son los posibles factores que influyen en la gestión de acciones en Facebook para generar visibilidad dentro del mercado museístico?

\subsection{Justificación}

Se consideró investigar la iniciativa en Facebook del recorrido nocturno aplicada en el Museo Fortaleza Real Felipe, enfatizando el grado de visibilidad obtenida por este medio y con respecto a la aceptación por parte del público por tres razones:

En primer lugar, esta investigación representa un aporte a las especialidades de Comunicaciones y Publicidad, ya que muestra la forma de adaptación con respecto a temas de comunicación de un museo que posee escasos recursos para publicidad, pero que realizó su inserción al mundo digital de forma notable y, pese a las limitaciones, continúa promoviendo sus eventos e información a través de la red.

En segundo lugar, representa un caso práctico peruano que posee un producto cultural único en el país, que cuenta con potencial para ser explotado aún más con nuevas acciones. De esta manera, se forman precedentes para los futuros gestores de redes sociales para considerar nuevas maneras de acercamiento al público en el formato digital y con contenido relevante. Cabe resaltar que ya se vienen implementando estrategias que buscan fomentar el diálogo y la interacción con los usuarios en el país, como es el caso del Museo de Arte de Lima, el cual es muy activo en cuanto a promoción de eventos y talleres en sus redes.

En tercer lugar, esta investigación propone dar información sobre un nuevo caso de estudio que utiliza el marketing experiencial en un recorrido nacional que es único y diferenciado frente a los servicios de otras instituciones culturales. Al tratarse de un tema que no se ha estudiado a detalle ni se ha ahondado en los distintos aspectos que envuelven los factores de la experiencia, además de no existir mucha data ni información sobre casos locales a nivel nacional, se desea fomentar la continuación de 
investigaciones relacionadas con este tema en otras instituciones ya que aún existe mucho más por analizar. La constante búsqueda de información y descubrimiento de nuevos conocimientos es sumamente relevante ya que la cultura como industria trae consigo muchos beneficios para el país como es el turismo local y extranjero, pues los productos culturales de cada región se ven expuestos para un público más amplio. Otro beneficio es la democratización de la educación con respecto a temas culturales e históricos del país; la apertura y el acceso a instituciones es importante para contribuir con el desarrollo educativo. Además, otro beneficio es la generación de puestos de trabajo y el incremento del PBI. Para poder hallar soluciones y mejoras con respecto a las estrategias que se aplican en el sector cultural nacional, es relevante poder tomar conciencia de lo necesaria que es la constante búsqueda de información relacionada con este tema de investigación.

\subsection{Objetivos de investigación}

Objetivo general:

- Determinar el grado de visibilidad que ha obtenido el recorrido nocturno del Museo Fortaleza Real Felipe mediante el contenido publicado en Facebook, así como el impacto y la aceptación de la oferta experiencial entre los públicos visitantes.

Objetivos específicos:

- Determinar si las acciones en Facebook y la gestión han favorecido la visibilidad del Museo Fortaleza Real Felipe.

- Identificar el nivel de afluencia medido en el número de visitantes al recorrido nocturno desde que se iniciaron las actividades en Facebook.

- Identificar la aceptación y la experiencia obtenida con la oferta del recorrido nocturno.

\subsection{Metodología técnica}

Esta investigación se desarrolla mediante una metodología mixta: se aplican herramientas cualitativas y cuantitativas para la realización de un estudio más 
exhaustivo. Se busca la obtención de datos y de información mediante el análisis de contenido y la entrevista a profundidad, todo lo cual se complementa después con los resultados de las muestras que permiten medir las variables del público a estudiar (Hernández, Fernández \& Baptista, 1994). La entrevista a profundidad permitirá identificar el nivel de afluencia medido en el número de visitantes al recorrido nocturno desde que se inició con el contenido relacionado a este en Facebook. Las variables planteadas en esta investigación se desprendieron de los objetivos, y estas son: impacto, popularidad, gestión en medios digitales, aceptación y experiencia vivida. En cuanto al público a estudiar, se considera a los visitantes del recorrido nocturno. El detalle de lo mencionado se explicará minuciosamente en la sección 5.5.

Además de lo mencionado, se usará el marketing cultural para analizar lo realizado por el museo, ya que se trata de una organización con objetivos que están enfocados al beneficio de la sociedad a través del fomento del conocimiento de sus productos culturales (Quero y Jiménez, 2011). Sumado a ello, se usa el marketing experiencial como fundamento para responder si existe aceptación por parte de los públicos visitantes con respecto al recorrido nocturno. Se desea medir si la propuesta del museo que apuesta por vivir una experiencia única tiene acogida, además de evaluar si el fanpage del museo ayuda a su visibilidad y aceptación. La medición se hará a través de las técnicas que usa el marketing digital para medir la efectividad de sus acciones de comunicación digital. Se hará un análisis de sus publicaciones en el fanpage y se verá el alcance orgánico obtenido, el cual es una métrica que arroja Facebook para visualizar el número de personas que han visto una publicación y las interacciones realizadas. Dentro del marketing digital, también se encuentra el net sentiment, el cual consiste en obtener un porcentaje que refleje el tono emocional detrás de las interacciones para entender las actitudes y aceptación suscitadas en el fanpage (Bannister, 2015). El análisis detallado de los comentarios e interacciones ya sean positivos, negativos o neutros dará información acerca de las expectativas que tienen los usuarios sobre el tour nocturno y el interés que les genera realizar el recorrido, además de arrojar respuestas para determinar si el contenido publicado en Facebook ha favorecido la visibilidad del Museo Fortaleza Real Felipe. También, permitirá visualizar los temas prioritarios y tono de comunicación que posee la organización. El porcentaje del análisis mediante el net sentiment se halla sumando el número de interacciones 
positivas y neutrales para luego restarle los comentarios negativos y dividirlo entre el número total de comentarios.

$$
\text { Net Sentiment }=\underline{(\text { C. Positivos }+ \text { C. Neutrales }- \text { C. Negativos })}
$$

Comentarios totales para la marca

Tanto el net sentiment como el análisis de contenido, la entrevista a profundidad y demás conceptos relacionados con el marketing, permitirán dar respuesta a los objetivos propuestos en la investigación. A continuación se detalla la aplicación de las técnicas de recolección y la aplicación para cada uno.

\subsection{Técnica de recolección y aplicación}

En primer lugar, para dar respuesta al siguiente objetivo:

- Identificar el nivel de afluencia medido en el número de visitantes al recorrido nocturno desde que se iniciaron las actividades en Facebook.

Se utiliza la entrevista a profundidad como una de las técnicas de recolección. Esta técnica es vital para responder al objetivo mencionado y a otro que se explicará más adelante, ya que se conocerá información valiosa dentro de la institución que solo está en poder de los colaboradores del museo. Mediante una entrevista estructurada al coordinador de marketing (ver anexo 1) se da respuesta a la siguiente pregunta de investigación:

- ¿Cuáles son las variables que determinan el aumento de visitantes a un museo mediante el contenido en Facebook?

El señor José Luis Núñez es el responsable de manejar tanto el fanpage del museo como la página web del Real Felipe, y es quien tiene el cargo de coordinador de marketing. La variable que se considera para este objetivo es el impacto; el concepto que se desprende como objeto de análisis es la variación positiva en el número de visitantes.

Para adicionar la respuesta a este objetivo también se consideró aplicar encuestas a una muestra de visitantes, en la que se incluyen preguntas referentes a la forma en que tuvieron noticias sobre el recorrido y por qué medio llegaron a él. Las encuestas fueron 
estructuradas (ver anexo 4 y 6). Más adelante se detalla las distintas preguntas que contienen las encuestas, ya que se puso énfasis en preguntas experienciales

Seguido de ello, para poder responder al siguiente objetivo:

- Determinar si las acciones en Facebook y la gestión han favorecido la visibilidad del Museo Fortaleza Real Felipe

Se tomó como variable la gestión en medios digitales y, como concepto, el tipo de gestión que ha favorecido al alcance y aceptación (ver anexo 3). Aquí también se utiliza la técnica de entrevista al coordinador de marketing, con preguntas orientadas a resolver cuestionamientos relacionados con la gestión y la visibilidad, ya que mediante esta técnica se busca conocer acerca del proceso de inserción del museo a las redes y si la experiencia que brinda el recorrido de noche fue el detonante para poder promoverlo en redes. Además, se recogen los puntos de vista del coordinador sobre los logros alcanzados en materia de la visibilidad del museo, tomando en cuenta el método, el surgimiento y la viabilidad de las acciones tomadas en Facebook, así como el alcance entre el público y las estrategias a mediano plazo y largo plazo que tiene en proyectos la institución.

Esta investigación también utiliza el análisis de contenido y el análisis métrico para responder este objetivo con el motivo de identificar el alcance de las publicaciones relacionadas con el recorrido nocturno en Facebook, mediante el net sentiment y, con ello, visualizar la aceptación que está teniendo. Además, se desea saber cómo la comunidad comenta en esa plataforma dicha experiencia.

El análisis cualitativo del contenido se realiza a la página de Facebook del Museo Fortaleza Real Felipe (https://www.facebook.com/fortalezarealfelipe/), en la que se identifican tipos de publicaciones, álbumes de fotos y videos desde su inserción en la red social en marzo de 2016 hasta marzo de 2018. Desde el inicio, el fanpage se mantuvo activo con publicaciones casi diarias, relacionadas todos con reforzar la visibilidad del museo como una institución histórica cultural, mediante fotos y videos de las visitas de personajes representativos del país y del extranjero. Además, se utilizó imágenes relacionadas con el acontecer nacional e histórico para llamar la atención de los usuarios, álbumes de fotos de eventos que se realizan en las instalaciones del museo, datos curiosos e información de los recorridos. 
Luego de eso, se realiza una medición exhaustiva manual de las publicaciones relacionadas con el recorrido nocturno. Se considera analizarlas de octubre de 2016 hasta abril de 2018, agrupándolas por fecha, tipo de publicación y cantidad de comentarios y veces que se ha compartido para tener resultados más actuales. Se agregará a los datos obtenidos las métricas de la página del Facebook del museo, las cuales fueron proporcionadas por los gestores del sitio web; se trata de información que solo está disponible para ellos y que el público no puede visualizar. Se otorgaron gráficos del alcance por publicación, por lo que se pudo contrastar tanto la información visible como la interna. Se toma en consideración solo la información de los gestores con respecto a publicaciones relacionadas al recorrido nocturno, en la que se visualiza el número de alcance obtenido, es decir las personas que vieron el post pero que no necesariamente tuvieron alguna interacción con este, o que es definido como el número de personas que fueron impactadas con la comunicación. Esta métrica se da de acuerdo al alcance orgánico, ya que ninguna publicación en el período de investigación tuvo inversión publicitaria. Las publicaciones se separan por fechas para poder obtener una visión más panorámica de la información que visualizan los usuarios y potenciales visitantes al recorrido, el detalle de esto se explica en el capítulo VI.

A través del objetivo mencionado se resuelven las siguientes preguntas de investigación:

- ¿Cuáles son los posibles factores que influyen de manera positiva o negativa en la estrategia de promoción del museo para obtener visibilidad y aceptación entre los públicos visitantes?

- ¿Cuáles son los posibles factores que influyen en la gestión de acciones en Facebook para generar visibilidad dentro del mercado museístico?

Por último, para responder al objetivo:

- Identificar la aceptación y la experiencia obtenida con la oferta del recorrido nocturno.

Otra técnica de recolección que se utiliza es la encuesta aplicada a una muestra de visitantes. Al ser una investigación enfocada también en los visitantes del recorrido nocturno, se considera realizar una primera muestra (ver anexo 4) in situ para conocer el perfil del usuario y la aceptación que le otorgan al tour. Por medio de una serie de preguntas estructuradas se examina la eficacia de las acciones realizadas en Facebook, 
la experiencia de los visitantes de manera general y las novedades del museo de las cuales están informados.

En este caso, se considera una muestra de 70 personas, a las cuales se encuestan en dos grupos: el 27 de mayo de 2017 (51 personas) y el 3 de junio de 2017 (19 personas), fechas en que se realizan los recorridos nocturnos. Los días analizados fueron escogidos al azar sin ningún criterio específico, no hubo ningún evento especial ni ocurrieron sucesos relevantes en esas fechas.

El Museo Fortaleza Real Felipe realiza por lo general dos recorridos nocturnos al mes los días sábados. De manera extraordinaria, como sucedió en junio de 2017, se llevó a cabo cuatro recorridos. También aplica la misma política en fechas especiales, como Semana Santa.

El 27 de mayo, el museo organizó el recorrido nocturno y lo publicitó en sus plataformas digitales. El 3 de junio, el tour fue organizado por las agencias de turismo que trabajan con el Real Felipe; en esta ocasión el museo brindó el servicio de guías, pero no publicitó la visita en las redes. El museo suele ofrecer este tipo de servicio todo el año, previa coordinación con las agencias de turismo socias, responsables de dirigir las visitas que son privadas. En la tabla 5.1 se detalla algunas características de la muestra:

Tabla 5.1 Detalle de la muestra: 1era encuesta en Real Felipe

\begin{tabular}{|l|l|l|}
\hline Grupos & Asistentes & Encuestados \\
\hline Independientes/museo & 65 & 51 \\
\hline Agencia de Turismo & 35 & 19 \\
\hline \multicolumn{2}{|c|}{ Total } & 70 \\
\hline
\end{tabular}

Fuente: Elaboración propia

Los asistentes en el grupo de personas independientes que llegaron por su cuenta y con conocimiento a través de Facebook fueron de 65, lo cual es un número de visitantes más alto que el promedio normal, que oscila entre 30 a 40 . El número de asistentes el día en que se desarrolló el recorrido con la agencia de turismo se obtuvo un número promedio.

Esta primera muestra se realizó en 2017 y fue netamente para obtener información del perfil del usuario y la aceptación que le otorgan al recorrido nocturno. Preguntas relacionadas estrictamente con su experiencia y basadas en el concepto de 
marketing experiencial no se incluyeron, por lo que se desarrolló una segunda muestra (ver anexo 6) con preguntas estructuradas para recabar información acerca de la experiencia vivida en el recorrido para obtener, además, puntos de mejora del desarrollo del tour y la experiencia otorgada a los visitantes.

Tabla 5.2 Detalle de la muestra: 2da encuesta en Real Felipe

\begin{tabular}{|l|l|l|}
\hline Grupos & Asistentes & Encuestados \\
\hline Agencia de Turismo & 100 & 36 \\
\hline
\end{tabular}

Fuente: Elaboración propia

Tal como se realizó en la primera muestra, la segunda encuesta también fue in situ. El 16 de junio fue realizada y la fecha fue escogida al azar, sin ningún motivo en específico, pero se realizó durante la mañana coincidiendo con el primer partido de Perú en el mundial. El público estaba animado y sociable. El recorrido de ese día fue organizado por una agencia de turismo que trabaja con el Real Felipe; el museo brindó el servicio de guías pero no publicitó la visita en las redes. El total de asistentes fue dividido en tres grupos de 30, 35 y 35 personas, con horarios de 7 pm, 7:15 pm y 7:30 $\mathrm{pm}$, respectivamente.

Los museos y galerías han tenido una rápida adopción de la técnica de muestreo para poder obtener información demográfica y feedback de los visitantes. De manera similar a la venta de un producto, los museos usan las muestras para mejorar sus exhibiciones y crear nuevas estrategias. Esto debido a que el mercado ha ido transformándose y no solo se le debe enseñar a los visitantes sobre cultura y arte sino también adicionar las preferencias y gustos de ellos para mejorar su experiencia. (Wallace, 2000).

Basado en lo mencionado por Wallace, con el fin de lograr que un museo esté centrado en sus visitantes y brinde lo que es del interés de ellos, es importante que la institución se mantenga en el tiempo como un museo atractivo y que se preocupe por otorgarle actividades de acuerdo a sus preferencias. Además, mediante las muestras se abren caminos para poder acercarse más a las necesidades y gustos de los visitantes para la innovación constante. 
A través de lo mencionado anteriormente acerca de la experiencia y la aceptación por parte de los visitantes se podrá responder las siguientes preguntas de la investigación:

- ¿Qué tipo de experiencia y aspectos son los que llevan a la aceptación del recorrido nocturno por parte de los visitantes?

- ¿Qué componentes envuelven la experiencia del recorrido nocturno?

- ¿Qué aspectos sugieren mejoras dentro del recorrido para darles mayor satisfacción a los visitantes?

En el capítulo VI se detallará los resultados obtenidos con respecto a cada objetivo y preguntas de investigación. 


\section{Resultados}

\subsection{El museo en los ojos del público}

El Museo Fortaleza Real Felipe cuenta actualmente con 5.288 fans en Facebook que van de los 18 a los 44 años en su gran mayoría, siendo el más alto porcentaje el de mujeres (64\%). En la figura 6.1 se muestra los porcentajes de género y edades de los fans:

Figura 6.1 Detalle de edad y sexo de fans del Facebook del Real Felipe

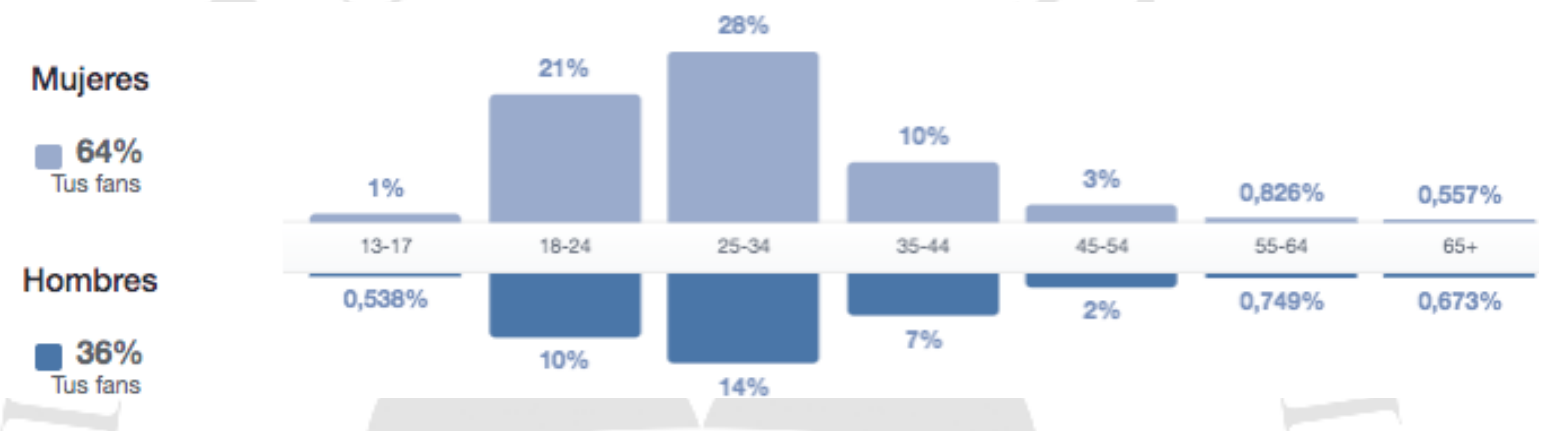

Fuente: Métrica proporcionada por los gestores del fanpage del museo (Junio 2018).

Estos porcentajes representan similitud con las respuestas de las encuestas en las dos muestras realizadas durante días de recorridos nocturnos.

Tabla 6.1 Detalle de edad y sexo de los visitantes del tour nocturno en los días de muestreo.

\begin{tabular}{|c|l|l|l|l|}
\hline 1era encuesta: 70 & Mujeres & $57 \%$ & 18 a 35 & $70 \%$ \\
\cline { 2 - 5 } & Hombres & $43 \%$ & 35 a más & $30 \%$ \\
\hline 2da encuesta: 36 & Mujeres & $50 \%$ & 18 a 35 & $78 \%$ \\
\cline { 2 - 5 } & Hombres & $50 \%$ & 35 a más & $22 \%$ \\
\hline
\end{tabular}

Fuente: Elaboración propia

Como se visualiza en el cuadro, las mujeres fueron las visitantes predominantes en la primera muestra, mientras que en la segunda el porcentaje fue equitativo. Las edades de los visitantes en ambas muestras fueron en su mayoría entre 18 y 35 años. Para entrar a mayor detalle sobre el público, se obtuvo la información de países y 
ciudades donde se tiene mayor cantidad de seguidores, sumado a ello los idiomas predominantes (ver tabla 6.2).

Tabla 6.2 Detalle de país, ciudad e idioma de los seguidores de la fanpage del museo

\begin{tabular}{|l|c|l|c|l|c|}
\hline País & Número de fans & Ciudad & Número de fans & Idioma & Número de fans \\
\hline Perú & 5.055 & Lima & 4.112 & Español & 4.132 \\
\hline E.E.U.U & 34 & Callao & 339 & Español(España) & 956 \\
\hline Chile & 29 & Bellavista & 52 & Inglés (E.E.U.U) & 68 \\
\hline Argentina & 13 & Trujillo & 46 & Inglés (UK) & 17 \\
\hline Otros & 157 & Otros & 739 & Otros & 115 \\
\hline
\end{tabular}

Fuente: Información proporcionada por los gestores del fanpage del museo (Junio 2018).

La mayoría de usuarios que siguen al museo en redes son hispanohablantes y de Sudamérica, la mayoría de la capital de Perú y solo una provincia está entre las primeras cinco ciudades. En cuanto a los idiomas, español e inglés son los que tienen mayor número de fans, lo cual depende de la configuración de la cuenta de Facebook del usuario, por lo que puede haber variaciones en este aspecto.

Seguido de ello, para conocer un poco más sobre los perfiles de los visitantes al tour se consideró preguntar dentro de las encuestas si suelen seguir a museos en Facebook, lo que resultó en un 64\% de respuestas afirmativas y 36\% de negativas. La pregunta se considera relevante, ya que esta información no la brindan las métricas otorgadas por Facebook. Los museos que la mayoría siguen son el del Real Felipe, el MALI y el Museo de Arte Contemporáneo, con 42, 24 y 11 votos respectivamente. La pregunta en la encuesta permitía marcar más de una opción dando como resultado la información mostrada en la figura 6.2. 
Figura 6.2 Detalle de los museos en Lima que siguen en Facebook los visitantes
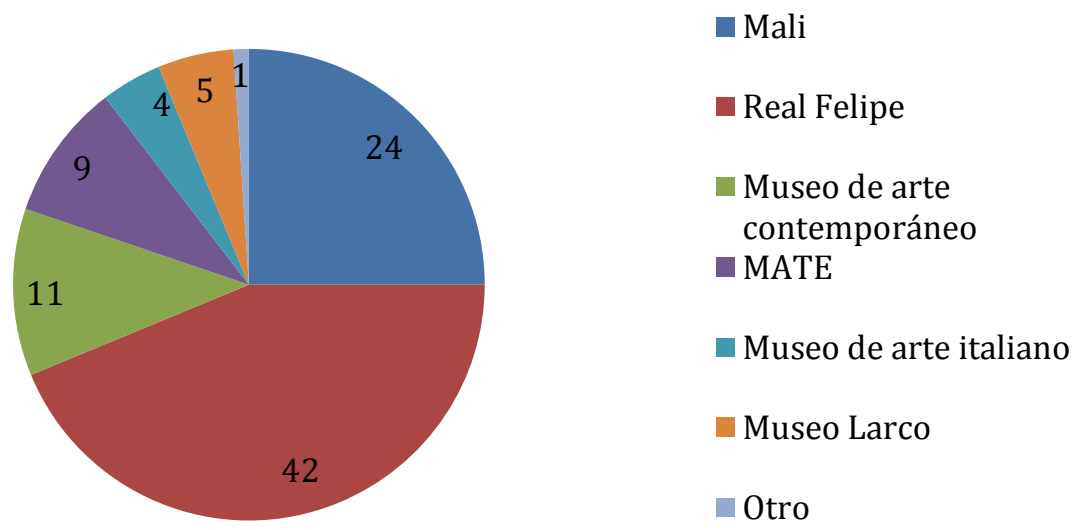

Fuente: Elaboración propia

Con respecto a la variable de novedades y últimas noticias escuchadas relacionadas al museo, se les preguntó a los encuestados si habían oído algo relacionado a esto, lo cual resultó en un $60 \%$ de respuestas negativas y $40 \%$ de respuestas afirmativas. La mayoría mencionó haber leído acerca de los recorridos (58,6\%), mientras que el 27,6\% mencionó datos relacionados a la historia del museo, y el 13,8\% consideró noticias relacionadas a Félix Moreno en el contexto del escándalo suscitado por el desvío de fondos del Gobierno Regional de Callao para la construcción de un "sauna spa", dinero que estaba destinado a remodelaciones del Real Felipe.

\subsection{La visibilidad del museo Fortaleza Real Felipe como consecuencia de las acciones de comunicación en Facebook..}

Para responder al objetivo de determinar si las acciones en Facebook y la gestión han favorecido la visibilidad del Museo Fortaleza Real Felipe, se debe mencionar el surgimiento de estas. Antes de la inserción del Real Felipe a medios digitales, el museo usaba volantes para promocionar el recinto, era sede de eventos culturales y canales nacionales e internacionales hacían reportajes en las instalaciones esporádicamente. De esta forma, el museo tenía exposición de un alcance medio a un público amplio. José Luis Núñez, coordinador de marketing del museo, afirma que el surgimiento de la iniciativa para promocionar el recorrido nocturno en el fanpage se debió a una necesidad de ampliar el número de visitantes, ya que es una experiencia única y que 
solo el museo posee, y era una oportunidad para aplicar el tema digital de manera efectiva y económica.

Sumado a lo mencionado por el coordinador de marketing, en 2016, los directivos del museo se dieron cuenta que, para llegar a un mayor público y estar a la par con los demás museos de la ciudad, debían tener presencia en redes sociales. Se evaluaron las plataformas y seleccionaron Facebook, ya que el alcance es alto y el presupuesto que usarían sería bajo. Además, crearon la página web oficial del museo, la cual comparte cierta información del Facebook, como la información general de precios y horarios.

José Luis, coordinador de marketing del museo, menciona que Facebook es la red social que permite contacto inmediato con los seguidores de la página, por lo que la comunicación con ellos trata de ser fluida y rápida pese a no darse abasto de estar pendientes las 24 horas del día. Un problema que les impide tener una mejor interactividad desde que se inició con la publicación de contenido es el no poseer una persona que se encargue exclusivamente de las redes sociales para que esté en constante contacto con los usuarios y responda las preguntas y comentarios que se hacen.

Desde que se inició con el contenido relacionado al recorrido nocturno, las publicaciones han tenido un tono de comunicación amigable y cercano, además de ser constantes. Con respecto a los contenidos, difieren un poco en el fanpage y en la página web, ya que son diferentes públicos. En la página web incluyen información importante del museo como horarios, recomendaciones, fechas y correos de contacto, ya que perdían muchas visitas al museo por no tener esos datos; en cambio en la página de Facebook tratan de incluir información más variada e interactiva para generar interés.

El museo no cuenta con presupuesto para invertir en estrategias digitales o para colocarle pauta digital a todas las publicaciones relacionadas con el recorrido nocturno; sin embargo, sí lo hace con publicaciones específicas, tal como sucedió en febrero de 2017 para poder promocionar la semana de los museos del Ejército, en la cual los visitantes podían tener descuentos en las entradas y ver las nuevas exhibiciones temporales. Gracias a ello, el número de visitas al museo aumentó con respecto a semanas anteriores. A diferencia de las publicaciones del recorrido nocturno, que no han contado con ninguna inversión publicitaria desde que se inició pero han tenido un buen alcance. 
El contenido en Facebook permitió que el museo sea conocido por un mayor número de personas y a través de las encuestas se pudo identificar la visibilidad que está teniendo el recorrido nocturno entre los visitantes, así que se consideró importante incluir entre las preguntas de ambas encuestas la manera en la cual conocieron el tour. Como se ve en la tabla 6.3, los porcentajes de los resultados son variados.

Tabla 6.1 Detalle de las fuentes de conocimiento del tour en la 1era y 2da muestra.

\begin{tabular}{|l|l|l|l|}
\hline \multicolumn{2}{|c|}{ 1era muestra } & \multicolumn{2}{c|}{ 2da muestra } \\
\hline $\begin{array}{l}\text { Facebook Museo Real } \\
\text { Felipe }\end{array}$ & $51,4 \%$ & $\begin{array}{l}\text { Facebook Museo Real } \\
\text { Felipe }\end{array}$ & $38,9 \%$ \\
\hline Amigos & $21,4 \%$ & Amigos & $33,3 \%$ \\
\hline Agencia de turismo & $12,9 \%$ & Agencia de turismo & $13,9 \%$ \\
\hline Otro & $12,9 \%$ & Otro & $13,9 \%$ \\
\hline Periódico / radio/ TV & $1,4 \%$ & Periódico / radio/ TV & $0 \%$ \\
\hline
\end{tabular}

Fuente: Elaboración propia

El porcentaje más alto de ambas muestras demuestra que los visitantes conocieron el recorrido nocturno por medio del Facebook del museo. José Luis Núñez, coordinador de marketing del museo, mencionó además, que los visitantes que acuden al tour por su cuenta, es decir que compran ellos mismos las entradas en el museo el mismo día y no a través de agencias, es que llegan por el Facebook. Además, son quienes conocen del servicio mediante el fanpage y obtienen la información que necesitan. El segundo porcentaje en ambas muestras es el conocimiento del recorrido nocturno a través de amigos. El público que se enteró de la existencia del tour a través de periódico, radio o TV tiene un porcentaje casi nulo, ya que el museo no invierte en medios masivos.

\subsubsection{Relación del público con el fanpage}

Para complementar la información de conocimiento del recorrido nocturno, se pidió a los visitantes encuestados seleccionar lo que más les interesa encontrar dentro de la 
fanpage, resultando "datos curiosos" con 22 respuestas marcadas, lo que la convierte en la opción más seleccionada. En la tabla 6.4 se muestran los aspectos de interés.

Tabla 6.2 Detalle de la información que le interesa a los visitantes en la fanpage.

\begin{tabular}{|l|l|}
\hline Datos curiosos & 22 \\
\hline Información de eventos y promociones & 18 \\
\hline Información de la institución & 14 \\
\hline Álbumes de fotos & 4 \\
\hline
\end{tabular}

Fuente: Elaboración propia

La información acerca de eventos y promociones también causa interés por parte de los visitantes; muy de cerca le sigue la información de la institución que abarca horarios, datos históricos y datos generales sobre esta.

José Luis Núñez, encargado del fanpage del museo, mencionó en la entrevista realizada que los usuarios suelen interesarse por los "datos curiosos" e información que no se encuentra fácilmente en los libros, por lo que suele publicar estos tipos de estados de Facebook para generar el interés del público, como se muestra en la figura 6.3.

Figura 6.3 Publicación "dato curioso" 30 de octubre 2016

\section{Museo Fortaleza Real Felipe}

October 30, $2016 \cdot$

Dato tenebroso del Real Felipe:

Cuando José Ramón Rodil, Comandante Militar de las fuerzas del Callao, se rehusa a aceptar la independencia del Perú (1824), este se encierra en la Fortaleza del Real Felipe con 13 mil personas entre militares y civiles, casi dos aňos despues este se rinde y de la Fortaleza solo salen 400 personas.

Las otras 12600 aun siguen ahi. Esperandote.

31 de octubre, recorrido nocturno.

(1) 155 Comments 1Share

Fuente: Fanpage Museo Fortaleza Real Felipe 
En cuanto a interacción con la fanpage del museo, el 52\% de encuestados respondió no comentar ni compartir ninguna publicación, pero el $48 \%$ restante sí. Además, el $81 \%$ sí suele dar "me gusta" a alguna publicación que ve, mientras el resto manifestó no hacerlo.

Desde la perspectiva de la institución, la comunicación y el contenido deben ir acorde a este y mantener la relevancia entre el público. Al tratarse de una institución perteneciente al Ejército, los lineamientos y directrices de comunicación son estrictos y no se tiene mucha apertura para usar lenguaje informal; sin embargo, son versátiles cuando se tratan de publicaciones relacionadas al recorrido nocturno. Contextualizando el estilo de comunicación del museo, en la sección 6.2.2 se presentará el análisis del contenido de manera general de la fanpage del museo, y de forma específica de las publicaciones relacionadas al recorrido nocturno, para visualizar el tono emocional de las interacciones de los usuarios. Esto se refiere a los tipos de comentarios que están teniendo las personas con respecto al contenido del museo.

\subsubsection{Popularidad del contenido}

A marzo de 2018, la página de Facebook del Museo Fortaleza Real Felipe cuenta con más de 200 publicaciones desde su creación, en marzo del 2016. Desde el inicio, se mantuvo activa con publicaciones casi diarias, relacionadas todas con reforzar la imagen del museo como una institución histórica cultural, mediante fotos y videos de las visitas de personajes representativos del país y extranjeros, además de imágenes relacionadas con el acontecer nacional e histórico para llamar la atención de los usuarios. Incluyen también álbumes de fotos de eventos realizados en las instalaciones del museo, datos curiosos e información de los recorridos.

El museo pertenece a la Dirección de Museos del Ejército, por lo que se trabaja en sinergia con el Facebook de esta instancia para informar sobre los eventos relacionados con los museos del Ejército. En el fanpage se pudieron encontrar publicaciones compartidas del Facebook de la Dirección de Museos para promover las actividades culturales que se realizan.

En relación específicamente con la estrategia usada en el recorrido nocturno, las publicaciones en el Facebook del Real Felipe empezaron en setiembre de 2016, mediante contenido relacionado con los próximos eventos del recorrido nocturno. 
Algunas son publicaciones netamente escritas por el encargado del fanpage, y otras son eventos creados por la página del Facebook de "Los Misterios del Real Felipe", las cuales el mismo Facebook del museo comparte y promociona. Esta página de Facebook es gestionada por las guías turísticas del museo, y se vincula con el museo porque deben seguir las directrices de comunicación que ordena la institución pero se trata de una página independiente.

De todas las publicaciones realizadas hasta marzo de 2018, 39 fueron exclusivamente para promover los eventos del recorrido nocturno del museo.

Con un promedio de dos a tres publicaciones por mes, a través del análisis del fanpage se pudieron extraer y catalogar cuatro tipos de publicaciones relacionadas con el recorrido nocturno: eventos, posts (publicaciones) acompañados de texto y/o foto, video y datos curiosos.

Para catalogar los comentarios de las publicaciones, se toma como referencia el artículo de Gerolimos (2011), en el cual se analiza los comentarios de la fanpage de una biblioteca pública en Grecia, hallándose varios tipos de comentarios catalogados de la siguiente manera:

- Halagadores: los cuales hacen referencia al buen servicio de la institución.

- Generales/Informativos: preguntas, dudas y solicitud de información.

- Agradecimiento: palabras como gracias, saludos y gratitud.

- Quejas: referencia a algún aspecto desagradable.

- Amistad: conversaciones entre usuarios, etiquetas.

- Perdido/encontrado: consultas por objetos olvidados en el establecimiento.

La segregación de comentarios de Gerolimos no coincide con todos los tipos que se encuentran en la fanpage del museo, así que para la investigación estos se catalogaron como positivos (agradecimiento, amistad, halagadores), negativos (quejas) y neutros (generales, informativos) para poder incluir varias categorías. El detalle del análisis que se desarrolló a su vez a través del net sentiment es el siguiente:

- Positivos: los que contengan frases de emoción como "qué chévere", "genial" y "buen dato", además de cuando los usuarios etiqueten a otros.

- Negativos: los que contengan frases de desagrado como "qué es esto" o "porque no responden". 
- Neutros: los que contengan preguntas de información relacionadas con el recorrido nocturno.

Cabe resaltar que existen otros tipos de comentarios positivos, negativos y neutros, pero en el listado se consideraron los que engloban a la mayoría.

En la tabla 6.5 se muestran las publicaciones con mayor interacción:

Tabla 6.3 Detalle de comentarios más resaltantes de las publicaciones relacionadas con el recorrido nocturno

\begin{tabular}{|c|c|c|c|c|c|}
\hline Fecha & Tipo de publicación & Interacción & $\begin{array}{l}\text { Tipo de } \\
\text { interacción }\end{array}$ & Cantidad & Alcance \\
\hline $\begin{array}{l}31 \text { de enero } \\
2017\end{array}$ & $\begin{array}{l}\text { Evento Tour de noche } \\
\text { (compartido del Facebook } \\
\text { de "Los misterios del Real } \\
\text { Felipe") }\end{array}$ & Likes & & 24 & 613 \\
\hline \multirow{2}{*}{$\begin{array}{l}31 \text { de marzo } \\
2017\end{array}$} & \multirow[b]{2}{*}{$\begin{array}{l}\text { Post y foto de Tour de noche } \\
\text { Texto: Hoy 07:00 pm tour } \\
\text { nocturno en el Real Felipe. } \\
\text { Solo para mayores de } 18 \\
\text { años si ve alguna persona } \\
\text { menor, ignórela y aléjese. }\end{array}$} & Comentarios & Positivo & & \multirow{2}{*}{1.100} \\
\hline & & Likes & & 12 & \\
\hline \multirow{4}{*}{8 de julio 2017} & \multirow{4}{*}{$\begin{array}{l}\text { Texto: Hoy tenemos Tour } \\
\text { Nocturno en el Museo Real } \\
\text { Felipe desde las 18:45 horas, } \\
\text { solo para mayores de } 18 \\
\text { años, si observa algún menor } \\
\text { de edad IGNÓRELO Y } \\
\text { ALÉJESE. }\end{array}$} & Likes & & 79 & \multirow[t]{4}{*}{6.200} \\
\hline & & \multirow[t]{2}{*}{ Comentarios } & Positivos & & \\
\hline & & & Neutro & 6 & \\
\hline & & Compartidos & & 3 & \\
\hline \multirow{4}{*}{$\begin{array}{l}4 \text { de agosto } \\
2017\end{array}$} & \multirow{4}{*}{$\begin{array}{l}\text { Video tour de noche. } \\
\text { Texto: Hoy y mañana, tour } \\
\text { nocturno con temática } \\
\text { paranormal a las 7:00 pm. }\end{array}$} & Likes & & 73 & \multirow[t]{4}{*}{2.700} \\
\hline & & \multirow[t]{2}{*}{ Comentarios } & Positivos & 43 & \\
\hline & & & Neutro & 10 & \\
\hline & & Reproducciones & & 7,870 & \\
\hline \multirow{4}{*}{$\begin{array}{l}12 \text { de agosto } \\
2017\end{array}$} & \multirow{4}{*}{$\begin{array}{l}\text { Texto: Hoy tenemos Tour } \\
\text { Nocturno, separa tu cupo } \\
\text { llamando al } 965060125, \text { o } \\
\text { puedes venir al museo desde } \\
\text { las 19:00 horas. Solo para } \\
\text { mayores de } 18 \text { años. Te } \\
\text { esperamos. }\end{array}$} & Likes & s. & 31 & \multirow[t]{4}{*}{3.200} \\
\hline & & Comentarios & Positivos & 15 & \\
\hline & & & Neutro & 4 & \\
\hline & & Compartidos & & 2 & \\
\hline \multirow{3}{*}{$\begin{array}{l}21 \text { de agosto } \\
2017\end{array}$} & \multirow{3}{*}{$\begin{array}{l}\text { Evento Tour de noche } \\
\text { (compartido del Facebook } \\
\text { de "Los misterios del Real } \\
\text { Felipe") }\end{array}$} & Likes & & 45 & \multirow[t]{3}{*}{1.300} \\
\hline & & Comentarios & Positivos & 9 & \\
\hline & & & Neutro & 4 & \\
\hline \multirow{2}{*}{$\begin{array}{l}28 \text { de agosto } \\
2017\end{array}$} & \multirow{2}{*}{$\begin{array}{l}\text { Fotos del tour. } \\
\text { Texto: ESTE MIÉRCOLES } \\
30 \text { DE AGOSTO } \\
\text { TENEMOS TOUR } \\
\text { NOCTURNO, NO TE LO }\end{array}$} & Likes & & 20 & \multirow[t]{2}{*}{953} \\
\hline & & Comentarios & Positivos & 3 & \\
\hline
\end{tabular}




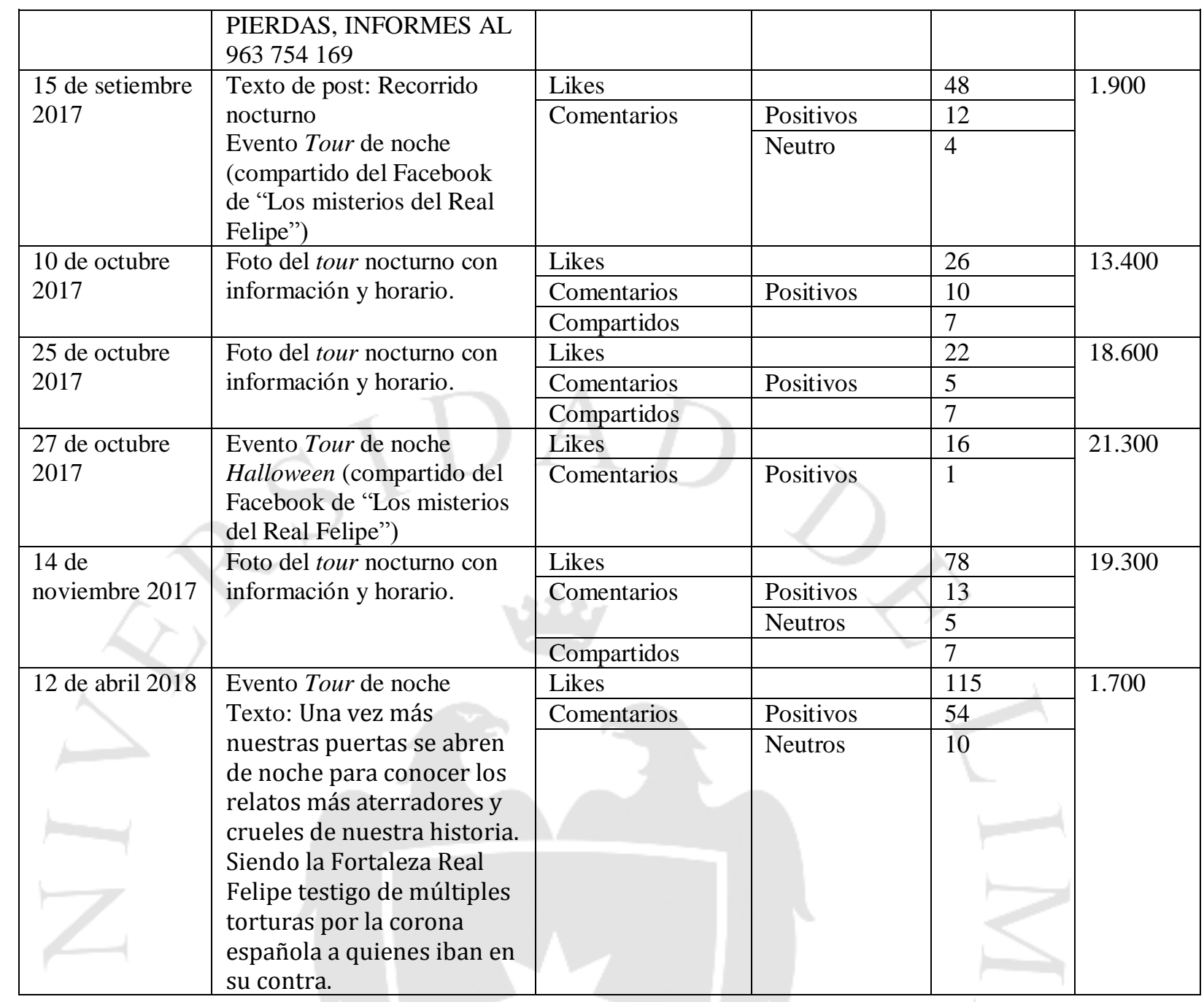

Fuente de alcance: Métrica de alcance proporcionada por los gestores del fanpage del museo (Junio 2018); elaboración propia (análisis de comentarios).

Las publicaciones de los eventos de los tours de noche cuentan con gran interacción y las de datos curiosos también, pese a no haber muchas. Cabe resaltar que la interacción se produce de manera orgánica y no se invierte en publicidad pagada en Facebook. La comunicación es amigable y cercana, dirigida a un público joven para llamar su atención pero manteniendo las directrices comunicacionales del Ejército. En cuanto al planeamiento, seguimiento y monitoreo del contenido aún no está claramente sistematizado por parte de los gestores del museo. Publican el contenido de acuerdo a cómo se van programando las fechas de recorridos, visitas importantes o alguna noticia que deseen comunicar. El seguimiento de los comentarios se da de forma diaria y tiene un nivel alto de respuesta en cuanto rapidez pero no para fomentar interacción entre usuarios. El monitoreo lo realiza el coordinador de marketing en el horario de 8am a 
$4 \mathrm{pm}$, horas en las cuales labora. El estilo gráfico de cada post varía (ver anexo 9) pero en la figura 6.4 se muestran tres ejemplos representativos:

Figura 6. 4 Publicación 27 de octubre 2017 del recorrido nocturno

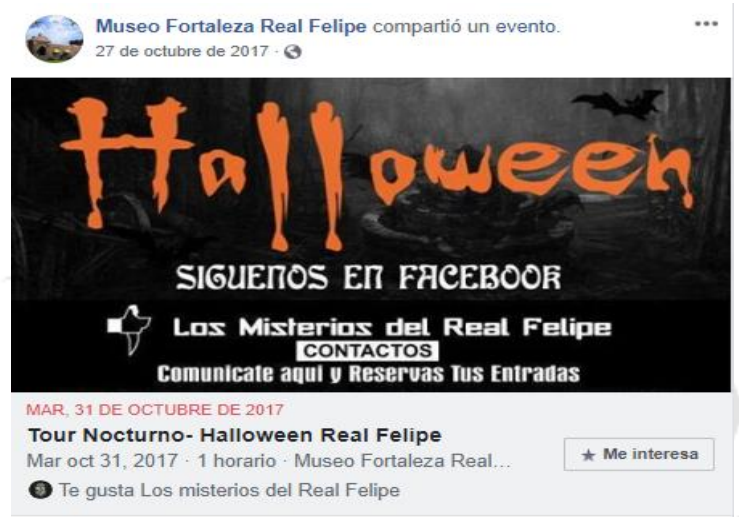

Fuente: Fanpage Museo Fortaleza Real Felipe

Figura 6.5 Publicación 25 de octubre 2017 del recorrido nocturno

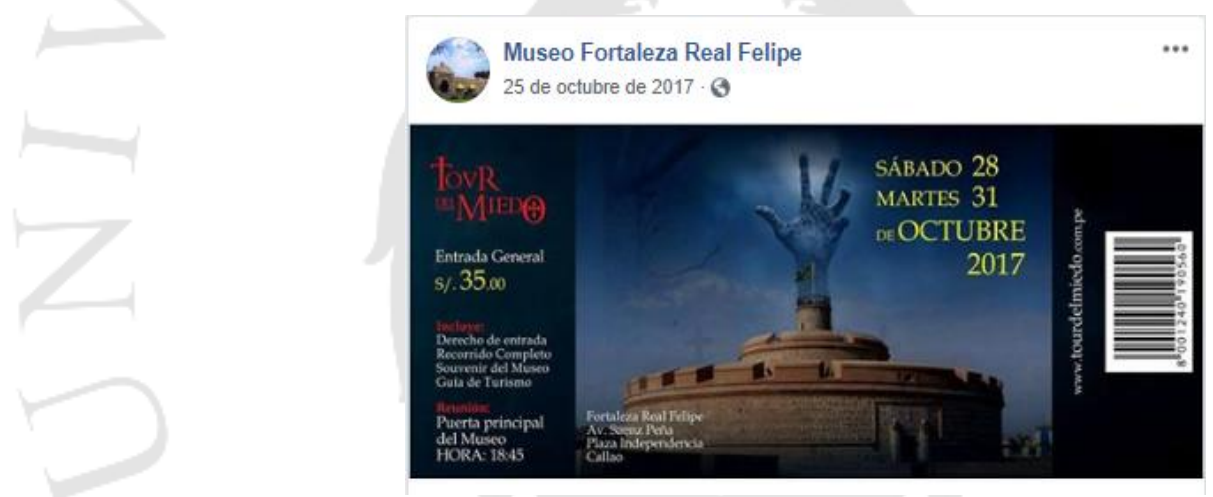

Fuente: Fanpage Museo Fortaleza Real Felipe

Figura 6. 6 Publicación 12 de abril 2018 del recorrido nocturno

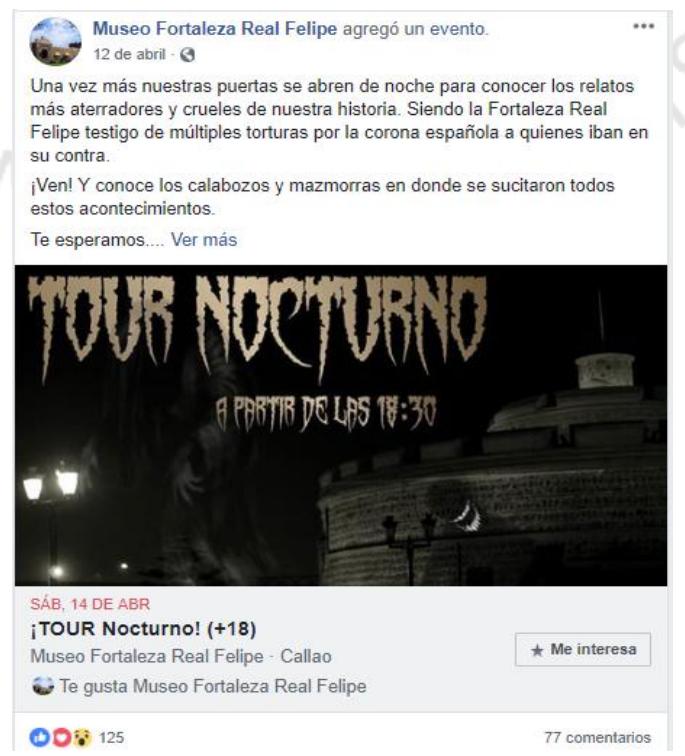


El análisis detallado de todos los comentarios e interacciones de los usuarios sobre el recorrido nocturno y el interés que les genera, y que se visualiza en la tabla 6.5 (ver anexo 8), se utiliza para hallar el net sentiment:

\section{Net Sentiment $=\underline{(\text { C. Positivos }+ \text { C. Neutrales }- \text { C. Negativos })}$}

Comentarios totales para la marca

La operación da como resultado 99\%, los comentarios negativos son casi nulos y en la mayoría de usuarios solo realiza comentarios positivos de satisfacción por el servicio del tour o de emoción por asistir y los comentarios neutros son más que todo informativos.

\subsubsection{Visitas a la página}

Como se visualiza en la figura 6.3, las visitas a la página varían de acuerdo al contenido, tipo de post e información que se proporciona. El cuadro de visitas totales solo es visible para los gestores de la fanpage, así que tomando en consideración las publicaciones de forma general se muestran los siguientes resultados:

Figura 6.7 Visitas totales de julio 2017 a mayo 2018

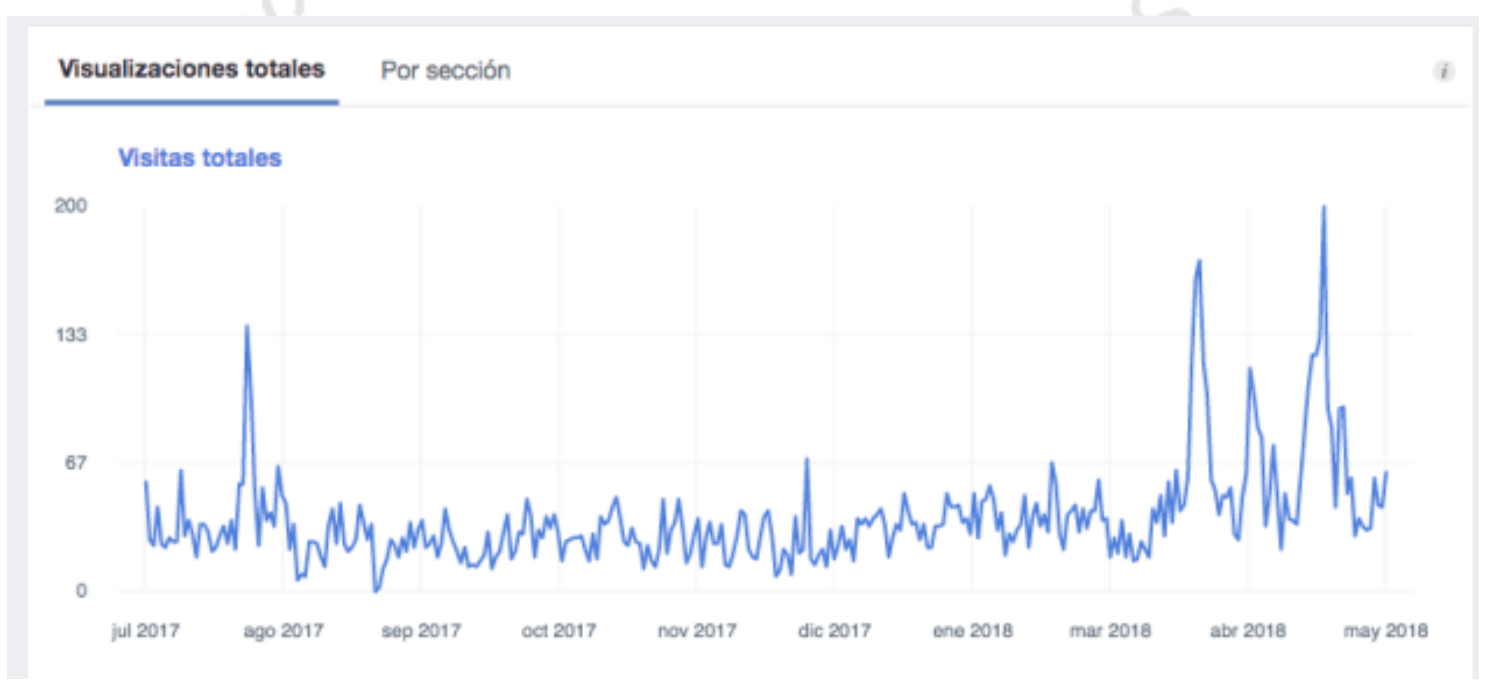


Fuente: Métricas proporcionada por los gestores del fanpage del museo (Junio 2018).

El cuadro demuestra gran cantidad de visualizaciones en los meses de julio/agosto de 2017 y abril/mayo del 2018. Los demás meses se mantienen de forma constante en un número promedio, bordeando las 70 visitas diarias.

Las visitas en todos esos meses se dieron de forma orgánica; sin embargo, como se puede notar en abril y mayo del presente año, el número de visitas es elevado debido al tipo de publicaciones que se hicieron con respecto al museo y al recorrido nocturno, mencionando las distintas fechas en las que se iba a desarrollar. Además, la interactividad y el número de likes de los posts relacionados al tour se incrementaron. El coordinador de marketing mencionó que los visitantes buscan experiencias que no les brinden otras instituciones, y lo que más llama su atención es el tema relacionado con el terror y el miedo, por lo que buscan brindarles ese tipo de contenido a los usuarios.

\subsubsection{Estrategias a futuro y beneficios del tour de noche}

El contenido del recorrido nocturno publicado en Facebook ha traído beneficios a la institución y ha abierto los ojos de los directivos para pensar en nuevas estrategias a aplicar, para continuar con el buen número de visitantes que posee actualmente el museo.

El coordinador de marketing del museo considera que la evolución de las publicaciones ha sido positiva desde que inició con estas, en términos de impacto en el público e interacción en el fanpage. Sumado a ello, el coordinador y el equipo de marketing del museo vislumbran estrategias que lo favorezcan a futuro tales como:

- Insertar publicidad en el aeropuerto, por temas de cercanía y para captar público extranjero.

- Contar con más presencia en televisión.

- Alianzas estratégicas con empresas para que colaboren con remodelaciones y mantenimiento de las áreas del museo.

Además, el coordinador de marketing menciona que los beneficios de promocionar la oferta experiencial del museo han sido los siguientes:

- Reconocimientos de otros museos. 
- Invitaciones a eventos.

- Se ha convertido en referente en temas culturales relacionado con museos.

- Es considerado como una parada de turismo en el Callao.

El efecto de las publicaciones ha sido hasta el momento de igual manera positivo, considera el coordinador de marketing, ya que los usuarios expresan su buena experiencia y lo bien que la han pasado en el recorrido nocturno mediante los comentarios y los mensajes privados (inbox) que se recibe por parte de los visitantes. En adición a esto, la presencia en medios masivos también ha sumado la visibilidad que posee el museo. Durante el verano de 2018, América Televisión realizó grabaciones de un conocido programa en las instalaciones del museo; años atrás un canal de temática paranormal también hizo lo mismo y puso en vitrina al museo para un público aún mayor.

\subsection{Afluencia al recorrido nocturno desde la publicación de contenido en}

\section{Facebook}

Uno de los beneficios más relevantes que mencionó el coordinador de marketing del museo durante la entrevista fue el aumento de las visitas en recorridos diurnos y nocturnos desde la creación del fanpage, incrementándose aún más a partir de octubre y noviembre de 2017, cuando las publicaciones relacionadas con el tour nocturno aumentaron en cantidad. El número de recorridos nocturnos se incrementaron en un mínimo de dos al mes a partir de esos meses, a diferencia del número que poseían antes de tener presencia en medios digitales, cuando el museo solo ofrecía un tour cada dos meses o incluso podían tomar hasta tres meses, dependiendo de qué tan rápido llenaran el cupo mínimo de visitantes midiéndolo a través de los eventos previos. El recorrido diurno siempre ha tenido un gran número de visitantes diarios, incluso en feriados; sin embargo, mediante la página web y el Facebook, el número de interesados en visitar el tour aumentó en más del 100\% desde la inserción del museo a medios digitales.

Otro aspecto importante actualmente es que el museo atiende sin importar el número de visitantes que aparezcan en determinado recorrido, si son solo 20 personas o 50, brindan la misma calidad para todos y la misma duración del tour. Antes, lo que sucedía, tal como se ha mencionado, es que realizaban recorridos de noche 
esporádicamente ya que deseaban que el día del tour el número de visitantes sea bastante alto, pues abrir las puertas del museo por la noche y solventar los gastos de las guías significaba un presupuesto extra.

\subsection{Aceptación y la experiencia del tour nocturno}

El recorrido nocturno tiene una duración de dos horas y media. Las entradas se pueden adquirir el mismo día en el museo o a través de las agencias de turismo que trabajan con él. En primera instancia, los visitantes ingresan a una sala donde transmiten un video resumen sobre la historia del museo, narrada como si fuera un cortometraje de terror. Luego de ello, la guía del grupo se presenta e invita a los asistentes a iniciar el recorrido mencionándoles el número de grupo que serán. Así sucedió en la primera muestra, en la cual los grupos se diferenciaban por números ya que no se ocurrieron sucesos relevantes en ese momento; a diferencia de la segunda muestra, que se realizó el día del primer partido de Perú con Dinamarca en el Mundial de Rusia, en que el jugador Cuevas falló el penal, y el grupo se identificó como Los Cuevitas, otorgándose identidad y viviendo un rato ameno durante el recorrido.

El primer espacio a observar son los cañones de guerra que se ubican a la entrada. Después, se ingresa al primer torreón del rey, allí hay cuartos con pinturas en las paredes y piezas de guerra junto con uniformes considerados reliquias. Durante el trayecto, la guía va narrando los datos históricos de los espacios y absolviendo dudas. Los pasajes que conectan las salas son angostos y oscuros, por lo que caminar agarrados de la mano o sosteniéndose del hombro entre los visitantes es común. En especial, el espacio de los calabozos donde los visitantes incluso encienden las linternas de sus celulares por estar muy oscuro. En un lugar especial se sienten vibraciones de eco y los visitantes pueden colocarse al centro en uno de los calabozos y replicar sonidos que se escucharán alrededor de las salas. Ese es el último espacio visitado en la primera parte del recorrido, seguido de ellos dan 15 minutos de descanso, durante el cual se puede comprar algo para comer y visitar la tienda de suvenires; hay un espacio llamado "Soldado por un minuto", donde por un monto mínimo la persona que desee se puede disfrazar de un soldado de guerra y tomarse fotos con el fondo del museo. Al término del descanso, el grupo se reúne nuevamente y visita la Casa del Gobernador, un espacio en el cual residía el gobernador de la época junto con su familia. El Torreón de la Reina 
es la siguiente parada; para llegar a lo alto se debe subir varios pisos angostos en espiral y cruzar un pequeño puente. Para mostrarles a los visitantes como subían los esclavos durante la guerra, la guía ofrece vendajes a cada persona para que no pueda ver nada y así pueda sentir lo que vivían los esclavos al cruzar en la oscuridad. El vendaje, obviamente, es opcional. Al llegar al tope del torreón, la guía divide al grupo en dos y realiza una dinámica: dice que el primer grupo en llegar a la entrada principal se lleva un premio. Al ser los caminos empinados y oscuros, los visitantes viven un momento divertido ya que quieren ganar pero deben ir despacio. Aquí se termina el tour; el guía agradece por la visita e invita a seguirlos en redes y compartir su experiencia. Cabe añadir que durante el recorrido aparecen también en momentos inesperados, personajes disfrazados de corsarios para asustar a los asistentes, etcétera.

Figura 6.8 Momento de eco durante recorrido

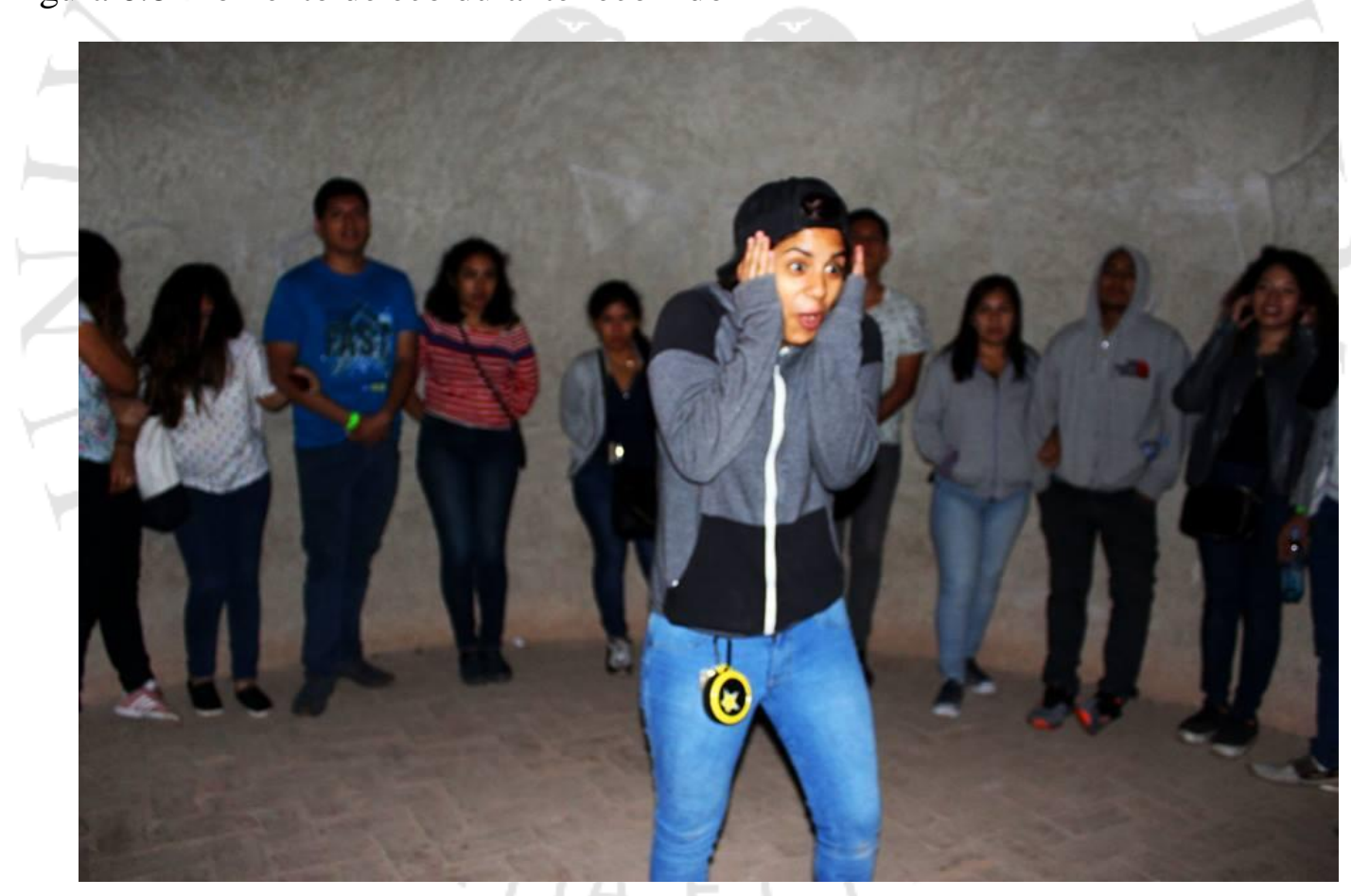

Fuente: Fanpage "Los Misterios del Real Felipe" 
Figura 6.9 Visitantes en el torreón de la reina

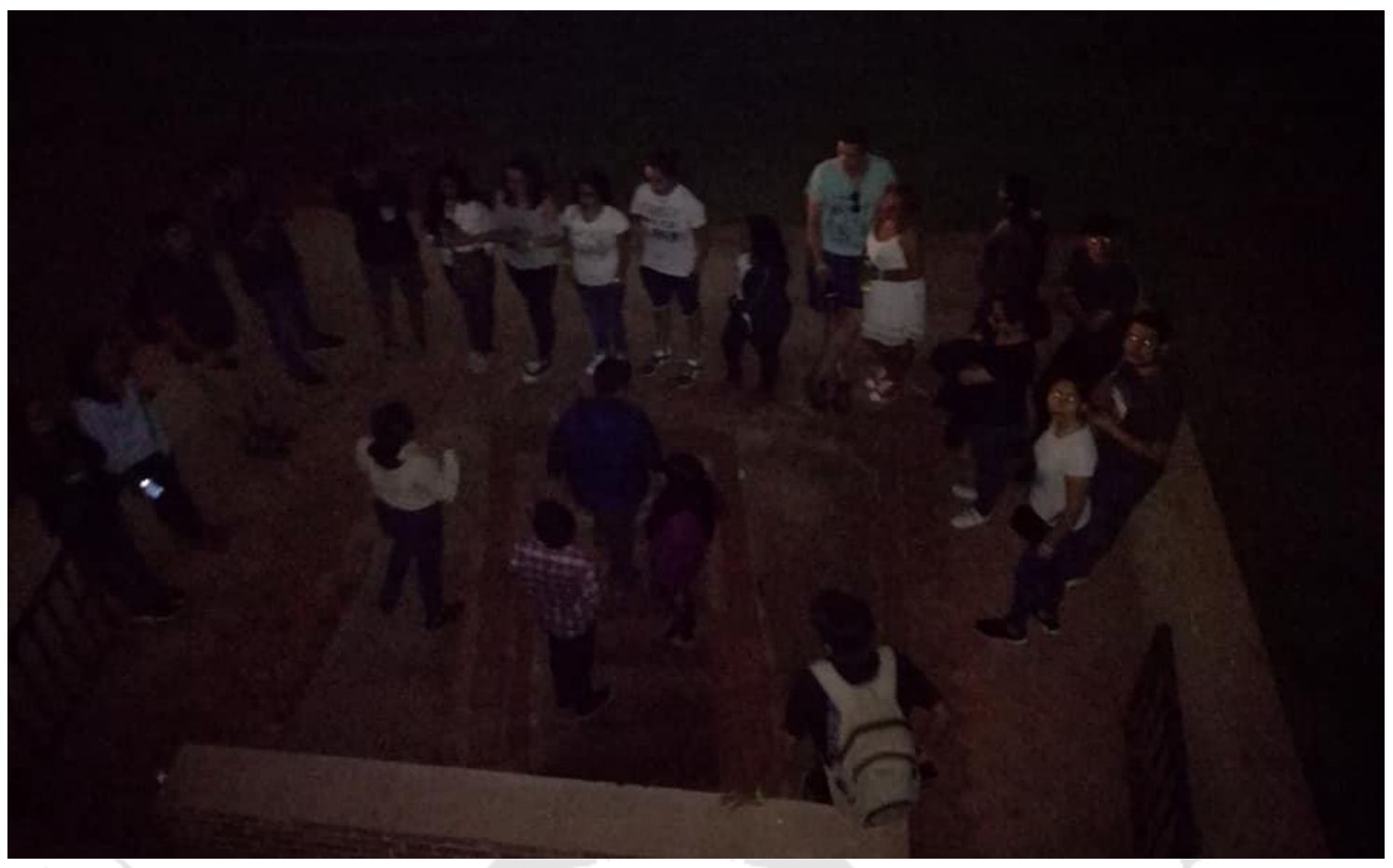

Fuente: Fanpage "Los Misterios del Real Felipe"

Figura 6.10 Módulo de Soldado por un minuto

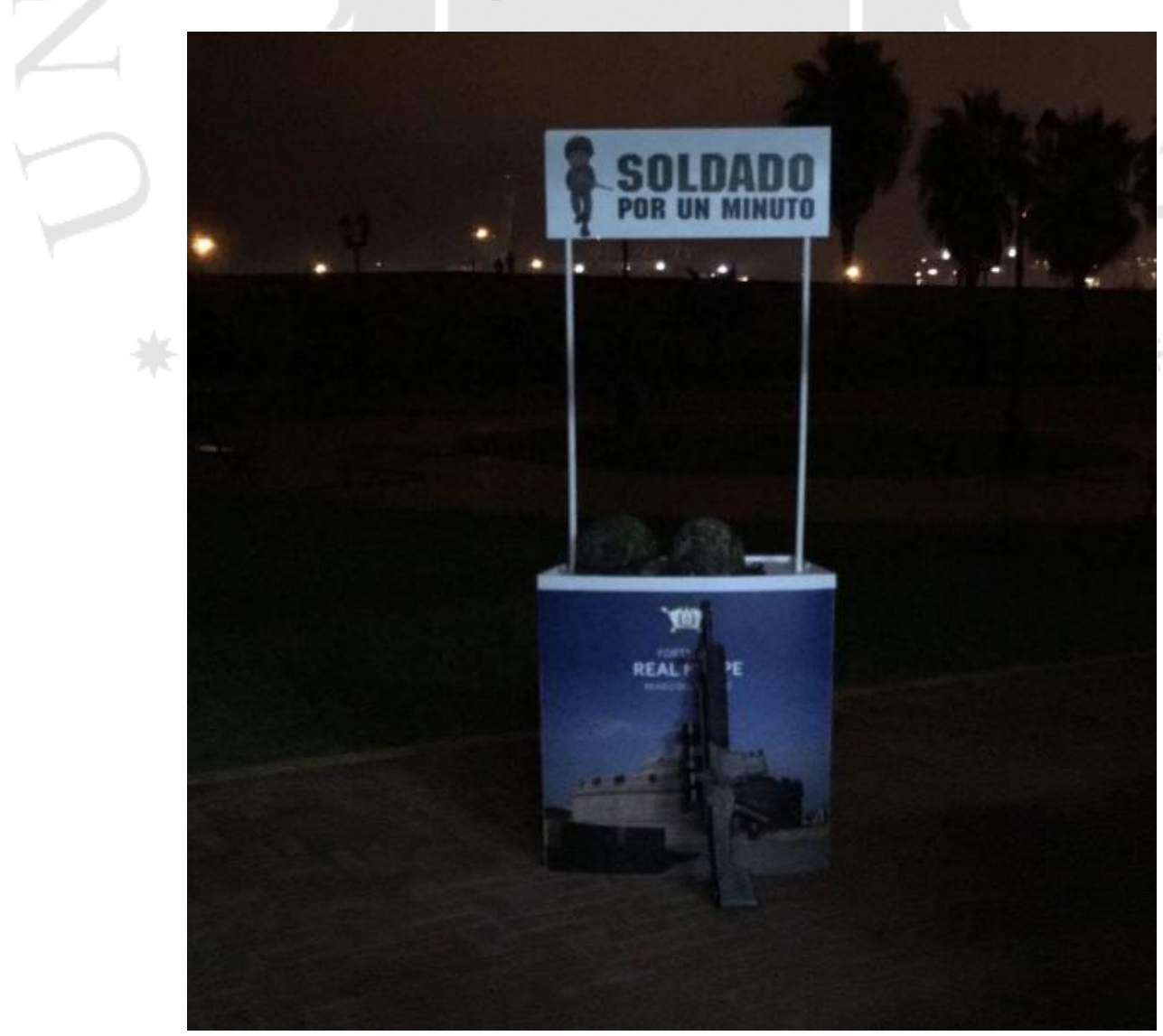

Fuente: Elaboración propia 
Para poder evaluar la experiencia del recorrido nocturno se aplicó una primera encuesta a 70 visitantes. En primer lugar, se les pidió a los encuestados considerar del 1 (siendo muy malo) al 5 (siendo muy bueno) diferentes aspectos del museo. A continuación se presentan los porcentajes obtenidos:

Tabla 6.4 Aspectos del recorrido evaluados en la primera muestra

\begin{tabular}{|c|c|c|c|c|c|}
\hline & 1 & 2 & 3 & 4 & 5 \\
\hline Desempeño del guía del tour & $1,4 \%$ & $1,4 \%$ & $25,7 \%$ & $41,5 \%$ & $30 \%$ \\
\hline Organización y estructura del tour & $0 \%$ & $0 \%$ & $27 \%$ & $54 \%$ & $19 \%$ \\
\hline Ambientes que se visitan en el tour & $0 \%$ & $1,4 \%$ & $18,6 \%$ & $48,6 \%$ & $31,4 \%$ \\
\hline Concurrencia de visitantes & $0 \%$ & $0 \%$ & $18,6 \%$ & $62,8 \%$ & $18,6 \%$ \\
\hline
\end{tabular}

Fuente: Elaboración propia

Como se puede notar en la tabla superior, los más altos porcentajes se ubican en 4 (bueno) y 5 (muy bueno) en todos los aspectos relacionados al tour. Los porcentajes fueron casi nulos en 1 (muy malo) y 2 (malo), el término neutro (3) también ha obtenido considerado porcentaje en los cuatro aspectos mencionados del tour, lo cual resulta en que una determinada cantidad de visitantes no tiene una percepción definida del tour ya sea positiva o negativa.

Seguido de ello, basado en el módulo de sensaciones de Schmitt (1999), se les pidió a los visitantes que respondan los sentidos que consideran predominantes en el recorrido, ya que estos cobran protagonismo con el motivo de crear experiencias sensoriales. Se les dio la opción de seleccionar más de un sentido. 
Figura 6.11 Sentidos que involucró el tour de noche según la experiencia sensorial de visitantes.

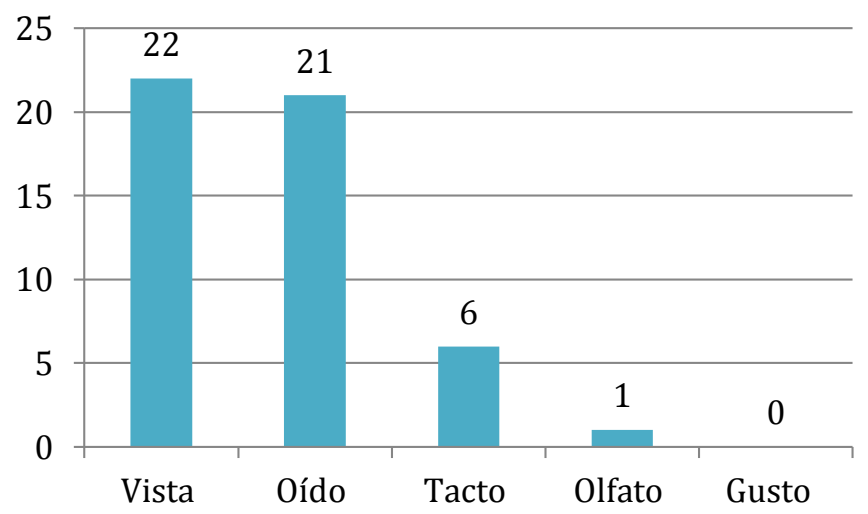

Fuente: Elaboración propia

La vista y el oído fueron los sentidos con mayor porcentaje. Además de lo señalado, Barrios (2012) afirma que las claves para el éxito de una experiencia son: el servicio memorable, la integración del modelo y la consideración de los pensamientos, relaciones, actuaciones, sensaciones y sentimientos de los visitantes; ahí radica la relevancia de la pregunta para poder obtener un mejor análisis de la experiencia.

Seguido del tema de la experiencia sensorial, se preguntó a los visitantes acerca de las emociones que les hizo vivir y sentir el tour. Basado en la teoría de Eckman (2003) y Barrios (2012), se seleccionaron las emociones que más se relacionan con lo que ofrece el tour de noche, ya que no todas las que mencionan los autores aplicaban. Se les dio la opción de marcar más de una opción.

Tabla 6.5 Número de respuestas de emociones seleccionadas en la muestra

\begin{tabular}{|l|c|}
\hline \multirow{2}{*}{ Emoción } & Número de respuestas \\
\hline Sorpresa & 19 \\
\hline Satisfacción & 10 \\
\hline Miedo & 10 \\
\hline Alegría & 7 \\
\hline Descontento & 2 \\
\hline Asombro & 1 \\
\hline Tristeza & 0 \\
\hline Ira & 0 \\
\hline
\end{tabular}

Fuente: Elaboración propia 
Sorpresa, satisfacción y miedo fueron los más seleccionados entre los asistentes; sin embargo, tristeza e ira no fueron consideradas por ninguno de ellos.

Las motivaciones que los visitantes tienen para estar presentes en el recorrido y que los atrajo a comprar la entrada son relevantes para conocerlos más, ya que como menciona Soydanbay (2017), los visitantes pueden sufrir drásticos cambios de motivaciones al ser impactados por la visita al museo. De acuerdo a ello, se busca saber cuál fue la principal motivación que tuvieron para estar presentes. La motivación intelectual fue la más seleccionada en la muestra, seguida de la social.

Figura 6.8 Tipos de motivaciones que los asistentes tuvieron para asistir al tour de noche.

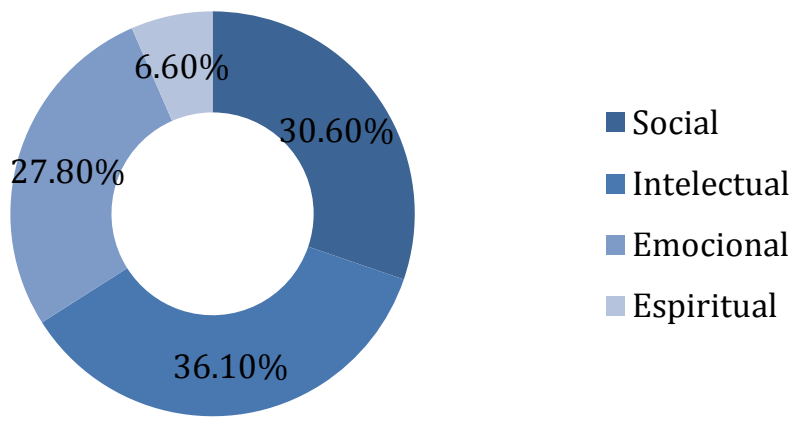

Fuente: Elaboración propia

Durante el recorrido nocturno, se visualizan varios espacios y se realizan actividades, tal como se describió en párrafos anteriores, por lo que se pidió a los encuestados que mencionen la parte del recorrido que les gustó más. Se les dio como opciones las partes más resaltantes del recorrido y la posibilidad de que escriban el lugar que les gustó más. 
Tabla 6.6 Detalle de las partes favoritas de los visitantes del recorrido

\begin{tabular}{|l|c|}
\hline La visita a los torreones & $52,8 \%$ \\
\hline El momento de eco en los antiguos calabozos & $27,8 \%$ \\
\hline Los personajes andantes & $11,1 \%$ \\
\hline El momento de vendaje en el puente & $2,8 \%$ \\
\hline La casa del gobernador & $2,8 \%$ \\
\hline Los tanques & $2,8 \%$ \\
\hline
\end{tabular}

Fuente: Elaboración propia

En cuanto a las expectativas de los visitantes, el 72,2\% considera que el recorrido cumplió con las expectativas que tenía, 2,8\% dio respuesta negativa y el $25 \%$ no tenía expectativas con respecto al tour.

Para poder tener una visión panorámica de la experiencia, se les pidió a los encuestados en ambas muestras, referirse a la experiencia vivida, definiéndola en un rango que iba de muy agradable a muy desagradable.

Tabla 6.7 Detalle de la experiencia vivida por los visitantes en la 1era y 2da muestra.

\begin{tabular}{|l|l|l|l|}
\hline \multicolumn{2}{|c|}{ 1era muestra } & \multicolumn{2}{c|}{ 2da muestra } \\
\hline Muy agradable & $25,7 \%$ & Muy agradable & $27,8 \%$ \\
\hline Agradable & $62,9 \%$ & Agradable & $55,6 \%$ \\
\hline Ni agradable ni desagradable & $8,6 \%$ & Ni agradable ni desagradable & $13,9 \%$ \\
\hline Desagradable & $1,4 \%$ & Desagradable & $2,8 \%$ \\
\hline Muy desagradable & $1,4 \%$ & Muy desagradable & $0 \%$ \\
\hline
\end{tabular}

Fuente: Elaboración propia

Como se refleja en los resultados, el mayor porcentaje en ambas muestras está en agradable, seguido de muy agradable y de la posición neutra. La consideración de desagradable y muy desagradable abarcó solo una mínima parte.

El Museo Fortaleza Real Felipe ofrece actualmente solo recorridos diurnos y nocturnos y alquiler de espacios para eventos importantes. Durante fechas especiales, como Fiestas Patrias o el Día del Ejército, realizan actividades diferentes, pero de forma muy esporádica. Una de las preguntas en la muestra fue consultar a los visitantes si les 
gustaría que el museo ofrezca otro tipo de exposiciones y exhibiciones, a lo que el $75 \%$ dio una respuesta afirmativa y el $25 \%$, negativa.

Por medio de la experiencia se desprende los cambios sufridos en la imagen que tenían los visitantes del museo luego de haber participado en el recorrido, por lo que se les pidió indicar qué tipo de cambios ha sufrido la percepción de la institución. El 70\% de respuestas resultó en cambios positivos en la percepción, seguido del 27,1\% que representa no haber sentido ningún tipo de cambio. Solo el 2,9\% consideró haber sufrido cambios negativos en la imagen que poseían del museo.

Al ser consultados si consideran compartir, recomendar o publicar fotos o videos de su visita en sus cuentas de redes sociales, el $81,4 \%$ de encuestados coincidieron en que sí consideraban hacerlo, y el 18,6\% dijo que no. Seguido a ello, para comparar la experiencia que vivieron en comparación con otras, se les cuestionó si el recorrido le ha llamado más la atención que otros; el $80 \%$ respondió que sí y el resto dieron una respuesta negativa. En adición a eso, el 83\% mencionó que recomendaría a otras personas realizar el recorrido, mientras que $13,9 \%$ dijo que no.

La opinión de los visitantes acerca del tour se recabó mediante una pregunta en que se les pedía a los encuestados comentar qué les gustaría que cambie. El 56\% mencionó estar satisfecho con el tour y que no cambiaría nada; el resto mencionó lo siguiente:

- La recomendación previa de portar linternas.

- La existencia de otro tipo de actividades.

- El guía debe ser más didáctico. 


\section{Discusión}

De acuerdo a lo planteando en esta investigación, se pudo determinar el grado de visibilidad que ha obtenido el recorrido nocturno del Museo Fortaleza Real Felipe mediante el contenido en Facebook, así como el impacto y aceptación de la oferta experiencial entre los públicos visitantes.

Para validar las interrogantes de la investigación, se procederá a analizar los resultados obtenidos con respecto a cada objetivo específico planteado y luego se dará respuesta a cada una de ellas.

El primer objetivo propuesto fue identificar el nivel de afluencia medido en el número de visitantes al recorrido nocturno desde que se iniciaron las actividades en Facebook; se buscaba responder también a la pregunta de investigación que contiene las variables que determinan el aumento de visitantes a un museo a través del contenido en Facebook. Se halló por medio de las muestras que la mayoría de personas compró su ticket y llegó a ser partícipe del recorrido nocturno gracias a la fanpage del museo, ya que conocieron del servicio por allí. Las dos muestras arrojaron porcentajes de aproximadamente $40 \%$ que afirmaron lo mencionado, por ende, se concluye que la página de Facebook del museo logró atraer a la gran mayoría de visitantes que realizaba el tour en las fechas de muestreo. Este resultado es interesante ya que como se menciona en El Momento Zero de la Verdad (Lecinski, 2011): ahora el usuario toma la decisión de compra a través de internet; el visitante, en este caso, averiguó sobre el recorrido mediante la red social y decidió vivir la experiencia a raíz de esa información. Un porcentaje menor pero también importante de visitantes llegó por recomendaciones de amigos, lo que demuestra que está teniendo aceptación y las personas están contando de forma positiva su experiencia, motivando a amistades a ser partícipes del recorrido. Otro porcentaje se informó mediante agencias de turismo, las cuales también trabajan con Facebook.

La red social usada por el museo sigue las propuestas de Carter (2008), quien sostiene que determinados medios permiten descentralizar su información y tener un mayor impacto en nuevos visitantes. De esta manera también se posibilita la visibilidad de la institución en nuevos sectores. Esto se ve avalado por la entrevista con el coordinador de marketing del museo, quien confirmó que la creación del fanpage junto 
con las publicaciones que realizaban para atraer a la audiencia, permitieron incrementar el número de visitantes a los recorridos tanto nocturno como diurno. El número de tickets promedio vendidos del nocturno era de 20 a 40 como máximo por cada dos meses durante el 2016, cuando no existían publicaciones relacionadas al tour de noche. Gracias a las publicaciones en Facebook, los visitantes aumentaron en casi 200\% por mes, siendo tres recorridos al mes con 80 visitantes promedio. Dentro de esta red social, el "marketing o promoción de eventos" es relevante según Walker (2015), ya que es una manera factible de alcanzar a una mayor audiencia y coincide con lo que se realiza en la fanpage del Real Felipe, ya que promocionan los eventos del recorrido nocturno, publicando posts específicos de estos junto con la información necesaria para el potencial visitante. Sumado a ello, se puede ver que el museo sigue la estrategia de creación de valor que Jiménez \& Quero (2011) mencionan en su Manual de Marketing y Comunicación Cultural, ya que a través del fanpage están incrementando la rentabilidad del Real Felipe mediante el desarrollo de contenido en redes sociales y con ello intensifican su visibilidad.

El aumento del nivel de afluencia de visitantes al museo Real Felipe también se debe a la segmentación acertada que se realizó desde el inicio de publicación de contenido relacionado al recorrido nocturno, ya que se penetró en los visitantes potenciales y en los interesados en participar. El coordinador de marketing afirmó que el público objetivo al que se orienta actualmente son jóvenes que buscan vivir una experiencia que se relacione con la actividad paranormal, genere miedo y sea única. El coordinador agrupa a su target en el rango de edades de 18 a 30 años, hombres y mujeres, lo cual se ratifica en la información demográfica de la fanpage, en la que la edad de la mayoría de fans va de 18 a 34 años, de Lima y Callao, abarcando el 49\% entre del total de fans. Contrastando con las muestras se demostró que el público objetivo al cual se orienta el museo es el correcto, ya que en ambas muestras se obtuvo que más del $70 \%$ de visitantes tenía entre 18 y 35 años. En este sentido, se puede afirmar que el museo está llegando de manera asertiva a los potenciales visitantes en las redes y que el público se interesa por vivir la experiencia del recorrido gracias a las publicaciones, siguiendo a su vez la estrategia de captación propuesta por Jiménez \& Quero (2011), ya que el museo introduce al usuario en una actividad cultural específica para lograr que este asista al evento y persuadir en su decisión de compra. 
El rango de edades del target se ha convertido en una ventaja para el museo, ya que son los jóvenes quienes hacen uso de mayor tiempo en redes (Cox, 2011; Liu, 2016). Facebook es el medio más factible para satisfacer el deseo de información de los jóvenes ya que, como se mencionó anteriormente, la gran mayoría también respondió haberse informado mediante el fanpage del museo.

Con respecto al género del público en las métricas de Facebook, el mayor porcentaje son mujeres con $64 \%$ y los hombres ocupan el 36\%. Los porcentajes en las muestras son casi similares entre sí, con $57 \%$ y $43 \%$ de mujeres y hombres respectivamente en la primera muestra y $50 \%$ y $50 \%$ en la segunda muestra. Este dato nos hace notar que tanto hombres como mujeres desean vivir la experiencia del recorrido, acompañados de sus parejas, amigos o familiares, tal como sucedió en ambas muestras, donde se encontró grupos mixtos de jóvenes que querían pasar un buen rato. Sumado a ello, gracias al detalle de país y ciudad de donde provienen los fans del museo, se puede confirmar que están penetrando a los visitantes potenciales, ya que casi el $90 \%$ proviene de Lima y quienes tienen más fácil acceso al museo cuando se realice el tour nocturno. Además, la mayor parte de los fans proviene de Perú, seguido de Estados Unidos y otros países de Sudamérica, lo cual resulta atractivo para que el museo pueda aplicar estrategias digitales con bases segmentadas, con el fin de penetrar en estos públicos y motivarlos a visitar la capital, enfatizando el atractivo que ofrece el museo. Según el idioma que hablan los usuarios, el español es el que predomina y todas las publicaciones son hechas en ese idioma ya que no se basa en ni se ha adaptado a la estrategia de Internacionalización de Pešić (2014), la cual tiene como objetivo alcanzar visibilidad fuera de la ciudad donde se encuentre el museo. El Real Felipe ha alcanzado a otros países pero no a un nivel global, ya que su público en el recorrido nocturno es mayoritariamente limeño.

El público a quien orienta su contenido el museo, tal como mencionó el coordinador de marketing, son personas que están interesadas por vivir una experiencia diferente pero que también les interesa aprender más de la historia y cultura nacional. Las muestras arrojaron que los visitantes en su gran mayoría suelen seguir a museos en Facebook, tales como el Mali, el Museo de Arte Contemporáneo y el MATE, aparte del Real Felipe. Estos museos se insertaron a medios digitales mucho tiempo antes que el Real Felipe y tiene sentido que los visitantes estén al tanto de las noticias de estas instituciones también. 
Con respecto al segundo objetivo de la investigación, se buscó determinar si las acciones en Facebook y la gestión han favorecido la visibilidad del Museo Fortaleza Real Felipe, además de responder a las siguientes preguntas de investigación:

- ¿Cuáles son los posibles factores que influyen de manera positiva o negativa en las acciones en Facebook que realiza el museo para obtener visibilidad y aceptación entre los públicos visitantes?

- ¿Cuáles son los posibles factores que influyen en la gestión de acciones en Facebook para generar visibilidad dentro del mercado museístico?

En este punto se investigó la popularidad del contenido relacionado con el recorrido nocturno por medio del análisis de contenido, métrico y net sentiment. Con un total de 39 publicaciones desde setiembre de 2016 hasta marzo de 2018, se deduce que el mayor interés de los gestores de la página es atraer al público ofreciéndoles una experiencia paranormal; esto, mediante publicaciones con textos o acompañándolos con un soporte visual, sea imágenes o videos. En los textos se especifican los horarios y días del recorrido con el call to action de motivar la visita al museo con mensajes como "no te lo pierdas" o "adquiere tus entradas en el museo". Se pudo notar que las publicaciones que contenían frases como "si observa algún menor de edad, ignórelo y aléjese", o que incluían una foto referente al tour que generase miedo y misterio, eran las más compartidas y comentadas. Considerando que la interacción de todas las publicaciones son orgánicas sin ninguna inversión publicitaria, es relevante resaltar el peso que se le otorga a los compartidos, ya que no solo es visto por los usuarios seguidores de la fanpage sino también por las amistades y círculos que poseen dentro de esta red social, dándole aún más valor a la visibilidad del museo.

Además de esto, el alcance en cada publicación relacionada con el recorrido nocturno ha obtenido un buen número de personas impactadas con los posts, lo que ratifica que existe relación entre personas las alcanzadas y las que finalmente se convierten en visitantes.

Sin embargo, si bien esto se ve reflejado en el resumen de interacciones de las publicaciones, aún existe el problema de generación de contenido por parte de los visitantes. Villaespesa (2013) y Kotler (2012) afirman que la difusión de la imagen de un museo en particular no solo viene de su propio contenido en línea, sino que debe hallar las formas de motivar a sus públicos a generarlo ellos mismos, lo cual aún no es 
fomentado de manera efectiva por el museo. Este no anima a los usuarios a dejar sus comentarios o experiencias en las publicaciones, por lo que no pueden aún extraer información valiosa para el beneficio de los visitantes y la institución (Crespo, 2012; Malavé, 2016) y con ello implementar nuevas estrategias. Las publicaciones no permiten abrir las puertas de un diálogo por ambas partes, ni generar respuestas recíprocas por el momento ya que los textos son estáticos y no motivan de forma general a ir más allá, con comentarios que abran debates sobre arte, cultura u opiniones con respecto a sus experiencias.

Las publicaciones han dado a conocer el evento; pero, en cuanto al contenido que se pudo recabar y lo dicho por el coordinador de marketing, se encontraron diferencias y difieren en cierto sentido lo uno de lo otro. Al realizar el análisis de las publicaciones desde que se inició con el contenido, se encontró solo una publicación conteniendo un "dato curioso", la cual obtuvo una regular cantidad de interacciones con comentarios y "me gusta". El coordinador de marketing conoce al público al que se dirige e indicó que lo que más buscan los usuarios son temas de interés, "datos curiosos" y cosas que no se encuentren fácilmente en libros de colegio o en internet, por lo que se concentra en comunicar justamente aquello. Contrastando los resultados del análisis de contenido con lo dicho por el coordinador de marketing, se llega a la conclusión que existen contradicciones, ya que él no fomenta contenido "curioso" pero afirma que el público busca eso. Además, contrastando los resultados de la primera muestra, se reafirma la información que desean los visitantes sobre estos "datos curiosos", siendo el $51 \%$ de estos quienes manifestaron su interés por este tipo de publicaciones.

Con el fin de hallar el porcentaje de net sentiment de la marca, el cual refleja el tono emocional detrás de las interacciones para entender las actitudes y aceptación suscitadas en el fanpage por parte de los usuarios (Bannister, 2015), se segregó los comentarios de las publicaciones en comentarios positivos, neutros y negativos. Analizándolos de esa manera, se permitió ver qué tipo de contenido específico obtiene mayor número de comentarios y qué tono utilizan los usuarios, dando como resultado de net sentiment un $99 \%$ debido a que los comentarios negativos hacia la marca son casi nulos y priman los positivos y neutros. De este resultado, se puede destacar que los usuarios expresan satisfacción o emoción con respecto a los servicios que ofrece el 
museo y permite visualizar el interés que genera entre ellos el recorrido de noche específicamente, favoreciendo además a la visibilidad del museo.

La inserción en Facebook, junto con la gestión y contenido publicado del recorrido nocturno, ha traído reconocimiento para el museo frente a otras instituciones ya que, como menciona el coordinador de marketing, ahora el Real Felipe posee visibilidad frente a otros museos y los representantes de este son invitados a diferentes eventos. Ahora, tanto el museo como sus representantes son considerados referentes en temas de cultura. Antes del contenido que se publica actualmente en Facebook, la institución no poseía la notoriedad que ahora tiene, y es debido a la buena gestión que realiza para promover el recorrido nocturno y el museo en general como institución histórica, que ahora distintas entidades particulares y públicas buscan hacerles reportajes, grabar en sus instalaciones, hacer tours en horarios especiales, etcétera.

El último objetivo trató de identificar la aceptación y la experiencia obtenida con la oferta del tour nocturno y de responder las siguientes preguntas de investigación:

- ¿Qué tipo de experiencia y aspectos son los que llevan a la aceptación del recorrido nocturno por parte de los visitantes?

- ¿Qué componentes envuelven la experiencia del recorrido nocturno?

- ¿Qué aspectos sugieren mejoras dentro del recorrido para darles mayor satisfacción a los visitantes?

El recorrido nocturno es uno de los productos culturales que tiene el museo, el cual ha sido convertido en una experiencia que envuelve varios aspectos. Los factores visuales, sonoros, olfativos, táctiles y gustativos (Rieunier, 2000; Barrios, 2012), son componentes estándares usados en las instituciones culturales para lograr la máxima satisfacción de los visitantes y diferenciarse de otras organizaciones. Sin embargo, el recorrido nocturno no se adapta a todos ellos. Al inicio del tour, se muestra a todos los visitantes un video representativo que genera intriga y resume lo que será la experiencia; allí cumple con factores visuales que aún se podrían potenciar a lo largo del recorrido. No poseen gráficas ni otro tipo de estímulo visual, solo los cuadros, pinturas históricas y el módulo "Soldado por un minuto". En cuanto al factor sonoro, hay una sala especial donde cada visitante tiene la oportunidad de recrear la manera de comunicación de los prisioneros en la época de la guerra, lo cual es interesante ya que es una vivencia única que no hay en otro museo del país. El momento del eco en los 
antiguos calabozos es uno de los momentos favoritos por los visitantes como lo demuestra la segunda muestra realizada in situ. En adición a ello, también se tiene en el factor sonoro, los gritos en momentos inesperados propiciados por los personajes andantes durante el recorrido con el motivo de sorprender a los presentes y generar miedo. No posee ningún componente olfativo pero sí táctil, pues antes de ingresar a una de las salas, a la cual se accede mediante un puente, los visitantes que deseen se pueden vendar los ojos y recrear lo que vivían los esclavos al trasladarse de una celda a otra sin ningún tipo de iluminación. El componente gustativo aquí no se podría incluir ya que no encaja con lo que el recorrido ofrece. A través de estos factores, se promueve la experiencia del tour tratando a los usuarios que llegaron a través del Facebook como racionales y emocionales, a quienes les interesa ganar experiencias únicas (He y Huang, 2015). Esto coincide con lo dicho por Schmitt (2010), quien menciona que el valor no reside en el objeto o servicio de consumo sino en el valor que se apoya en la experiencia. Tratándose de un producto cultural único, el recorrido nocturno se enfoca en eso y se ratifica además en lo que menciona el coordinador de marketing y lo que viven los visitantes.

Además de lo mencionado, basado en el módulo de sensaciones de Schmitt (1999), se halló en los resultados de la segunda muestra que los visitantes consideran el sentido de la vista como el predominante con respecto a la experiencia sensorial del recorrido nocturno. Esto coincide con la descripción del recorrido, ya que la parte visual es lo que prima por ahora en el recorrido. La visita a los Torreones del Rey y la Reina fue la preferida por los visitantes durante la segunda muestra; allí se potencia el sentido de la vista al tratarse de un tema netamente visual y de apreciación de piezas. La segunda opción con mayor porcentaje en la muestra con respecto al módulo de sensaciones fue el oído, lo cual se avala con las actividades sonoras que el tour realiza actualmente, teniendo a/los personajes andantes y el momento de eco antes mencionados. Los sentidos de tacto y olfato tienen el menor porcentaje seguido de gusto que no tuvo ningún porcentaje por parte de los visitantes. Si bien, estos tres últimos sentidos no son tan relevantes en la temática del recorrido nocturno, se pueden explotar mucho más y adaptar partes del recorrido para que se enfaticen en esa parte de la experiencia sensorial.

Con respecto a las emociones sentidas por los visitantes al finalizar el recorrido nocturno, sobre la base de la teoría de Eckman (2003) y Barrios (2012), la gran mayoría 
expresó haber sentido sorpresa, seguida de satisfacción y miedo. Estos resultados van acorde a lo que el museo desea proyectar ya que, como mencionó el coordinador de marketing, desean que los visitantes sientan miedo y sorpresa durante el recorrido. Esto se ve ratificado de forma positiva mediante las encuestas. Se rescata además lo dicho en el Módulo de sentimientos de Schmitt (1999), ya que las emociones se producen durante el recorrido.

La propuesta de valor que ofrece el museo está definida para el mercado turístico como "La mejor entidad cultural a visitar en el Callao", pues se diferencia del resto de instituciones culturales para atraer a visitantes, ya que ningún otro museo tiene este tipo de eventos en horario nocturno. Como menciona François (2016), definir la propuesta debe ser una de las prioridades en la estrategia de marketing cultural cuando una institución decida implementarla, ya que todo se comunicará sobre la base de ella. Además se puede concluir, a través de estos resultados, que el museo posee una Proposición de venta holística (HSP, Holistic selling proposition) satisfactoria, ya que ha adoptado características de la experiencia sensorial para elevar el producto que ofrecen y comprometen los sentidos de los visitantes mediante las instalaciones y el espacio que recorren; ellos se ven inmersos en estos escenarios y crean valoraciones más críticas y profundas con respecto a su experiencia (Linsdtrom, 2006).

Un aspecto a considerar en el proceso de análisis de la experiencia es el motivo que tienen los visitantes para asistir al recorrido ya que, dependiendo a eso, se puede conocer más a fondo los intereses del público. Las muestras arrojaron a la motivación intelectual como la más seleccionada; tratándose de un museo histórico, el principal motivo del público es conocer más sobre la cultura y de la historia. Esto concuerda con el público a quien dirige su comunicación el museo, ya que se centra en personas interesadas en la historia y que buscan educarse sobre este tema. Además, coincide con el Módulo de pensamientos de Schmitt (1999), relacionándose con experiencias cognitivas y de intelecto que crean atracción en un nivel creativo.

La social es la segunda motivación según los porcentajes; los visitantes consideran al museo como una atracción llamativa (Soydanbay, 2017) e ir con amigos y familiares para disfrutar un momento juntos es una de las razones por la que participan del recorrido nocturno. Un aspecto resaltante de estos resultados es que ambas motivaciones convergen en lo que ofrece el tour: vivir una experiencia única de miedo a través de la historia que envuelve el museo y compartir el evento con otras personas. 
En cuanto a los aspectos más tangibles y medibles de la experiencia, Barrios (2012) afirma que las claves para el éxito de la misma son el servicio memorable, la integración del modelo y la consideración de los pensamientos, relaciones, actuaciones, sensaciones y sentimientos de los visitantes. Desagregando lo dicho por el autor, en cuanto al servicio ofrecido, el Real Felipe posee guías capacitados y conocedores del tema, lo cual se sostiene en los resultados de las muestras en que se propuso la escala de muy mala a muy buena para calificar el desempeño del guía. El 41,4\% seleccionó la performance de quien los guió como buena, y el 39\% como muy buena. Sin embargo, el público mencionó como punto de mejora el dinamismo del guía ya que no era tan enérgico y sociable.

Con respecto a la organización y estructura del recorrido nocturno, los ambientes visitados y la concurrencia de visitantes, en las respuestas de los presentes, fueron catalogados por la mayoría como buenos. De esta manera, se puede notar que los aspectos claves que el museo ofrece para que la experiencia sea exitosa están siendo cumplidas y reconocidas por los propios visitantes, tal como se visualiza en los resultados de las muestras. Si bien, aún no se puede considerar el servicio como memorable ya que el resto de respuestas están en neutro y mala, la mayoría resultó satisfecha por el servicio ofrecido. Se puede concluir que la estrategia de Alineación con estándares profesionales de Pešić (2014) está siendo considerada por el museo, ya que el recorrido nocturno está alineado con los estándares básicos que debe ofrecer una institución cultural, tales como la visualización de alguna exposición o participación en eventos, contar con un espacio físico y servicios básicos como luz y agua, sumado con el personal capacitado.

Como menciona Barrios (2012), la integración de todos estos aspectos claves que se involucran con los visitantes y la institución, debe ir acorde a la experiencia que se desea brindar. Como el coordinador de marketing del museo mencionó, el recorrido nocturno es único y busca ofrecer una experiencia de terror y, con ello, dar a conocer el museo de forma positiva. Basado en esa afirmación, se pidió a los visitantes que expresen la sensación y percepción que se llevaron luego de ser partícipes del tour. En ambas muestras, más de la mitad de visitantes se refirió a la experiencia como agradable y el $24 \%$ de ambas muestras en promedio lo calificó como muy agradable. Esto coincide con lo que el coordinador de marketing menciona acerca de dar a conocer el museo de manera positiva, ya que el $60 \%$ en promedio de ambas muestras al finalizar 
el recorrido nocturno expresó tener cambios positivos con respecto al museo. Debido a este resultado, la visibilidad del museo se ve beneficiada de forma orgánica por parte de los visitantes, ya que más del 50\% de visitantes en promedio en ambas muestras, consideró compartir, recomendar o publicar fotos o videos de su visita al tour de noche en alguna de sus cuentas de redes sociales. Mediante esta variable en las muestras se puede notar que lo dicho por Kotler (2013) va por un camino alentador, en el sentido de generación de contenido por medio de la experiencia en sí, pero no por parte de las propias publicaciones en Facebook, tal como se menciona en párrafos anteriores.

Además, como mencionan Frow y Payne (2007), mediante la experiencia y la atmósfera en la que se sumergen, los visitantes se van forjando una imagen auténtica de lo que les ofrece en sí el museo, convirtiéndolos más adelante en los “defensores” de la institución, quienes serán los "voceros" y llevarán su experiencia a nuevas personas mediante el boca a boca. Basado en lo mencionado por los autores, se preguntó a los visitantes si el museo cumplió con las expectativas que tenían antes de realizar el tour, siendo que más del $70 \%$ respondió de forma afirmativa. En adición a ello, el mismo porcentaje expresó haber sufrido cambios positivos en la percepción que tenía del museo al finalizar el recorrido nocturno.

A través de estos resultados, se puede concluir que, al satisfacer las expectativas de los visitantes, estos compartirán su experiencia con otras personas y tendrán opiniones positivas con respecto a su experiencia en el recorrido nocturno.

Cabe resaltar que si bien los visitantes manifestaron que el tour cumplió con sus expectativas, también les gustaría que se ofrezcan otro tipo de servicios tales como exposiciones y exhibiciones temáticas de manera más frecuente, ya que por el momento solo se ofrecen de forma esporádica y en fechas conmemorativas. Este resultado es interesante para analizar ya que, por ahora, el museo básicamente solo ofrece los recorridos diurnos y nocturnos, pero para generar múltiples revisitas tendrían que contar con otro tipo de eventos que atraigan de igual manera a los potenciales visitantes o, en todo caso, implementar otras actividades o dinámicas durante estos recorridos. Tal como se sostiene en las muestras realizadas, en las que se halló que a los visitantes les gustaría que existan otro tipo de actividades dentro del museo, el resultado contradice lo dicho por Blas (2018), quien afirma que los museos pequeños o que se centran en un solo artista o tema son los que atraen mayor atención por la experiencia vivida en un nivel más personal. Si bien esto sucede con los visitantes del recorrido nocturno, ellos 
son los que además de la temática del terror desean que se ofrezca otro tipo de temas o actividades sin dejar de tener una experiencia personal.

Lindstrom (2005) enumera diez reglas con las cuales se construye una sólida experiencia para los visitantes. Sin embargo, el museo solo ha incluido cinco de estos componentes:

- Crear un sentido de autenticidad: es el único recorrido nocturno en el Callao y el que ofrece una experiencia de terror en una fortaleza.

- Establecer consistencia: A lo largo del tour se mantiene la calidad, siendo un recorrido ordenado y estructurado.

- Sumergir a las personas en un mundo perfecto: Los visitantes se sienten parte de la época histórica en que se suscitaron los eventos relatados en el recorrido.

- Crear atractivo sensorial: Varios sentidos se ven estimulados y hacen la experiencia más agradable.

- Desarrollar sentido de misterio: Las instalaciones junto con la estructura del recorrido generan un ambiente de misterio, sorpresa y miedo. 


\section{CONCLUSIONES}

Dado lo mencionado anteriormente se puede concluir que el impacto y la aceptación de la oferta experiencial entre los visitantes es positiva y ha traído beneficios para la institución. A través del contenido publicado en Facebook se ha logrado obtener efectivamente un mayor grado de visibilidad de la oferta experiencial que ofrece el tour nocturno del Museo Fortaleza Real Felipe.

En primer lugar, gracias al recorrido nocturno el museo aplica el marketing cultural de tal manera que permite ser un nexo entre la herencia cultural y la comunidad, promoviendo el desarrollo y la valoración del sector cultural, además de generar turismo y convertirse en una fuente importante de ingresos para el país (Jiménez, 2011; GomézTarragona, 2010). De esta manera, se está logrando la democratización de la historia y de la cultura nacional para todos los públicos, aumentando así su visibilidad frente a otros museos. Sumado a ello, las acciones en Facebook y la gestión de estas también han permitido que el museo obtenga aceptación por parte de los visitantes, ya que el recorrido nocturno es un evento dirigido al rango de edades adecuado. Aquí se pudo notar que la estrategia de Aspiración de Porter (2006), la cual consiste en alcanzar cierto número de visitantes, es aplicada por el museo, pues se vio incrementado en cantidad, al igual que los ingresos de la institución.

El amplio despliegue de publicaciones en la página de Facebook ratifica que la interacción que poseen, junto con el alcance de estas, logra impactar a la audiencia y motivarla a vivir la experiencia del recorrido nocturno. Sobre la base de esto, el museo desea verse expuesto de forma atractiva y entretenida para captar la atención; dejando de ser solo un lugar histórico que brinda conocimientos de forma lineal y poco interesante para ofrecer nuevas experiencias según los gustos de los visitantes.

El coordinador de marketing acertó en la selección de la red social Facebook ya que, como Drucker (2003) menciona, los directivos deben explorar el entorno e investigar nuevas tecnologías con el fin de encontrar mejores métodos para transformar los inputs en outputs con relación a los usuarios y lo que buscan en esos medios. Ello coincide con lo mencionado por el coordinador de marketing, quien se dio cuenta de 
que contar con un fanpage era la manera que les resultaba más accesible económicamente, así como la que les permitía tener el alcance que deseaban.

Si bien lo que impidió la pronta presencia del Real Felipe en medios digitales fue el aspecto económico, debido a que los ingresos del museo no se derivan a temas publicitarios o de modernización para implementar la página web o la fanpage, mediante la gestión en la red social el número de fans ha ido subiendo y el recorrido nocturno destaca entre los demás. Se ve entonces que los recursos pueden ser escasos en una institución, pero que siempre hay posibilidades de promover sus productos y darle la relevancia que se merecen. Los gestores del museo se adaptaron a las herramientas que tenían y poco a poco se insertaron en medios digitales. Cabe resaltar que, pese a ser un museo con apoyo económico del Gobierno Regional del Callao y del Estado, existen aún muchas prioridades dentro de este para poder derivar parte del presupuesto a temas digitales y de branding, por lo que la viabilidad de las estrategias a futuro se verá más adelante.

De esta manera, podemos anotar que para lograr visibilidad dentro del mercado museístico, la gestión en redes debe constar de tres factores: conocer el público al que le interese el servicio y pueda convertirse en visitante, comunicar de manera dinámica y fluida el servicio que se ofrece y, por último, cautivar a la audiencia y comprometerla con la institución por medio de las publicaciones. Estos factores son referentes a una institución cultural ya que pueden variar dependiendo del rubro de la institución o empresa.

Con respecto a la experiencia del recorrido nocturno, se puede concluir que existen también ciertos factores que llevan a la aceptación por parte de los visitantes. En primer lugar, el recorrido incluye ambientes oscuros y detalles que promueven el miedo y temáticas de terror; esto ayuda a sumergir a los visitantes en la época histórica de forma versátil. Aquí la infraestructura juega un papel importante. Otro factor es la estructura del tour: el orden de los segmentos, la ruta que siguen los visitantes y las pausas que se realizan se convierten en la base de la experiencia, junto con el desempeño del guía que también es un elemento relevante para englobar la experiencia. Al finalizar el recorrido, los visitantes tienen una valoración positiva de este ya que el personal está capacitado y se les brindan los estándares básicos acorde con el monto que pagan. 
Además de esto, a través de los Módulos Experienciales Estratégicos de Schmitt (1999) se halló que los visitantes quedan satisfechos con el recorrido y les agrada el momento vivido en el museo, ya que pasan por los módulos de sensaciones, emociones y pensamientos. Sin embargo, no se puede afirmar que se logra la experiencia holística desde el inicio y fin de lo que denomina Schmitt como rueda experiencial. La rueda experiencial no se logra producir en el caso del recorrido nocturno, ya que no cumple con el módulo de actuaciones; las experiencias físicas de las personas no se ven intervenidas influyendo en su estilo de vida, ni se les muestra otras formas de desarrollar actividades rutinarias (Schmitt, 1999, p.62). De igual manera sucede con el módulo de relaciones, ya que no se fomenta la conexión del individuo con su yo interior ni con otras personas (Schmitt, 1999, p.62). Schmitt menciona que para que la experiencia holística esté completa se deben pasar por los cinco módulos de forma aleatoria, lo que conlleva a afirmar que en el aspecto experiencial, el museo va por buen camino pero aún falta desarrollar ciertos módulos que permitan generar una experiencia sólida.

Actualmente no existe otro evento similar al recorrido nocturno en el país, lo que genera intriga e interés por parte del público. Tal como se mencionó en el capítulo anterior, el Real Felipe ofrece una propuesta de valor diferenciada y una propuesta de venta holística que no se asemeja a otras instituciones culturales en el momento. Sumado a esto, la experiencia sensorial que otorga el tour a lo largo del recorrido también es un aporte relevante para que el aumento de las visitas se dé, ya que las personas ahora buscan vivir experiencias y no solo asistir a un recorrido tradicional en el que los guías realicen un monólogo.

De acuerdo con el planteamiento de Lindstrom (2005), de medir los sentidos mediante ciertas dimensiones, se halló que la experiencia sensorial fue positiva en las personas con respecto a la institución, ya que sobre la base de las muestras se obtuvo que el mayor porcentaje está satisfecho con la experiencia del recorrido nocturno y que el museo ha tenido cambios positivos en su percepción gracias al servicio ofrecido. Además, la impresión que se llevan los visitantes en su gran mayoría ha sido distintiva ya que las muestras reflejaron que los visitantes consideran el tour de noche como uno de los que más le ha llamado la atención, en comparación con otros en que han participado. Asimismo, Lindstrom también considera a las emociones captadas en la experiencia sensorial como parte de las dimensiones; en este caso de estudio, la 
sorpresa, satisfacción y miedo fueron las que primaron. Además, el autor menciona el liderazgo de la marca como una dimensión más; en el caso del Real Felipe se confirma que la institución es auténtica y que está ganando popularidad gracias al tour.

Se concluye que las dimensiones en el tour de noche están cubiertas en su mayoría y se pudo lograr la medición de los sentidos para poder otorgarle valor a la experiencia.

En cuanto a las estrategias que han sido adaptadas por el museo, se halló que el museo ha seguido lo propuesto en la estrategia de Captación y creación de valor planteada por Jiménez \& Quero (2011), en la estrategia de Alineación con estándares profesionales de Pešić (2014) y la de Aspiración de Porter (2006). Esta última estrategia envuelve el incremento en el número de visitantes y el incremento de ingresos en la institución. Sin embargo, no se adapta al aspecto de duplicar el financiamiento, ya que al pertenecer al Estado se tiene un monto fijo para mejoras. Otra estrategia de Porter que también se percibe en el Real Felipe es la visión/misión, la cual consiste en dar aportes a la comunidad tanto cultural como de científicamente; por ser un museo público, este cuenta con un museólogo e historiador de forma perenne para que las piezas y reliquias tengan mantenimiento constante. De esta manera se promueve el cuidado de nuestras edificaciones históricas y se implementan mejoras constantes.

Si bien el museo cumple con varias de las estrategias, aún quedan pendientes otras que podrían potenciar su visibilidad y resultar beneficiosas. Una de ellas es la estrategia de Elevación de la calidad de la audiencia mediante el engagement, que propone Pešić (2014), la cual permitiría fidelizar a la audiencia y crear una conexión duradera con esta. El recorrido nocturno aún no es suficiente para esto, ya que no realizan acciones posteriores a la experiencia ni ningún tipo de seguimiento; la fanpage, de igual manera, no permite generar conexión duradera con la audiencia ya que el contenido no genera debate ni conversación. Otra estrategia del mismo autor que tampoco se visualiza en el museo es la Descentralización de programas y actividades, la misma que consiste en llevar las actividades y eventos que realiza el museo a otras zonas. Sin embargo, por la temática del museo y su infraestructura, no es posible que por el momento el Real Felipe pueda realizar este tipo de acciones. Porter (2006) menciona una estrategia interesante que el Real Felipe podría considerar para poder seguir ampliando su público y potenciar su propuesta diferencial; el autor propone la estrategia de Acción, la cual involucra expandir las exhibiciones y ampliación de la 
infraestructura. Como ya se mencionó en los resultados de las muestras, el público está interesado en que el museo ofrezca otro tipo de actividades y eventos, por lo que hay oportunidades y potencial aceptación por parte de ellos en caso el museo ofreciera diversidad.

Se concluye además que, de los diez componentes de Lindstrom (2005) para conformar una experiencia sólida al visitante, el museo solo ha adaptado cinco; sin embargo, implementar los otros cinco aspectos por parte de los gestores del museo produciría que la experiencia del tour sea más gratificante. El primer componente, crear sentido único de pertenencia, aún no está presente en el recorrido nocturno pero sería un aporte diferencial, ya que se puede aprovechar la historia que se guarda en el museo para sacar a relucir aspectos nacionalistas entre los turistas locales. De igual manera, se podría direccionar el componente que se refiere a crear un sentido de propósito. En cuanto al aspecto tomar poder de competidores, el Real Felipe está rodeado de otros dos museos que buscan promover la cultura, por lo que al tratarse de un museo público, se orienta principalmente a diferenciarse y sobresalir, lo cual está siendo logrado. Finalmente, el último componente que menciona Lindstrom pero que no está presente en el museo es la creación de símbolos representativos para la marca. Actualmente el museo tiene un logo que usa en algunos banners o volantes cuando se realiza un evento, pero que no es identificado aún por el público visitante. El único símbolo que poseen es ese y no lo promueven de forma visible; sería beneficioso que implementen otros símbolos que tengan coherencia además con el recorrido, tales como símbolos de piratas o de corsarios, ya que tienen relación con la historia que caracteriza al museo.

Como se analiza en este trabajo, el producto cultural — en este caso, el recorrido nocturno del Real Felipe - puede adoptar diversas formas y prácticas; lo importante es que se constituya en un evento único y diferenciado, promocionado mediante diversos medios y que busca ser valorado entre los visitantes para su posterior difusión, aplicando tanto marketing digital como marketing cultural, lo cual está logrando de manera óptima. Sin embargo, aún existen aspectos por mejorar y que el museo podría adoptar para ofrecer un servicio aún mejor y con ello implementar otras estrategias que permitan mayor interacción con los usuarios. 


\section{RECOMENDACIONES}

Para concluir con esta investigación, se presentan recomendaciones para los representantes y personas involucradas en el recorrido nocturno del Museo Fortaleza Real Felipe.

Con respecto a la poca inversión que se le otorga a temas digitales y promoción del recorrido nocturno en redes, el Museo Fortaleza Real Felipe no considera aún como una prioridad invertir en temas digitales, ya que recibe ayuda del Estado constantemente y toma por sentado los ingresos que reciben a diario, dejando de lado la promoción del recorrido en redes con pauta digital o publicidad en otras páginas. (Tugbay, 2012). Dicho esto, se recomienda darle mayor relevancia a la publicidad digital para dar a conocer a un público mucho mayor el recorrido nocturno, ya que aún existen personas que no lo conocen; así las cosas, aún se puede generar muchos más ingresos tanto en los horarios diurnos como nocturnos. Además se recomienda obtener más presencia en televisión y radio pues, tal como mencionó el coordinador de marketing, es una de las estrategias que el museo vislumbra a futuro y podría potenciar el recorrido mediante coberturas en medios por parte de programas culturales o especiales históricos.

Seguido de ello, a pesar del crecimiento de forma orgánica de la fanpage y del óptimo alcance de las publicaciones relacionadas al recorrido nocturno, se recomienda usar estrategias para motivar a los usuarios a generar su propio contenido e interactuar más con las publicaciones a través del uso de hashtags, invitando a etiquetar a amigos, haciendo concursos y promoviendo el debate dentro de la página.

Además de lo mencionado, François (2016) afirma que el turismo es un mercado heterogéneo, en el cual cada persona tiene gustos e intereses distintos, por lo que considerar diferentes canales de marketing para asegurar el mejor alcance a cada segmento es vital. A través de Facebook, el Real Felipe satisface solo a una parte de su público aprovechando lo que le otorga el medio. Sin embargo, pueden hacer uso de otras plataformas digitales como YouTube, por medio de la publicación de videos cortos de las instalaciones, de las visitas, de datos interesantes de historia, etcétera. De esta manera podrían llegar a un público más extenso, no solo nacional sino también global. 
Basado en el reconocimiento que el Real Felipe ya posee, se recomienda crear alianzas estratégicas con museos que se encuentren cerca de la zona, como el Museo Naval, el cual está ubicado al lado de Real Felipe, y el Museo Submarino Abtao, ubicado a unas cuantas cuadras. Se recomienda crear una red de museos del Callao que empiece con los dos museos mencionados y termine con el recorrido nocturno del Real Felipe. Así, el museo podría abrir incluso más fechas de recorrido nocturno durante la semana y todos los museos del área saldrían beneficiados. Además, el Real Felipe está ubicado a pocas cuadras de "Callao Monumental", el área que ha cobrado fuerza en los dos últimos años, convirtiéndose en uno de los puntos turísticos más visitados por nacionales y extranjeros al ser un área artística y bohemia, similar a Barranco. Se debe aprovechar también la cercanía del lugar para entregar volantes o promover el museo mediante algún mural artístico.

Con respecto a la experiencia que se ofrece actualmente, se recomienda una mayor interacción de los guías con los visitantes; estos deben ser más dinámicos e involucrar a la audiencia con ellos para que el recorrido sea más ameno y sociable.

Otra recomendación importante es generar una base de datos de visitantes, a través de la solicitud de los correos de los visitantes del recorrido diurno, para mandarles información del recorrido nocturno y motivarlos a que asistan. Esto permite trazar estrategias sobre la gestión de relaciones con la organización desde el principio, además de aplicar estrategias de marketing directo (Jimenez \& Quero, 2011).

Para concluir, como recomendación para futuras investigaciones, se propone realizar entrevistas a profundidad a algunos visitantes, para obtener información más profunda y amplia de lo que viven los asistentes, sus apreciaciones, opiniones y sugerencias, pues ellos son quienes facilitarán a la institución continuar mejorando. 


\section{REFERENCIAS}

Afrina Yasmin, S. T. (2015). Effectiveness of Digital Marketing in the Challenging Age: An Empirical Study. International Journal of Management Science and Business Administration Volume 1, Issue 5 , 69-80.

Armstrong, A. D. (2015). Principles of marketing. Pearson Australia.

Are museums still relevant? (12 de julio de 2017). CNN Travel. Recuperado en enero de 2018 de http://edition.cnn.com/travel/article/are-museums-stillrelevant/index.html

Ballard, C. (2011). What's happening”@twitter: a uses and gratifications approach. Kentucky .

Bannister, K. (26 de enero de 2015). Brandwatch. Recuperado el 11 de noviembre de 2017, de https://www.brandwatch.com/blog/understanding-sentiment-analysis/

Barrios, M. (2012). Marketing de la Experiencia: principales conceptos. Palermo Business Review , 1-24.

Bautista, S. S. (2014). Museums in the Digital Age: Changing Meanings of Place, Community, and Culture. Maryland: Altamira Press.

Benediktsson, G. (2014). Museums and tourism. Göteborg: Master's Dissertation International Museum Studies Museion.

Bertacchini, E. (2013). The Future of Museums in the Digital Age: New Models of Access and Use of Digital Collections. International Journal of Arts Management, 15(2) - 60-72.

Blas, B. (Febrero de 2018). Villafañe y asociados. Recuperado el abril de 2018, de http://www.villafane.com/reputacion-mudo-cultural-museos/

Cannell, M. (17 de Marzo de 2015). The New York Times. Recuperado el Enero de 2018, de https://www.nytimes.com/2015/03/19/arts/artsspecial/museums-turnto-technology-to-boost-attendance-by-millennials.html

Carter, S. M. (2008). The Day We All became Hokies:An Exploratory Uses and Gratifications Study of Facebook Use After the Virginia Tech Shootings. Virginia: Thesis Faculty Liberty University School of Communication.

Clairbone, L. (2004). Clued In: How To Keep Customers Coming Back Again and Again. Financial Times Prentice Hall.

Colbert, F. (2003). Entrepreneurship and Leadership in Marketing the Arts. International journal of arts management , 21. 
Colbert, F., \& Cuadrado, M. (2003). Marketing de la artes y de la cultura. Barcelona: Ariel.

Crespo, R. A. (2012). Planificación estratégica en medios digitales: Internet y redes sociales. Planificación estratégica y gestión de la publicidad. Madrid: ESIC EDITORIAL.

Día del Internet: Este es el perfil del internauta peruano (17 de mayo de 2017). RPP. Recuperado de http://rpp.pe/economia/economia/dia-del-internet-este-es-elperfil-del-internauta-peruano-noticia-1051335

Drucker, P. (2003). El management del futuro. Buenos Aires: Sudamericana.

Dudareva, N. (2014). What makes social media relevant for arts and culture marketing: a study applied to Facebook pages of three museums in Copenhagen. Copenhagen: Copenhagen: Master Thesis | Cand.soc. in Management of Creative Business Processes.

Ekman, P. (2003). Emotions revealed. New York: Henry Holt and Company.

François, J. (7 de marzo de 2016). Bring foreign tourists to museums with a great marketing strategy. The Guardian. Recuperado en enero de 2018, de https://www.theguardian.com/culture-professionals-network/2016/mar/07/bringforeign-tourists-museums-marketing-strategy

French, Y., \& Runyard, S. (2011). Marketing and Public Relations for Museums, Galleries, Cultural and Heritage Attractions. New York: Routledge.

Frow, P. a. (2007). 'Towards the 'Perfect' customer experience'. Brand Management $15,89-101$.

Frow, P. \& Payne, A. The Journal of Brand Management, Volume 15, Number 2, 2 November 2007, pp. 89-101(13).

Gerolimos, M. (2011). Academic Libraries on Facebook: An Analysis of Users' Comments. D-Lib Magazine, 5-7.

Gómez-Tarragona, D. (2010). ¿Qué es el marketing cultural? Dicendi Comunicación, S.L.

Guglielmino, M. M. (2007). La difusión del patrimonio. Actualización y debate. Revista de patrimonio, 3-21. Recuperado de http://www.revistadepatrimonio.es/revistas/numero1/difusion/estudios/_pdf/difu sion-estudios.pdf

He, L.; Huang, Z. (2015) Experiential marketing by attributes of experience design for hotel APPs. An empirical study from China. Master Thesis, Halmstad University

Hernández, R., Fernández, C., \& Baptista, P. (1991). Metodología de la investigación. Juarez: McGraw Hill Interamericana de México. 
Holbrook M. B. \& Hirschman E. C. (1982). The Experiential Aspects of Consumption: Consumer Fantasies, Feelings, and Fun. Journal of Consumer Research Vol. 9, No. 2 (Sep., 1982), pp. 132-140.

Huang, L. (2009). Twitter sentiment classification using distant supervision. CS224N project report, Stanford.

INEI. (2017). Estadísticas de las Tecnologías de Información y Comunicación en los Hogares. Lima. Recuperado de https://www.inei.gob.pe/media/MenuRecursivo/boletines/02-informe-tecnicon02_tecnologias-de-informacion-ene-feb-mar2017.pdf

Jimenez, A. \& Quero, M.; (2011). Manual de marketing y comunicación cultural. El observatorio cultural. Recuperado de http://observatoriocultural.udgvirtual.udg.mx/repositorio/bitstream/handle/12345 6789/238/Leal-marketingcultural.pdf?sequence $=1 \&$ isAllowed $=y$

José Marti, P. M. (2008). Engagement Marketing . Madrid: Prentice Hall.

Kerry Smith, D. H. (2015). Experiential Marketing: Secrets, Strategies, and Success Stories from the World's Greatest brands. New Jersey: Jhon Wiley \& Sons.

Kotler, P. (2012). Marketing 3.0. Bogotá: Ediciones de la U.

Lecinski, J. (2011). Winning the Zero Moment of Truth. Google Inc.

Lindstrom, M. (2005). Brand Sense Build Powerful Brands through Touch, Taste, Smell, Sight, and Sound. Illinois: Simon \& Schuster Inc.

Liu, Y. (2016). Museums on social media: how cultural institutions should reach out to millennials. Boston: Thesis Boston university college of communication.

Malavé, A. (2016). Convirtiendo las quejas expuestas en facebook en oportunidades: el caso de easy taxi perú. Lima: Universidad de Lima.

Malde, S. (2 de abril de 2013). Museums connecting cultural tourists: more substance over style, please. The Guardian. Recuperado en enero de 2018, de https://www.theguardian.com/culture-professionals-network/cultureprofessionals-blog/2013/apr/02/museums-cultural-tourists-digital-content

Marco Palomino, T. T. (2016). The Online Dissemination of Nature-Health Concepts: Lessons from Sentiment Analysis of Social Media Relating to "Nature-Deficit Disorder". International Journal of Environmental Research and Public Health, 142.

Martí, J. a. (2008). Engagement Marketing. Madrid: Pearson Education.

Martínez-Sanz, R.; Berrocal-Gonzalo, S. (2017). Museos y engagement. La calidad de los espacios web como soporte del compromiso. Revista Española de 
Documentación Científica, 40(1): el66. doi: http://dx.doi.org/10.3989/redc.2017.1.1383

Ministerio de Cultura (s/f). Recuperado de https://www.gob.pe/cultura

Monistrol, R. (2009). Evolución y aplicación del marketing cultural en los museos. Textos universitaris de biblioteconomia $i$ documentació. Recuperado de http://bid.ub.edu/23/monistrol2.htm

Muñoz, P. \& Martí, J. 2008. Engagement Marketing. Una Nueva Publicidad Para Un Marketing De Compromiso, 1a edición.

Museo Fortaleza Real Felipe (s/f). Recuperado en Abril de 2018 de http://www.realfelipe.com/museos-relacionados/museo-fortaleza-real-felipe

Peña, J. (2014). ¿Sirven para algo las redes sociales en el sector cultural? Anuario ac/e de cultura digital Tema 8 , 101-113.

Pešić, M. (2014). Importance of management strategies in museums and galleries. Osijek: University of Osijek, Department of Cultural studies.

Porter, M. E. (2006). Strategy for Museums. American Association of Museums.

Museo del Prado (s/f). Recuperado el 28 de enero de 2018, de https://www.museodelprado.es/museo

Rieunier, S. (2000). L'influence de la musique sur le comportement du consommateur. Paris: Doctoral dissertation.

Rusillo, M. (2013). Museos y Content Marketing. Hacia un nuevo. Zer-Revista de Estudios de Comunicacion (Universidad del pais Vasco) , 13-28.

Schmitt, B. (1999). Experiential Marketing. Journal of Marketing Management, 53-67.

Schmitt, B. (2006). Experiential marketing. Nueva York: The Free Press.

Schmitt, B. (2010). Experience marketing: Concepts, frameworks and consumer insights, foundations and trends in Marketing. New York: Columbia Business School Columbia University.

Simmons, J. (2012). The Starbucks story: how the brand changed the world. Singapure: Cyan Books.

Soydanbay, G. (noviembre de 2017). Undertourism: How to Make Archaeological Sites and Museums More Attractive as Destinations. The Place Brand Observer. Recuperado el 2 de noviembre de 2017, de http://placebrandobserver.com/howto-make-museums-attractive-destinations/

Tate (s/f). Recuperado el 28 de enero de 2018 de http://www.tate.org.uk/whats-on/tatemodern/exhibition/modigliani/modigliani-vr-ochre-atelier 
Tugbay, S. (2012). Museums and Visitors on the Web. A comparative study of visitor engagement on social media in Dutch and Turkish museums. . Rotterdam: Rotterdam: M.A. Thesis in Cultural Economics and Cultural Entrepreneurship Erasmus University Rotterdam.

Van Riel, C (29 de agosto de 2017). What businesses can learn from the high reputations of museums. RSM Discovery. Recuperado de https://discovery.rsm.nl/articles/detail/297-what-businesses-can-learn-from-the-highreputations-of-museums/

Villaespesa, E. (2013) Diving into the Museum's Social Media Stream. Analysis of the Visitor Experience in 140 Characters. In Museums and the Web 2013, N. Proctor \& R. Cherry (eds). Silver Spring, MD: Museums and the Web. Published January 31, 2013. Consultado el 14 de abril de 2018. Recuperado de https://mw2013.museumsandtheweb.com/paper/diving-into-the-museumssocial-media-stream/

Villalobos, M. R. (14 de Marzo de 2017). Más de 19 millones de peruanos se conectan a Facebook mes a mes. El Comercio. Recuperado de https://elcomercio.pe/economia/negocios/19-millones-peruanos-conectanfacebook-mes-mes-144752

Wallace, L. (2000). How museums can become more visitor-centered. New York: Lila Wallace-Reader's Digest Fund.

Walker, D. (2015). Social Media, Participation, Disciplinary Experts and the Public in the Contemporary Museum. Cambridge: Thesis Department of Archaeology and Anthropology. University of Cambridge.

Yasmin, Fatema \& Tasmeen. (2015). Effectiveness of Digital Marketing in the Challenging Age: An Empirical Study. International Journal of Management Science and Business Administration Volume 1, Issue 5, 69-80.

Yáñez, G. S. (2013). La estrategia digital de los museos.un primer paso en la evaluación. Universitat d'Andorra: España. 


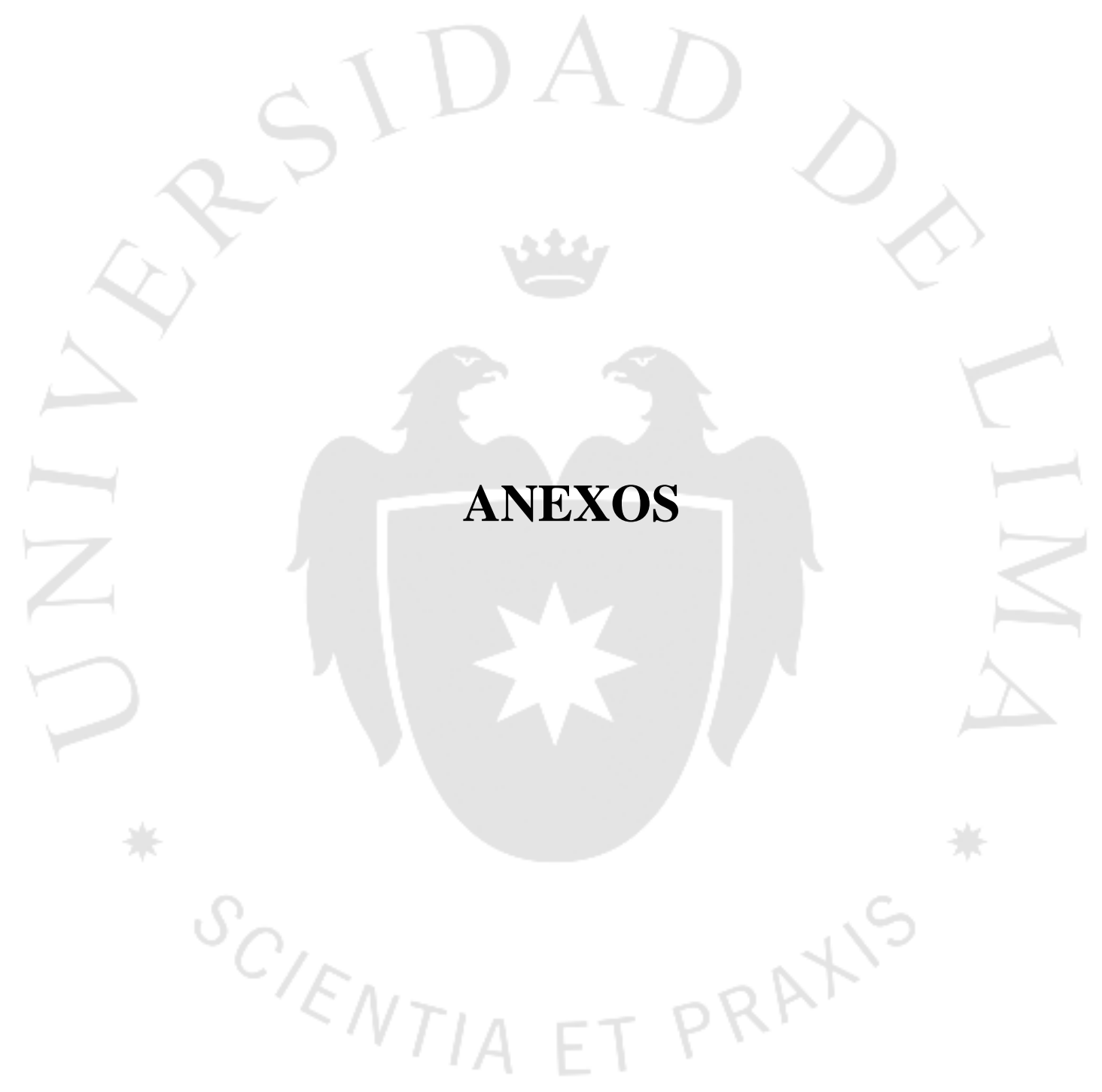




\section{Anexo 1 Guía de preguntas al coordinador de marketing}

1. ¿Qué aspectos se tomaron en consideración para la inserción del museo en medios digitales?

2. El Facebook del museo se creó en marzo de 2016 y en abril se lanzó la web. ¿Por qué el proceso de inserción a medios digitales del museo tardó un poco frente al del MALI (un par de años atrás) u otras instituciones culturales?

3. ¿Cuáles son los criterios para colocar un post (una publicación) sobre el museo en Facebook?

4. ¿Recuerda los post más populares?

5. ¿Cuáles cree que son los contenidos que busca la gente para poder seguir la página del museo?

6. ¿Cómo es la interacción con los usuarios?

7. ¿Comparten el mismo contenido en el Facebook del museo y en la página web?

8. ¿Cómo nació la estrategia digital del tour de noche (recorrido nocturno)?

9. ¿Cuál ha sido su evolución desde la creación?

10. ¿Qué beneficios ha traído para el museo?

11. ¿Han medido cuál es el efecto de la presentación de los posts?

12. En su opinión, ¿la estrategia del tour ha sido efectiva para el museo? ¿Cuánto pesó la promoción digital en la asistencia al tour de noche? ¿Cree que lo digital motivó a la gente a vivir la experiencia del tour?

13. A futuro, ¿cuáles son las estrategias que vislumbra? ¿Para qué? ¿Con qué finalidades? 


\section{Anexo 2 Transcripción de entrevista al coordinador de marketing}

\section{1. ¿Qué aspectos se tomaron en consideración para la inserción del museo en medios digitales?}

El primer aspecto es que ya todo el mundo está conectado, y un segundo aspecto es que no teníamos presencia alguna en medios digitales, y bueno... también con ello se suma problemas económicos. Por ello, dentro de todos los medios, los digitales eran los que más alcance tenían y también los más económicos.

2. El Facebook del museo se creó en marzo de 2016 y en abril se lanzó la web. ¿Por qué el proceso de inserción a medios digitales del museo tardó un poco frente al del MALI (un par de años atrás) u otras instituciones culturales?

Tardó un poco porque la dirección de museos son instituciones (Museo Chavín de Húantar, Museo Andrés A. Cáceres, Museo Combatientes del Morro de Arica) que están bajo el cargo del ejército, entonces no hay una prioridad. La prioridad en el ejército no son los museos sino otras cosas como el armamento, tropas, más que fijarse en sus propios museos, cosa que ahora recién hay una concientización de lo importante que son los museos que tienen, sobre todo el del Real Felipe, que en verdad son monumentos históricos que, por así decirlo, están abandonados en cuanto a temas publicitarios. Ahora el plan es ponerlos en valor y tratar de que estos sean más conocidos y a la vez más rentables, para que dentro y fuera del ejército sean más considerados. En general, se desea esto con todos los museos, pero en especial con el del Real Felipe que tiene más valor.

\section{3. ¿Cuáles son los criterios para colocar un post (una publicación) sobre el museo}

\section{en Facebook?}

El primer criterio es el tipo de comunicación que tiene el ejército; nosotros somos un museo (...), pero pertenecemos al ejército y nuestra forma de comunicación tiene que ser acorde con lo que el ejército manda en su forma de comunicación, que es un poco más seria y muy formal. Pero predominante seria, por lo que no se puede jugar mucho, no se puede quizás ser, por así decirlo, divertido. Otro criterio que tomamos es presentar temas interesantes de los museos, como pueden ser fechas importantes, acontecimientos, objetos interesantes que tienen cada uno, y captar al público objetivo. 
En este caso tenemos varios, que son entre jóvenes interesados en la historia, o que estudian historia del arte.

\section{4. ¿Recuerda los post más populares?}

Creo que fue uno de los primeros que hicimos, cuando vino un canal de televisión y aprovechamos la oportunidad e hicimos un disparo de cañón y tomamos fotos de todo el proceso, además que los soldados estaban disfrazados con los trajes de la Guerra con Chile. Como también la página recién había sido lanzada, publicamos las fotos y (eso) repercutió bastante, sobre todo en la gente que está interesada en la historia y actividades culturales. Un video que publicamos también fue bastante visto y algunos post de los tour de noche, ya que eso llama la atención con lo misterioso y tenebroso.

\section{5. ¿Cuáles cree que son los contenidos que busca la gente para poder seguir la} página del museo?

Más que todo el público posee interés por la historia o por la fortaleza en sí. Esta es una construcción que llama mucho la atención. Temas de interés, datos curiosos y eso es lo que más trato de comunicar, cosas que no encuentras así, fácilmente, en libros de colegio o internet, sino (que) son datos que gente e historiadores que han pertenecido al museo mucho tiempo han encontrado o saben porque son especialistas, por lo que eso es lo que más busco comunicar y en sí lo que la gente desea ver.

\section{6. ¿Cómo es la interacción con los usuarios?}

La interacción es un poco estresante, por así decirlo, porque actualmente no contamos con una persona que esté allí todo el tiempo, que sea netamente el community manager, que esté “24/7”. Yo me encargo con una compañera en el área de marketing de ver esos temas y en verdad es mucha gente que hace las mismas preguntas, gente que pide informes o datos que ya están la página web y que no es necesario preguntar. Pero tratamos de que sea fluido y rápido, aunque a veces ya es tanto que ya no se puede, ya que usan inbox o comentarios. Estas son las principales necesidades con las que contamos por el momento (sic), una persona que se encargue netamente de las redes sociales $\mathrm{y}$, siempre dentro de las directrices del trabajo, comunique y que esté respondiendo las preguntas y comentarios que se hace.

\section{7. ¿Comparten el mismo contenido en el Facebook del museo y en la página web?}


La página web recién tiene un año de haberse lanzado y el contenido allí hemos tratado de que sea solo comunicación básica o información importante del museo como horarios, recomendaciones, fechas, correos. Más que todo para contactarnos. No queremos que la gente se distraiga con otras cosas que publicamos en las redes sociales porque de ahí pierden la comunicación verdadera que queremos dar, que es todos nuestros datos de contacto porque antes no teníamos y perdíamos muchas visitas, porque antes no tenían cómo contactarnos, porque no sabían que éramos un museo o si atendíamos ciertos días, cosas así. Pero ahora recién este año estamos actualizando la página con fotos de eventos que también publicamos en las redes sociales, pero siempre queremos que sea un poco distinto, quizá algo más selectivo en la página web y en las redes sociales un poco más variado.

\section{8. ¿Cómo nació la estrategia digital del tour de noche (recorrido nocturno)?}

El tour de noche es un servicio que tenemos acá, que ya tiene su gente, su público. Retomando lo que te decía anteriormente, los medios digitales te permiten llegar a más público y tener más alcance de forma económica. Llegar a un público más amplio que esté interesado en el tour de noche, tal vez no tanto en la parte histórica o en la parte cultural del museo. Entonces este tour era una oportunidad para también aplicar todo el tema digital. Trabajamos en coordinación con el Facebook "Misterios del Real Felipe", que es solo específicamente de promoción del tour de noche, no va más allá y ese es su único foco. Ese Facebook lo manejan directamente los guías del museo que realizan el tour de noche, ellos son quienes hacen el recorrido, coordinan sus fechas, sus horas y todos los temas porque como coordinador ya no podía manejar más ese servicio. El museo siempre ha sido un espacio interesante para los medios porque está lleno de misterios y de historia; incluso medios internacionales han venido a cubrir este tema paranormal, por lo que queremos comunicar (es) esta experiencia única, que solo este museo en Lima posee.

\section{9. ¿Cuál ha sido su evolución desde la creación?}

La evolución ha sido de manera positiva, ha ido subiendo en visitas, en likes y bueno... tal vez no es tanto como quisiéramos porque en las redes sociales no aplicamos mucho dinero, no publicitamos los posts porque también eso implicaría más gente preguntando cosas y requeriría más tiempo, y como todavía no contamos con la logística para atender bien ese servicio de las redes, recién estamos haciéndolo de forma natural orgánica con 
el público. Creemos que este público que tenemos por el momento es un público (al) que sí le interesa los museos, el Real Felipe y la experiencia que te puede dar el tour de noche. Ya después veremos la publicidad en redes. Desearíamos hacer más, pero por temas logísticos y presupuestales aún no se puede. No se podría dar abasto para manejar una red social, de 3.000, 4.000, 5.000 likes porque en realidad el museo llama bastante la atención y por tanta gente preguntando y que de repente no pudiéramos contestarle, nos podríamos dar mala fama de atención al público paupérrima, por así decirlo. Porque incluso nos escriben agencias de turismo, hoteles, canales de televisión. Es un medio de doble vía y por esos motivos de repente podríamos perder clientes importantes. Hemos publicitado sí unos cuantos posts, pero en ocasiones específicas; por ejemplo, cuando hacemos algún evento. En cuanto al tour de noche, ningún post ha sido publicitado y son los que cuentan con bastante interacción entonces allí nos podemos dar cuenta que es un evento que a la gente le interesa y podemos seguir haciendo posts sobre esto.

\section{0. ¿Qué beneficios ha traído para el museo?}

El primer beneficio visible ha sido el aumento de las visitas en ambos tours, el diurno y el de noche. Además, reconocimientos de otros museos, invitaciones a eventos de entidades que nunca nos habían invitado o considerado, pero ahora sí nos toman en cuenta para que vayamos como entidad, o para que el coronel vaya y haga acto de presencia, como un referente en temas culturales relacionado a museos. El museo ahora es considerado como una parada de turismo en el Callao, ahora la gente nos voltea a ver. Desde que se implementó el área de marketing aquí, hace ya un poco más de un año, y con ello la inserción a medios digitales, el museo ha aumentado sus visitas increíblemente, podría decir en un 300, 400 por ciento. Incluido en el tour de noche, cuando recién se inició hace tres años, este sería el cuarto, solo se desarrollaba una vez cada vez y se trataba directamente con una agencia de turismo, quien se encargaba de traer a los visitantes; nosotros solo brindábamos el guía. Y para ello se tenía que llegar a un mínimo de personas. Sin embargo, desde el año pasado con la creación del Facebook se ha vuelto más conocido el tour, y se (ha) promocionado de tal manera que la gente viene en mayor cantidad, pudiendo haber incluso tres turnos por noche de unas 100 personas, y siete tours al mes, algo que antes no sucedía. Pero igual si solo vienen 20 personas, de todas maneras, se hace el tour. La afluencia de personas cada vez aumentó, lo cual es beneficioso porque además se difunde por las mismas personas que hacen el tour; hay un boca a boca potente, van, conocen y se dan cuenta que hay cosas 
tenebrosas, cosas ocultas que la mayoría de la población no conoce, no sabe y (de las que) a través de la difusión por redes sociales se entera, la mayoría que vienen al tour se enteran por este medio.

\section{1. ¿Han medido cuál es el efecto de la presentación de los post?}

Los usuarios reaccionan bien a los posts; solo hemos recibido dos comentarios negativos, creo, y eran básicamente de queja, porque no contestaban el teléfono o temas relacionados, de por qué no había respuestas rápidas a sus inquietudes. Pero luego (acerca) del tema del servicio, de la experiencia, de conocer el museo, todos son felices. Recibimos publicaciones con comentarios positivos, los usuarios nos expresan su buena experiencia y lo bien que la han pasado. Además, algunos se asombran que esto exista o lo miraban por afuera y no sabían que se podían dar una vuelta por acá.

12. ¿En su opinión, la estrategia del tour ha sido efectiva para el museo? ¿Cuánto pesó la promoción digital en la asistencia al tour de noche? ¿Cree que lo digital motivó a la gente a vivir la experiencia del tour?

Definitivamente ha pesado y ha sido efectiva; han aumentado las visitas de una manera positiva y se ha dado a conocer entre el público la existencia de los tours del museo. En especial el del tour de noche, donde incluso algunas agencias de turismo separan el sábado para llevar a su gente, arma grupos y van de manera independiente, y se comunican con nosotros por medio del Facebook. Claramente, el crear las páginas e insertarnos a medios digitales nos permitió llegar a más gente, y con ello, que ellos se interesen de vivir la experiencia (en el) tour. La gran mayoría de personas que vienen al tour con amigos y familiares es (sic) porque se enteraron en Facebook. Las redes sociales son ahora las que tienen más alcance y definitivamente han motivado a muchos a venir. También ha ayudado un tema de que trabajamos con canje y muchas veces han venido canales de televisión de todo tipo, culturales, de entretenimiento, concursos como certámenes de belleza pidiendo como locación a la fortaleza para grabar algo. Y nosotros prestamos la locación, siempre y cuando nos hagan publicidad en el programa. Antes, cuando no había una persona encargada de ver estos temas, no se podía ser específico en qué se buscaba y dónde hacerle publicidad ni la manera. No les convenían perder tiempo en buscar tu servicio porque el tiempo en la televisión es caro, pero gracias a la implementación del área (ahora) es más estructurada, y nos encargamos que la imagen que proyecten en las determinadas grabaciones sea la adecuada para el 
museo, pauteamos las menciones, la información de redes sociales, horarios, mostrar el logo y, bueno, los ubicamos en las partes de la fortaleza que son las más vistosas, las más resaltantes. Tal vez esa presencia en televisión, de señal abierta, la mayoría de veces también nos ha aumentado el número de seguidores en las redes sociales y (la) asistencia al tour.

\section{A futuro, ¿cuáles son las estrategias que vislumbra? ¿Para qué? ¿Con qué}

\section{finalidades?}

Ahora estamos en un plan de querer insertarnos (en el) aeropuerto; queremos implementar eso porque el aeropuerto es un lugar cercano, máximo (a) 30 minutos (de aquí). Sabemos que la gente que viene de visita al Perú, el $80 \%$ entra por Lima y muchos de ellos están en transición (sic). Están en Lima un rato y luego toman su siguiente vuelo a Cusco o a otro lugar. Por lo que queremos lograr captar a todo ese público extranjero, porque aún el índice de extranjeros que visita el museo es muy bajo y ellos son quienes buscan sitios así para conocer. Todo ello (queremos) comunicarlo mediante nuestras plataformas digitales. También deseamos tener más presencia en televisión y aprovechar el tema de la nueva Costa Verde que llegará hasta acá, y será más fácil la visita al museo desde lugares alejados como Chorrillos, San Juan de Miraflores, etcétera. Queremos más presencia para que recibamos visitas de todas partes. En cuanto alianzas estratégicas, por el momento no contamos pero estamos buscando, estamos actualmente en contacto de APM Terminals y DP World, que son operadores logísticos de contenedores que están por acá y ya hemos tenido un acercamiento, pero aún no se concreta nada. Nuestro plan es poco a poco trabajar con empresas que puedan apoyarnos en lo que es mantenimiento del museo, quizá abrir nuevas salas para jalar más público con las novedades. Y nosotros darles ese beneficio por impuestos, el cual es cuando (sic) ellos hacen labor social en el área que se desarrollan; eso ahorra impuestos. Entonces nosotros brindamos el certificado y ambas partes salen beneficiadas. 


\section{Anexo 3 Cuadro matriz de objetivos}

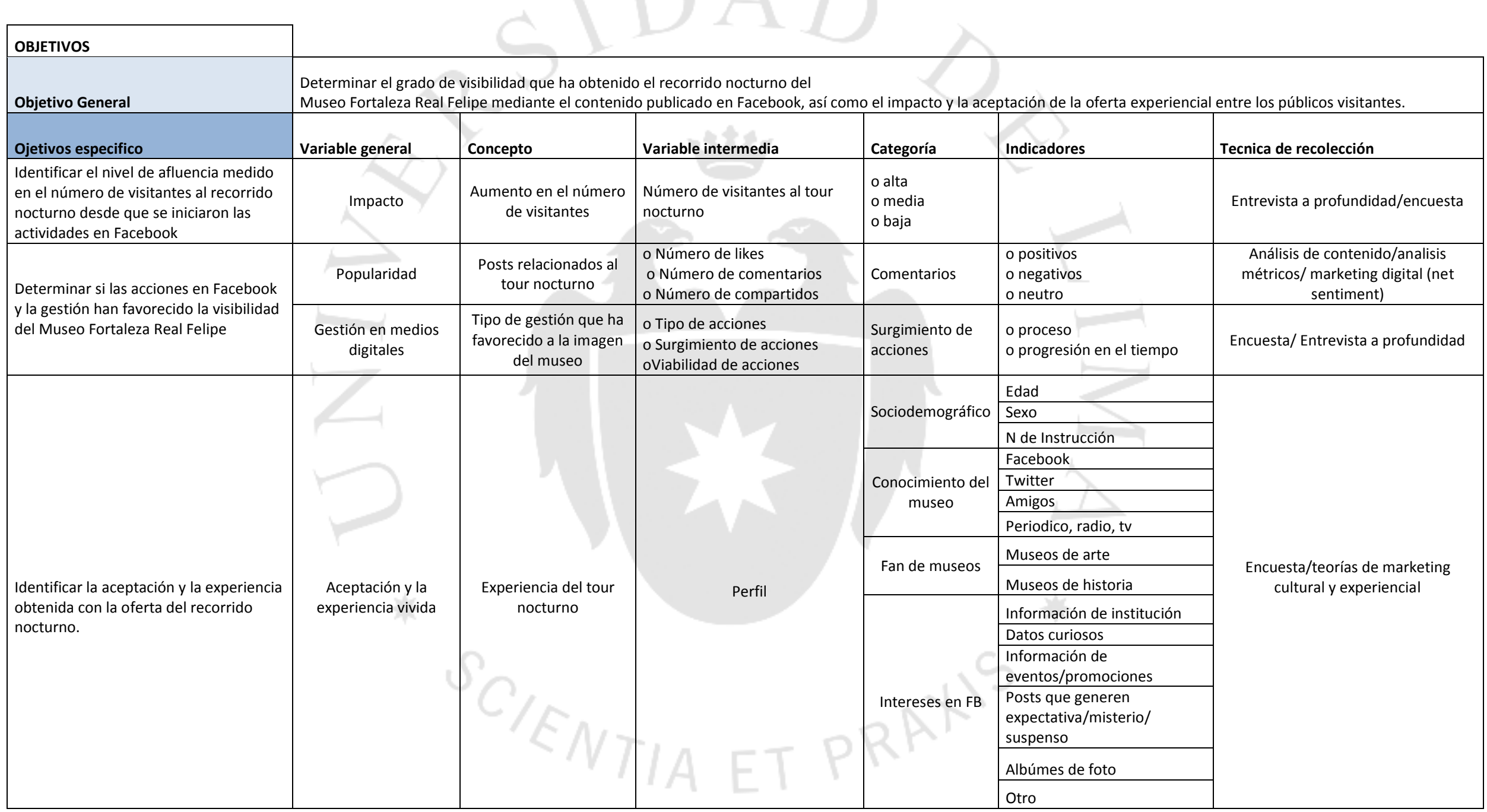




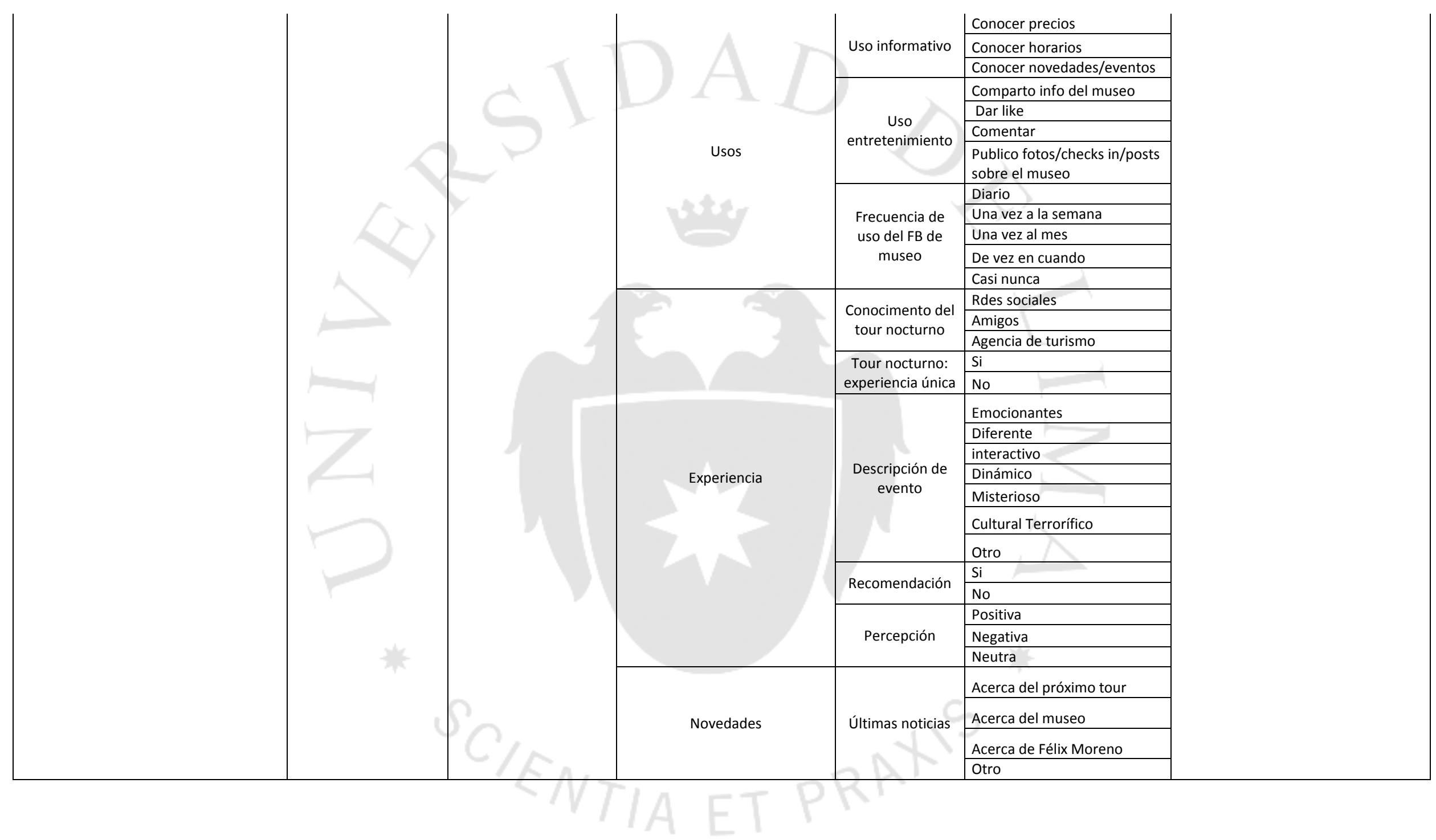




\section{Anexo 4: Guía de preguntas muestra 1}

1. Sexo

O $\mathrm{F}$

○ M

2. Edad

○ $18-35$

○ 36 a más

3. Nivel de instrucción

- Secundaria

- Técnico

○ Universitario

- Maestría/doctorado

4. ¿Cómo se enteró del tour nocturno?

○ Amigos

- Facebook delMuseo Real Felipe

- Agencia de turismo

- TV/ radio/ periódico

○ Otro

5. ¿Suele seguir a museos en Facebook? (Si su respuesta es No, ir a la pregunta 10)
○ Sí
○ No

6. ¿A qué museos suele seguir en Facebook? (Puede marcar más de uno)
○ MALI
○ Museo Fortaleza Real Felipe
○ Museo de Arte Contemporáneo
- MATE
- Museo de Arte Italiano
○ Museo Larco
○ Otro

7. Si menciona el Museo Fortaleza Real Felipe, ¿Qué es lo que suele buscar/ interesarle en el Facebook del museo? (Puede marcar más de uno) 

○ Información de la institución (historia, precios, horarios)
- Datos curiosos/ interesantes
○ Información de eventos/ promociones
○ Álbumes de fotos
○ Otro

8. Si menciona el Museo Fortaleza Real Felipe, ¿suele comentar o compartir algún post de la página de Facebook?
○ Sí
○ No

9. Si menciona el Museo Fortaleza Real Felipe, ¿suele dar "me gusta” a algún post de la página de Facebook?
○ Sí
○ No

10. ¿Cómo considera los siguientes aspectos del tour? (Siendo 1 "muy malo" y 5, "muy bueno")

\begin{tabular}{|l|l|l|l|l|l|}
\hline & 1 & 2 & 3 & 4 & 5 \\
\hline Organización y estructura del tour & & & & & \\
\hline Desempeño de la guía del tour & & & & & \\
\hline Ambientes que se visita en el tour & & & & & \\
\hline Concurrencia de visitantes & & & & & \\
\hline
\end{tabular}

11. En términos generales, usted diría que el haber participado en este tour ha sido una experiencia:

○ Muy agradable

○ Agradable

- Ni agradable ni desagradable

○ Desagradable

- Muy desagradable

12. Usted diría que después de esta visita al Museo Real Felipe, la imagen que tenía del museo ha sufrido:

- Cambios positivos 
- Se mantiene igual

○ Cambios negativos

13. ¿Considera compartir/recomendar/publicar su visita al tour de noche en redes sociales?
○ Sí
○ No

14. En las últimas semanas, ¿ha escuchado/leído noticias relacionadas con el museo Fortaleza Real Felipe? (Si su respuesta es no, este será el final de la encuesta).
○ Sí
○ No

15. ¿Qué es lo último que ha escuchado/leído acerca del Museo Fortaleza Real Felipe?

- Información acerca de tours

- Datos relacionados a su historia

○ Noticias relacionadas con Félix Moreno

o Otro 
Anexo 5: Gráficos de resultados de muestra 1

- Gráfico 1

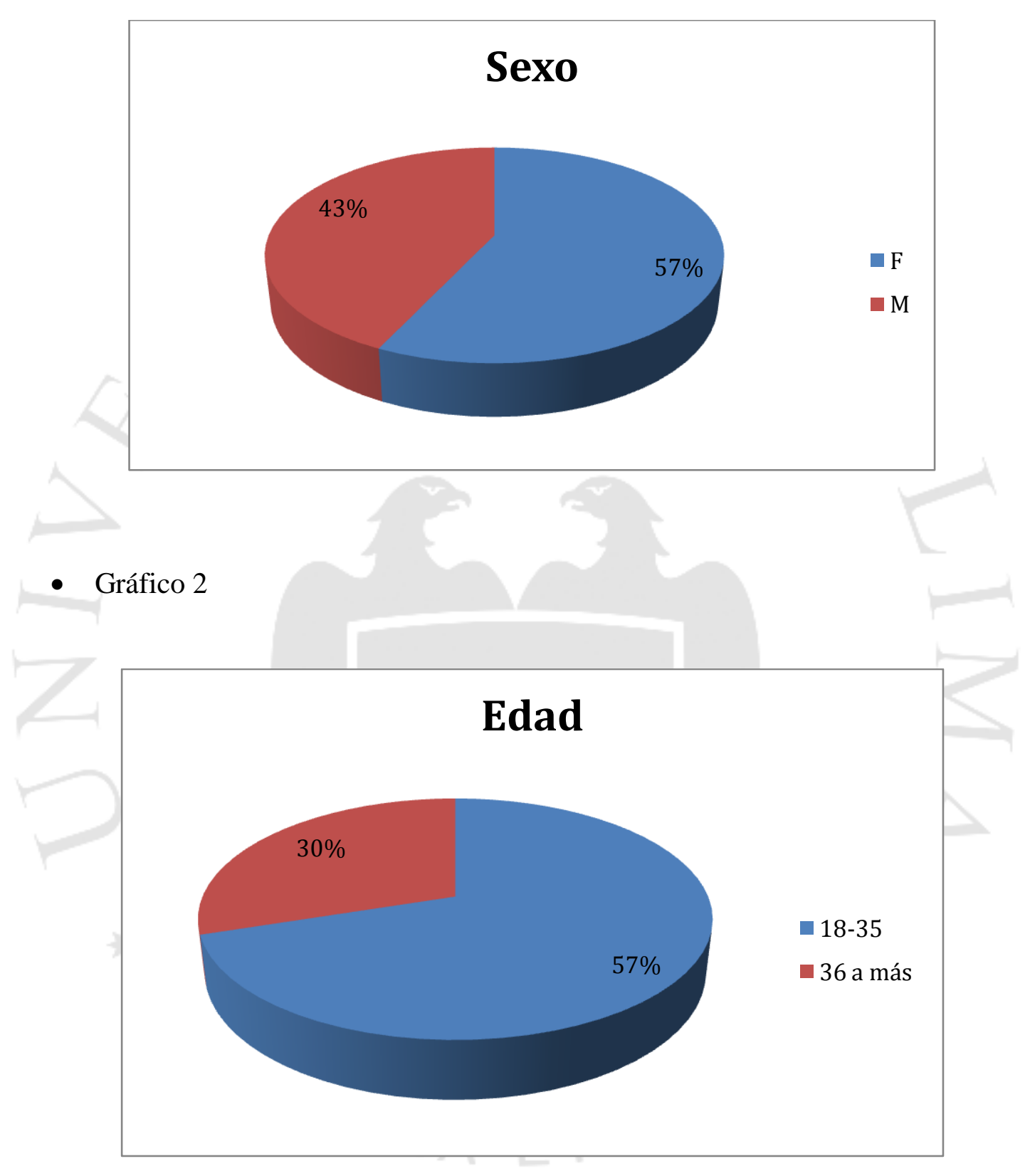


- Gráfico 3

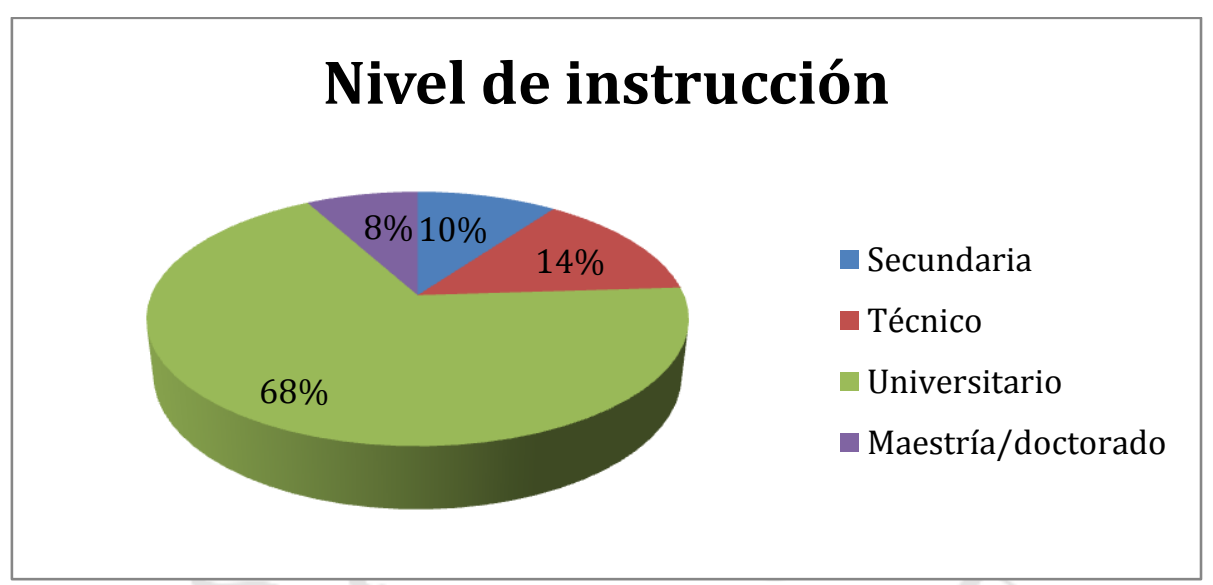

- Gráfico 4

\section{¿Cómo se enteró del tour nocturno?}

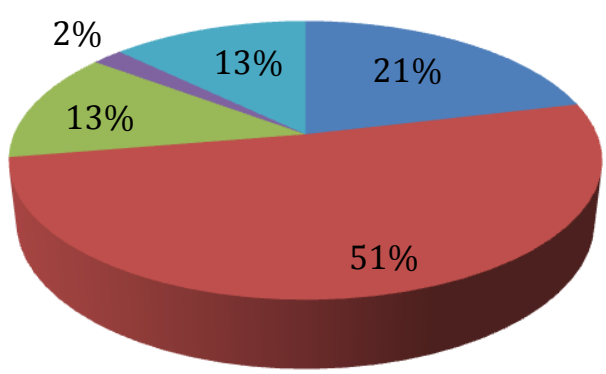

Amigos

- Facebook del Museo Real Felipe

Agencia de turismo

- Períodico/radio/TV

- Gráfico 5

\section{¿Suele seguir a museos en \\ Facebook?}

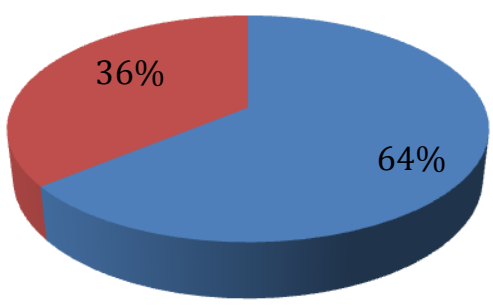


- Gráfico 6

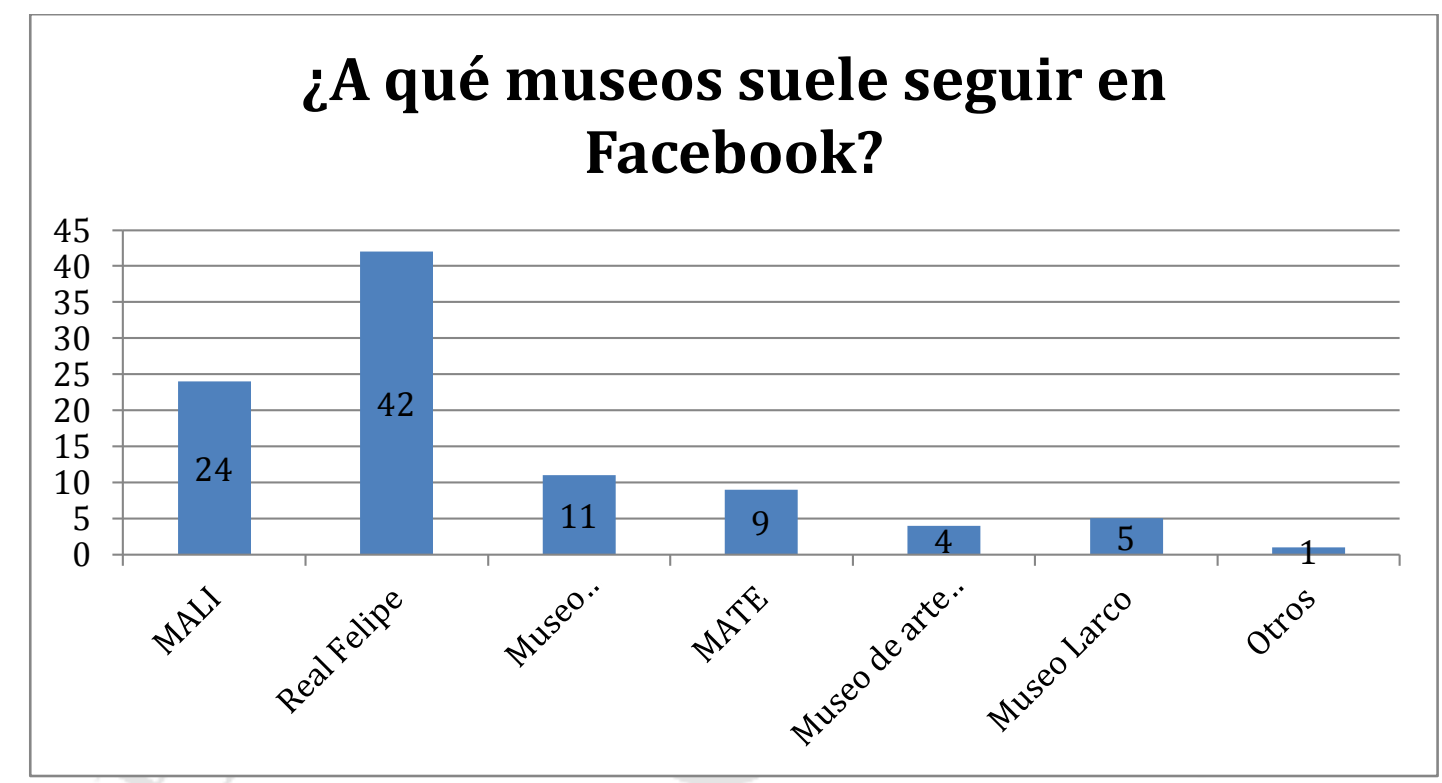

- Gráfico 7

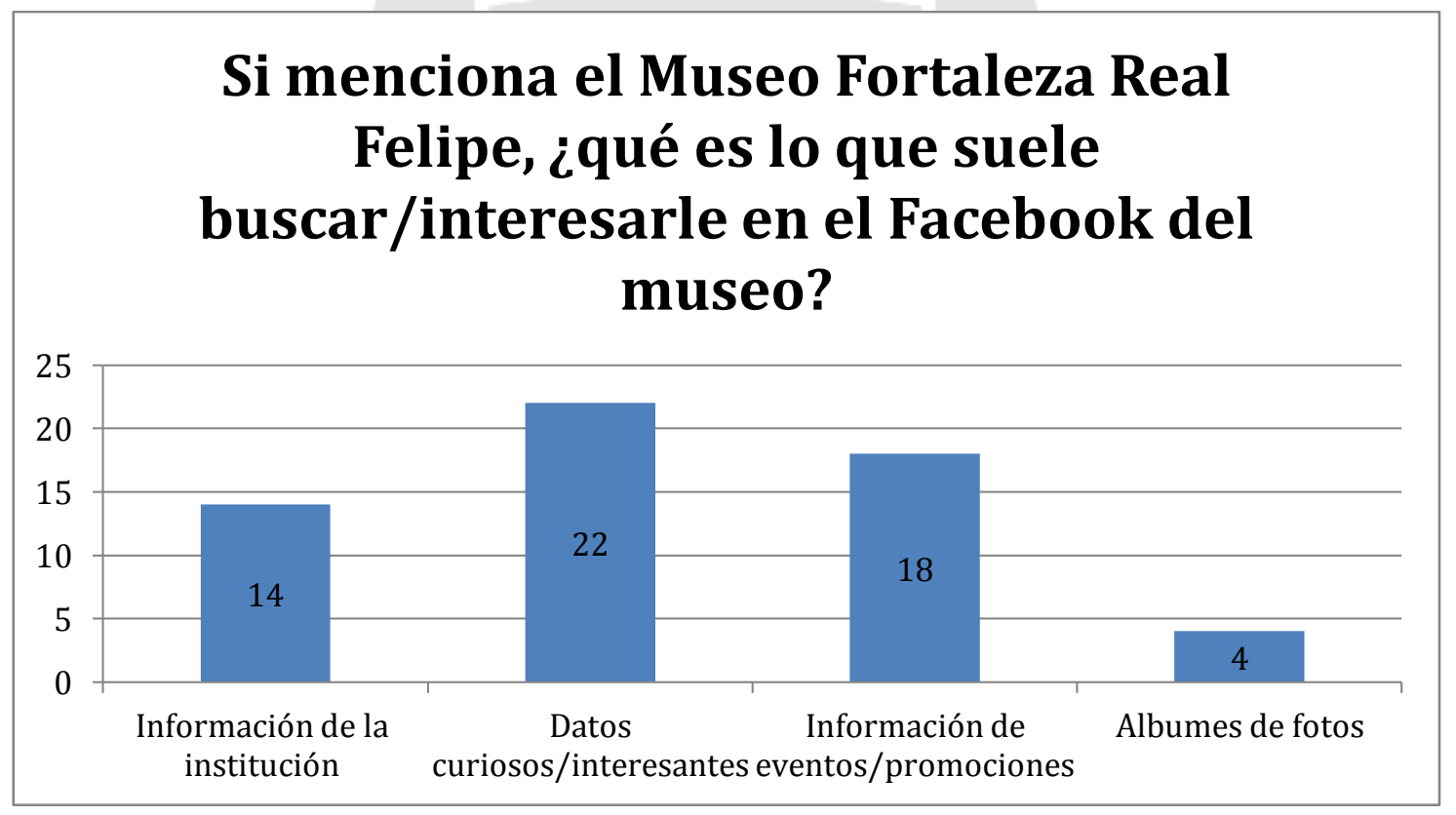


- Gráfico 8

\section{Si menciona el Museo Fortaleza Real Felipe, ¿suele comentar o compartir algún post de la página de Facebook?}

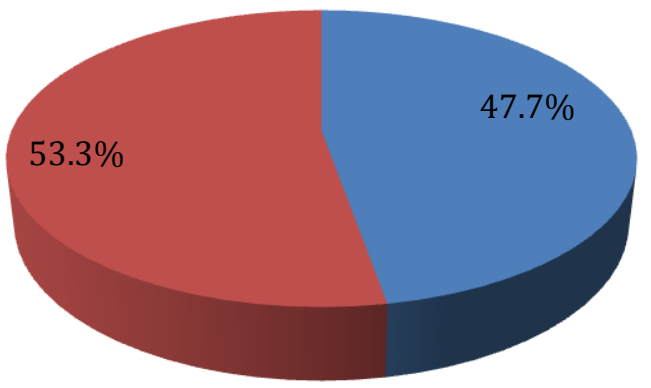

- Gráfico 9

Si menciona el Museo Fortaleza Real

Felipe, ¿suele dar "me gusta" a algún post de la página de Facebook?

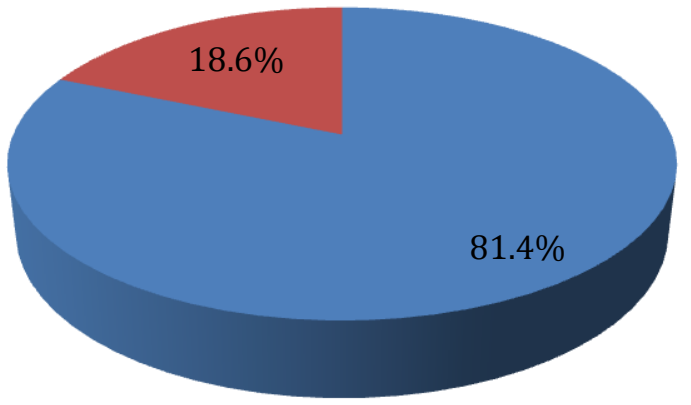


- Gráfico 10

¿Cómo considera los siguientes aspectos del tour? (Siendo 1 "muy malo" y 5 "muy bueno")

\begin{tabular}{|l|l|l|c|c|c|}
\hline & \multicolumn{1}{|c|}{1} & \multicolumn{1}{|c|}{2} & 3 & 4 & 5 \\
\hline Organización y estructura del tour & $0 \%$ & $0 \%$ & $27 \%$ & $54 \%$ & $19 \%$ \\
\hline Desempeño de la guía del tour & $1.4 \%$ & $1.4 \%$ & $26 \%$ & $41 \%$ & $30 \%$ \\
\hline Ambientes que se visita en el tour & $0 \%$ & $1.4 \%$ & $19 \%$ & $49 \%$ & $31 \%$ \\
\hline Concurrencia de visitantes & $0 \%$ & $0 \%$ & $18 \%$ & $63 \%$ & $19 \%$ \\
\hline
\end{tabular}

- Gráfico 11

\section{En términos generales, usted diría que el haber participado en este tour ha sido una experiencia:}

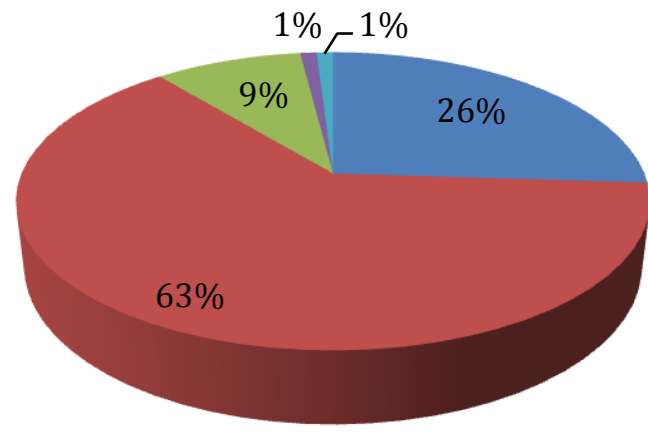

- Muy agradable

Agradable

Ni agradable ni desagradable

- Desagradable

Muy desagradable 
- Gráfico 12

\section{Usted diría que despúes de esta visita al Museo Real Felipe, la imagen que tenía del museo ha sufrido:}

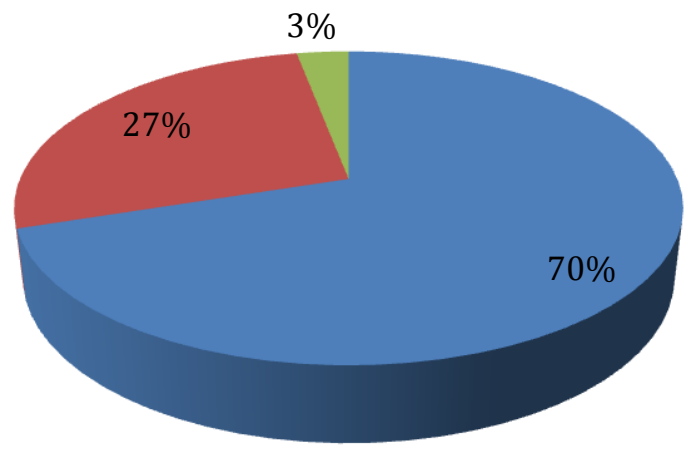

Cambios positivos

- Se mantiene igual

- Cambios negativos

- Gráfico 13

\section{¿Considera compartir/recomendar/publicar su visita al tour de noche en redes sociales?}

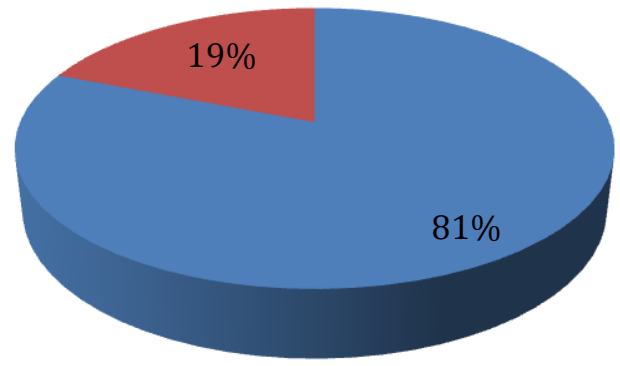


- Gráfico 14

\section{En las útimas semanas, ¿ha escuchado/leído noticias relacionadas con el Museo Fortaleza Real Felipe?}

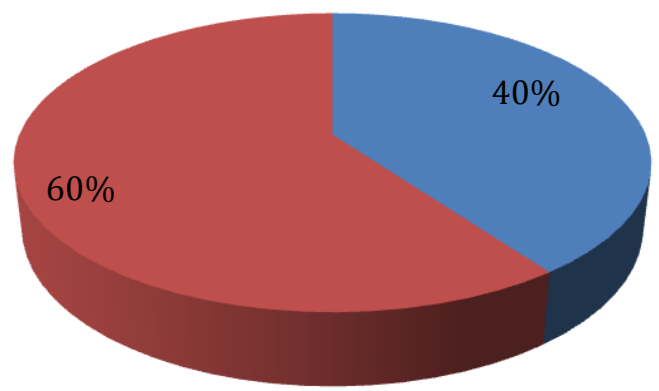

- Gráfico 15

\section{¿Qué es lo último que ha escuchado/leído acerca del Museo Fortaleza Real Felipe?}

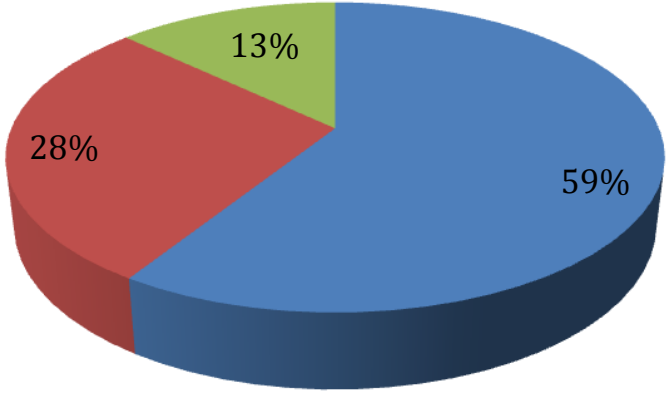

- Información acerca de tours

- Datos relacionados a su historia

Noticias realcionadas a Félix Moreno 


\section{Anexo 6: Guía de preguntas muestra 2}

1. Edad/sexo
○ $18-35$
o F
○ 36 a más
o M

2. ¿Cómo te enteraste del tour nocturno?

○ Amigos

- Facebook del museo Real Felipe

- Agencia de turismo

- Periódico/TV/radio

○ Otro

3. En términos de experiencia sensorial, ¿qué sentidos considera que involucró el tour? (puede marcar más de uno)

○ Oído

o Vista

○ Tacto

○ Olfato

○ Gusto

4. En términos de emociones, ¿qué le generó el recorrido del tour? (Puede marcar más de uno)

\begin{tabular}{|l|l|l|l|}
\hline miedo & sorpresa & alegría & descontento \\
\hline satisfacción & ira & aversión & tristeza \\
\hline
\end{tabular}

5. ¿Qué tipo de motivación tuvo al asistir al tour?

○ Intelectual

- Emocional

○ Social

○ Espiritual

6. ¿Qué parte del recorrido le gustó más?

○ La visita a los torreones

○ Los personajes andantes

- El momento de vendaje en el puente 
El momento de Eco en los antiguos calabozos

o Otro:

7. En términos generales, usted diría que el haber participado en este tour ha sido una experiencia:

○ Muy agradable

○ Agradable

○ Ni agradable ni desagradable

○ Desagradable

- Muy desagradable

8. ¿El tour nocturno cumplió con las expectativas que tenía antes de venir?

○ Sí

○ No

○ No tenía expectativas

9. ¿Le gustaría que hubiera otro tipo de exposiciones y exhibiciones en el museo Real Felipe?

○ Sí

○ No

10. Usted diría que después de esta visita al Museo Real Felipe, la imagen que tenía del museo ha sufrido:

- Cambios positivos

- Se mantiene igual

- Cambios negativos

11. ¿Cuál considera que es la utilidad del Facebook del Real Felipe? (puede marcar más de uno)

- Realizar consultas sobre los tours

- Conocer los servicios que ofrecen

- Aprender más de historia y cultura

○ Entretenimiento 
12. ¿Publicará alguna foto, post, texto o video con respecto al tour en alguna de sus redes sociales?
○ Sí
○ No
- Tal vez

13. ¿Considera que este tour le ha llamado más la atención que otros tours que haya visitado?
○ Sí
○ No

14. ¿Recomendaría a otras personas visitar el museo?
○ Sí
○ No
- Tal vez

15. ¿Existe algo que le gustaría cambiar del tour?

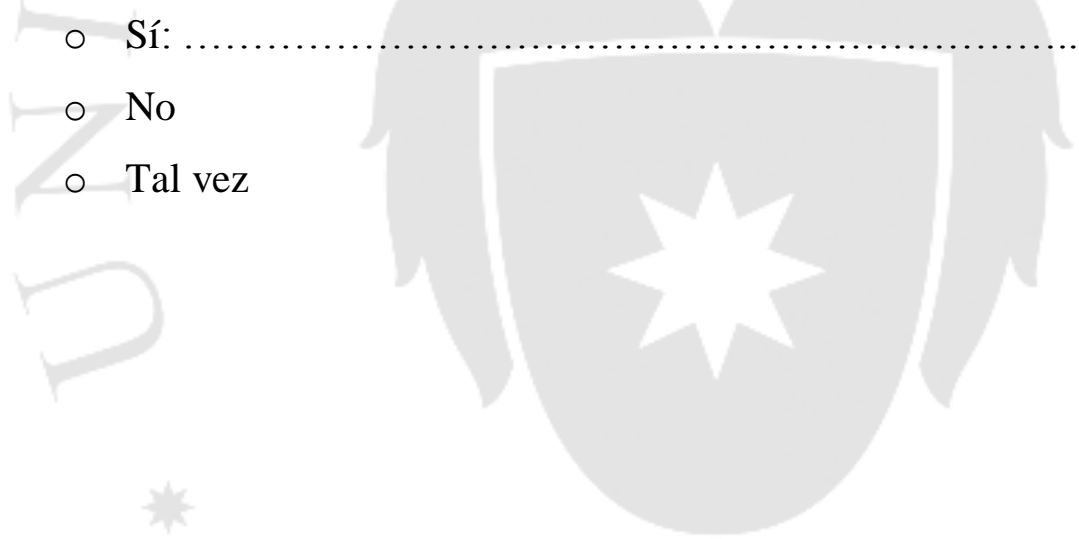


Anexo 7: Gráficos de resultados de muestra 2

- Gráfico 1

\section{Edad/sexo}

\begin{tabular}{|l|l|l|}
\hline $\mathrm{F}$ & $18-35$ años & 17 \\
\hline $\mathrm{F}$ & 36 a más & 1 \\
\hline $\mathrm{M}$ & $18-35$ años & 10 \\
\hline $\mathrm{M}$ & 36 a más & 8 \\
\hline
\end{tabular}

- Gráfico 2

\section{¿Cómo te enteraste del tour nocturno?}

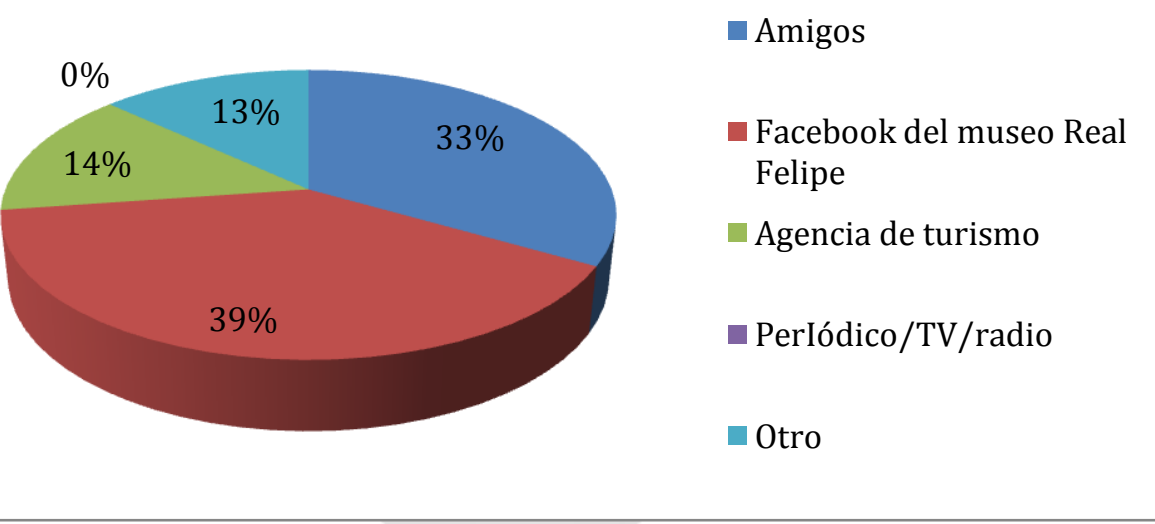


- Gráfico 3

En términos de experiencia sensorial, ¿qué sentidos considera que involucró el tour? (puede marcar más de uno)

$1_{0}$

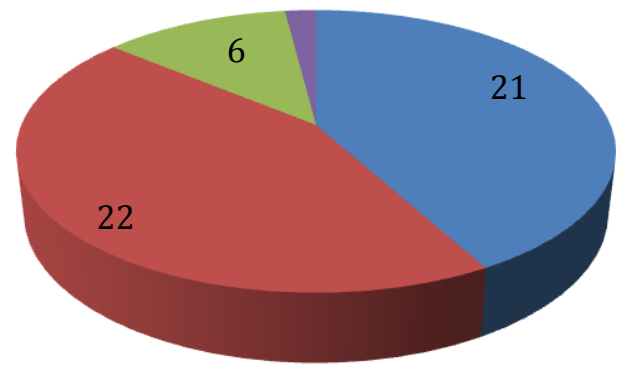

- Gráfico 4

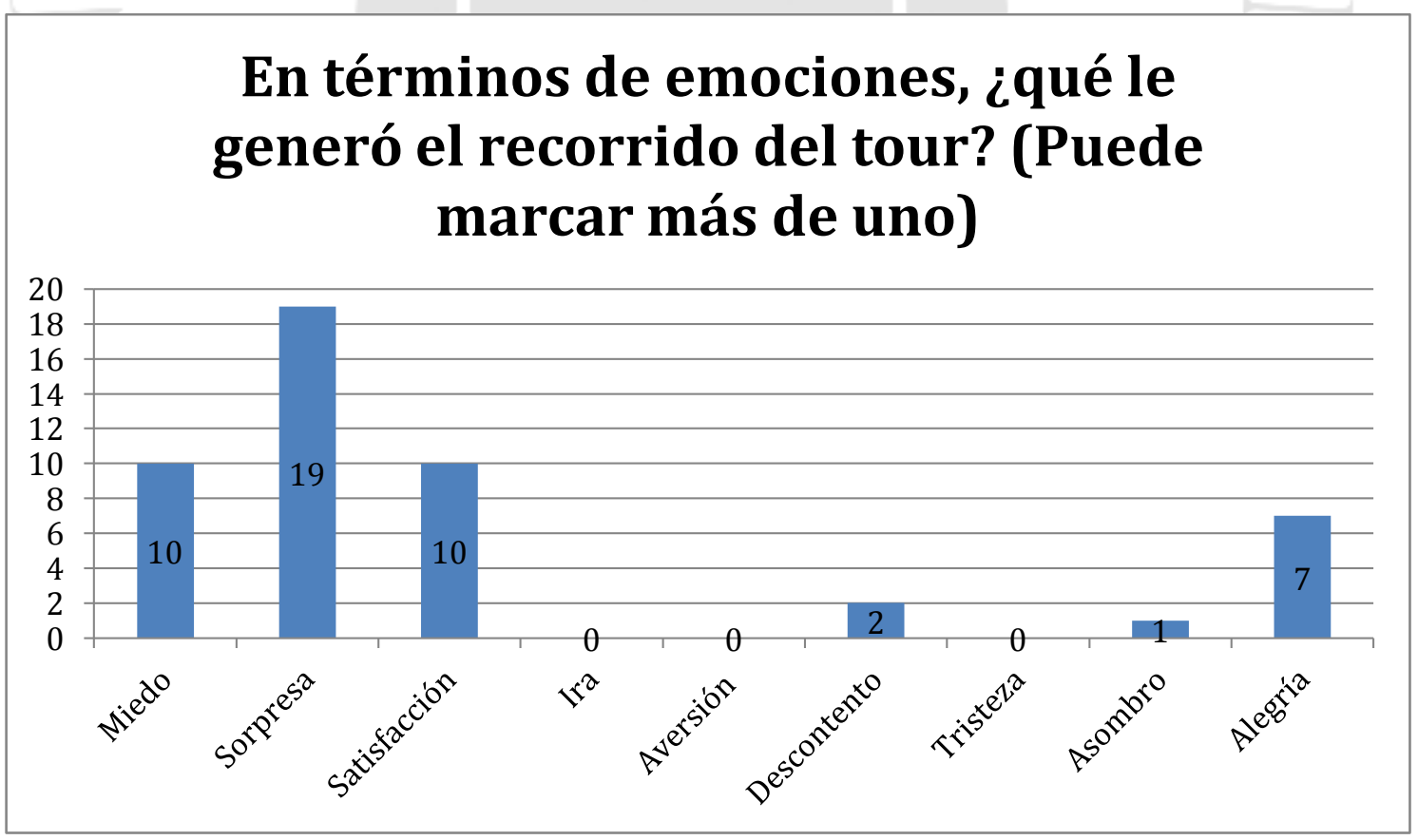


- Gráfico 5

\section{¿Qué tipo de motivación tuvo al asistir al tour?}

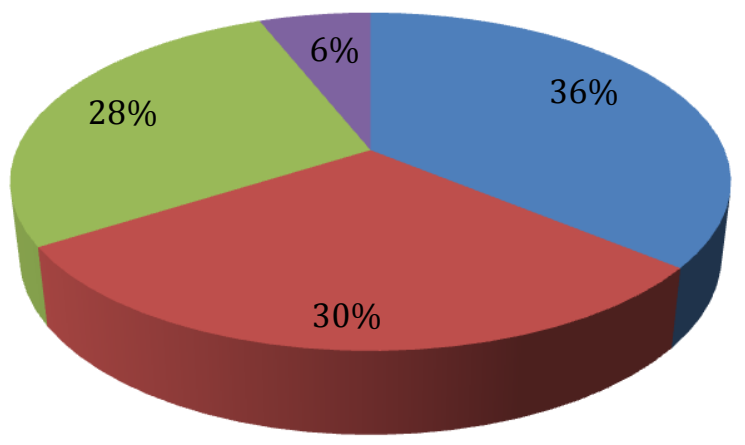

Intelectual

Emocional

Social

Espiritual

- Gráfico 6

\section{¿Qué parte del recorrido le gustó más?}

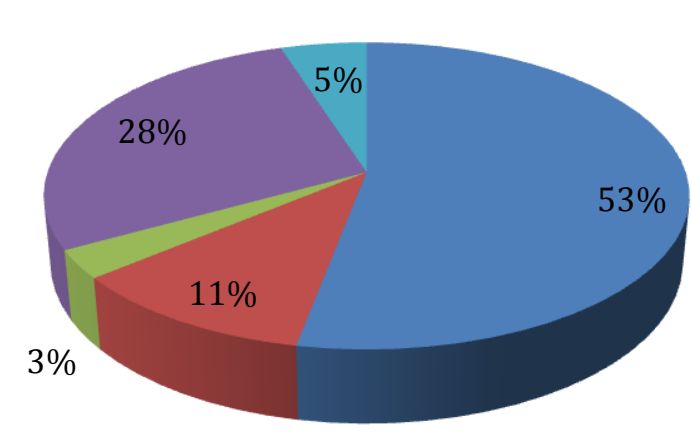

- La visita a los torreones

- Los personajes andantes

El momento de vendaje en el puente

El momento de eco en los antiguos calabozos

- Otro 
- Gráfico 7

\section{En términos generales, usted diría que el haber participado en este tour ha sido una experiencia:}

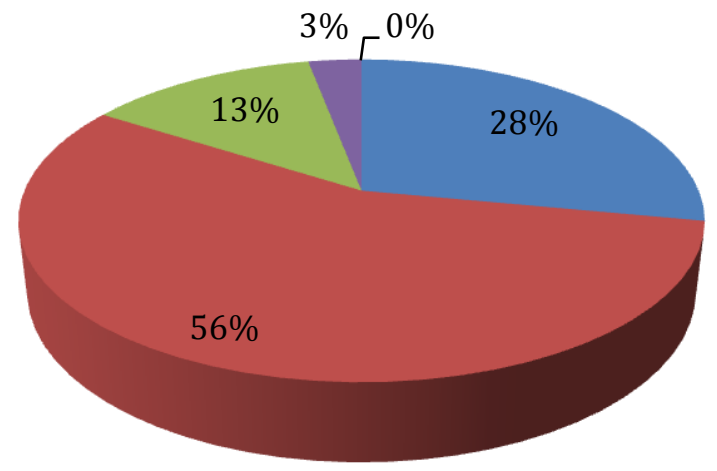

Muy agradable

- Agradable

Ni agradable ni desagradable

- Desagradable

Muy desagradable

- Gráfico 8

\section{¿El tour nocturno cumplió con las expectativas que tenía antes de} venir?

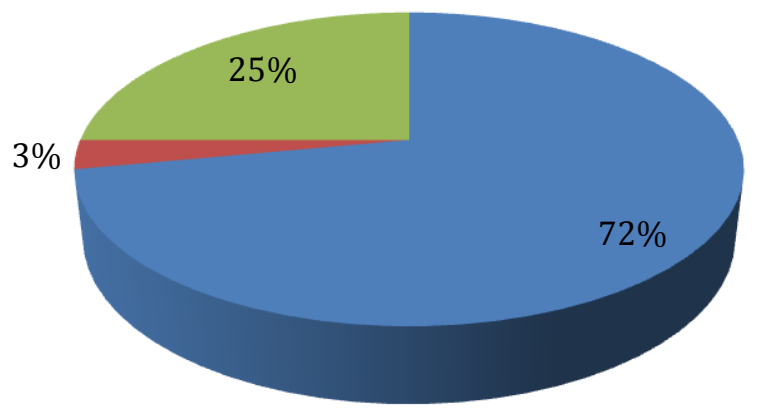

$\mathrm{Si}$

No

No tenía expectativas 
- Gráfico 9

\section{¿Le gustaría que hubiera otro tipo de exposiciones y exhibiciones en el museo Real Felipe?}

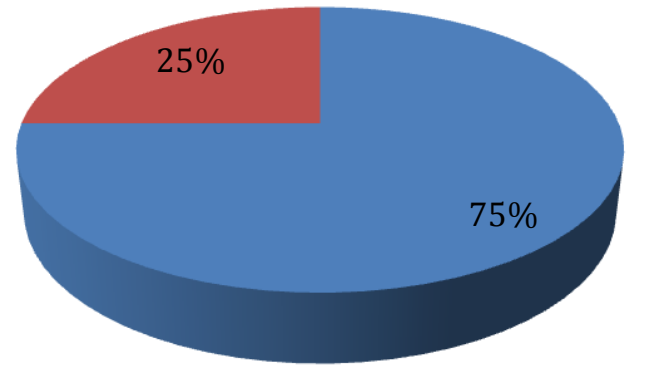

- Gráfico 10

\section{Usted diría que después de esta visita} al Museo Real Felipe, la imagen que tenía del museo ha sufrido:

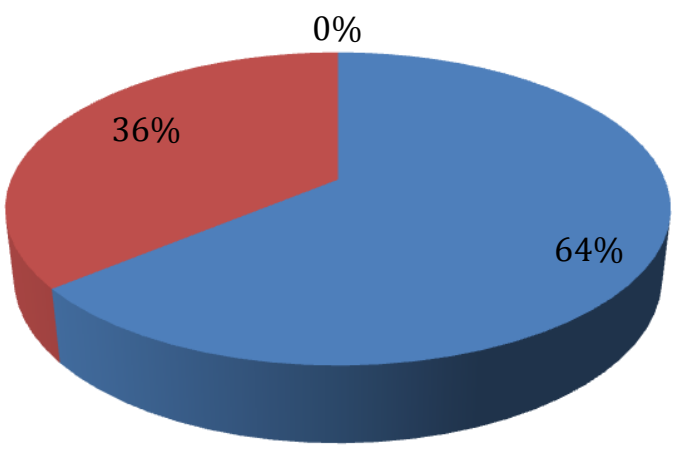

- Cambios positivos - Se mantiene igual

- Cambios negativos 
- Gráfico 11

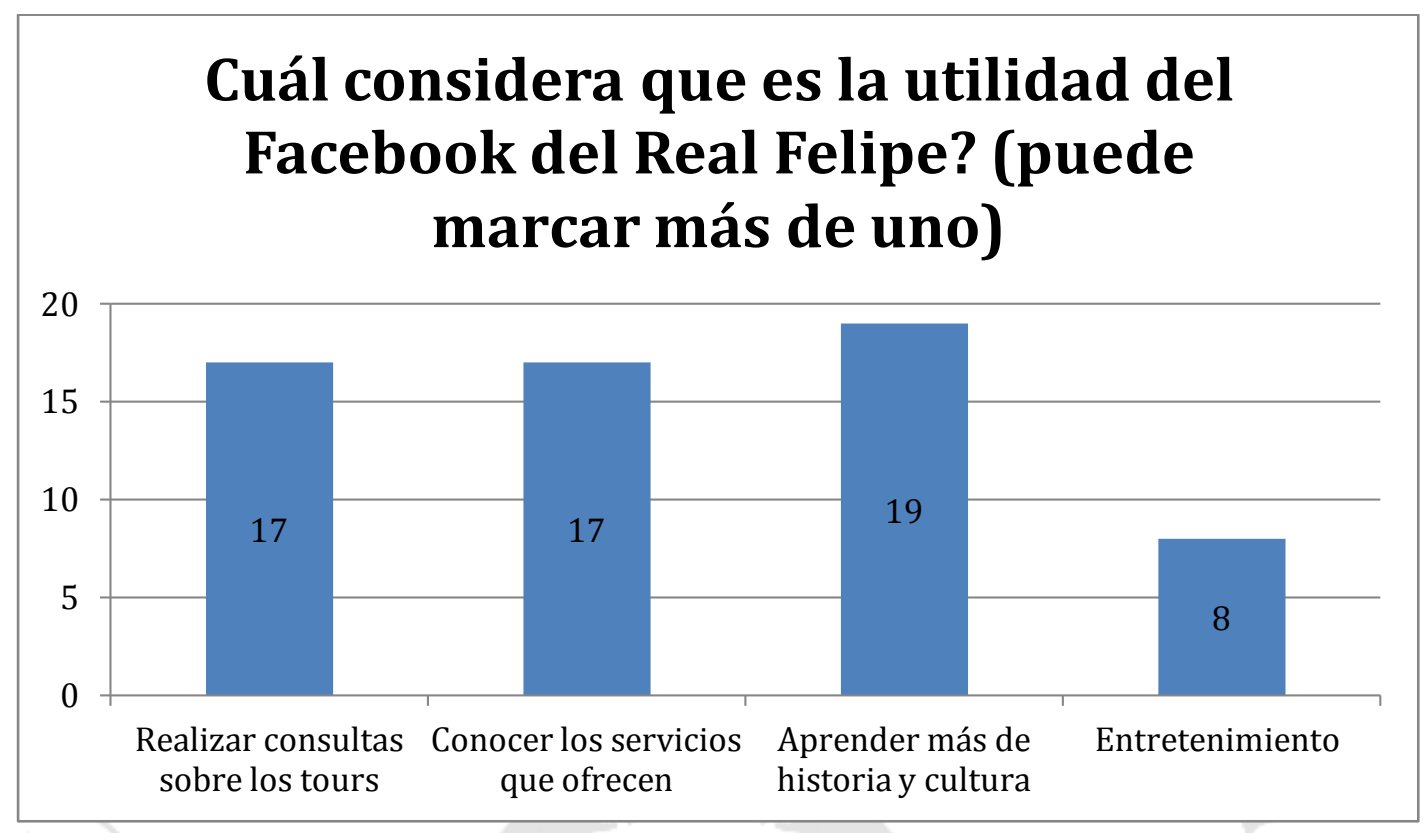

- Gráfico 12

\section{¿Publicará alguna foto, post, texto o video con respecto al tour en alguna de sus redes sociales?}

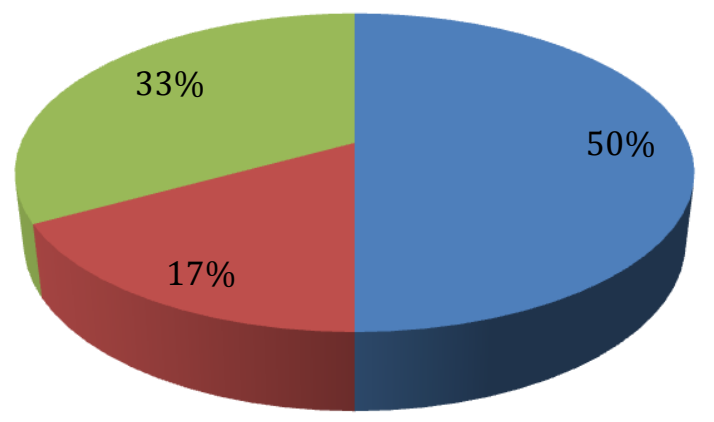


- Gráfico 13

¿Considera que este tour le ha llamado más la atención que otros tours que haya visitado?

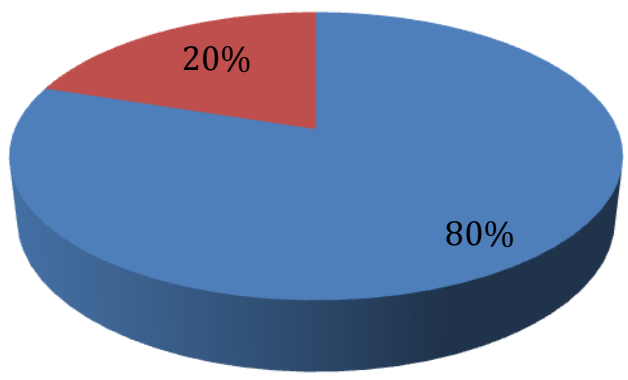

- Gráfico 14

\section{¿Recomendaría a otras personas} visitar el museo?

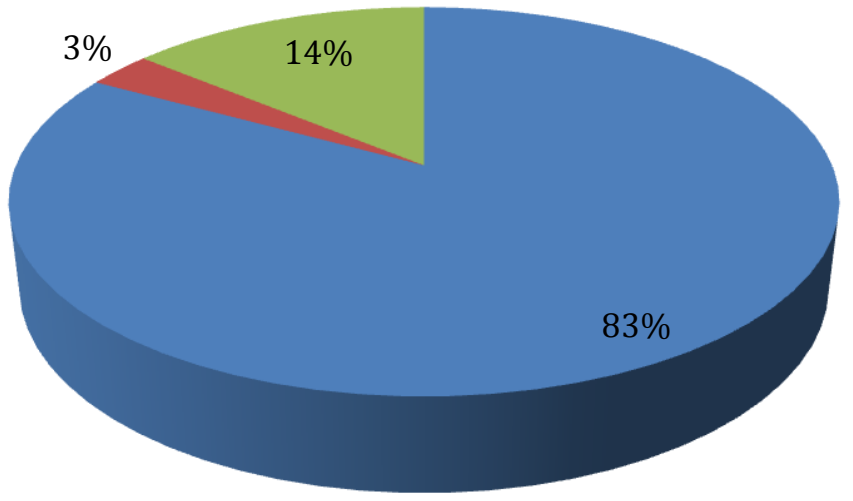


- Gráfico 15

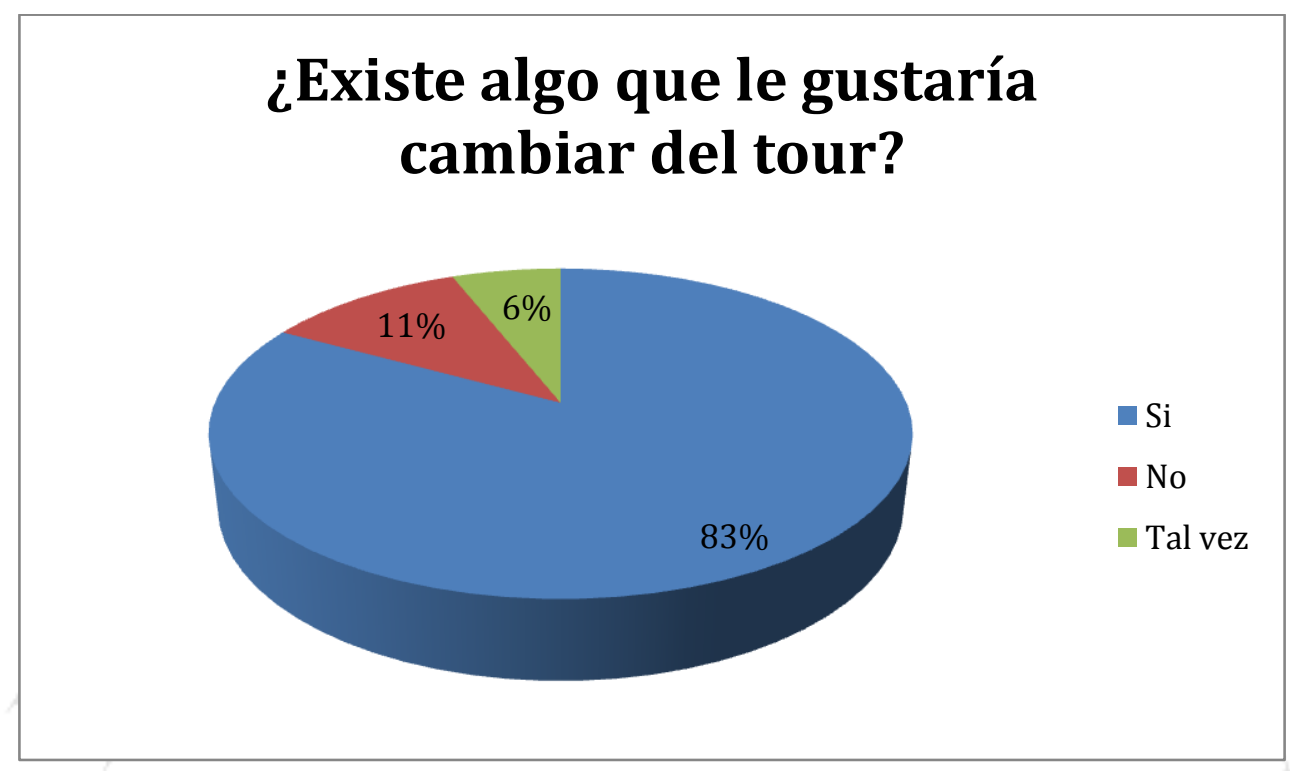

Respuestas obtenidas por los visitantes que marcaron Sí:

- Que se realice más tarde el tour 2.8\%

- Que el guía sea más didáctico 6\%

- Recomendación de portar linternas $4 \%$

- Que se realicen otro tipo de actividades $8 \%$ 


\section{Anexo 8: Cuadro de comentarios y alcance}

\begin{tabular}{|c|c|c|c|c|c|}
\hline Fecha & Tipo de publicación & Interacción & $\begin{array}{l}\text { Tipo de } \\
\text { interacción }\end{array}$ & Cantidad & Alcance \\
\hline \multirow{2}{*}{$\begin{array}{l}17 \text { de setiembre } \\
2016\end{array}$} & \multirow[b]{2}{*}{$\begin{array}{l}\text { Evento Tour de noche } \\
\text { (compartido del Facebook } \\
\text { de "Los misterios del Real } \\
\text { Felipe" } \\
\text { Texto: CONFIRMADO. } \\
\text { Hoy tenemos tour nocturno, } \\
\text { 19:30 horas en puerta. }\end{array}$} & Comentarios & Positivo & 5 & \multirow[t]{2}{*}{546} \\
\hline & & Likes & & 4 & \\
\hline \multirow{2}{*}{$\begin{array}{l}7 \text { de octubre } \\
2016\end{array}$} & \multirow[b]{2}{*}{$\begin{array}{l}\text { Evento Tour de noche } \\
\text { Halloween (compartido del } \\
\text { Facebook de "Los misterios } \\
\text { del Real Felipe") } \\
\text { Texto: Que mejor noche } \\
\text { para vivir una experiencia } \\
\text { escalofriante que la noche } \\
\text { del } 31 \text { de Octubre. Ven y } \\
\text { celebra tu Halloween con } \\
\text { nuestro recorrido nocturno. } \\
\text { Te esperamos. } \\
\end{array}$} & Comentarios & Positivo & 17 & \multirow[t]{2}{*}{602} \\
\hline & & 8 & & 23 & \\
\hline \multirow{2}{*}{$\begin{array}{l}21 \text { de octubre } \\
2016\end{array}$} & \multirow[b]{2}{*}{$\begin{array}{l}\text { Post de Tour de noche. } \\
\text { Texto: A pedido del público, } \\
\text { hoy tenemos recorrido } \\
\text { nocturno, empezamos a las } \\
\text { 19:00 horas. Los esperamos. }\end{array}$} & Compartidos & & 2 & \multirow[t]{2}{*}{424} \\
\hline & & Likes & & -4 & \\
\hline \multirow{2}{*}{$\begin{array}{l}30 \text { de octubre } \\
2016\end{array}$} & \multirow[b]{2}{*}{$\begin{array}{l}\text { Dato curioso sobre el tour de } \\
\text { noche. } \\
\text { Texto: Dato tenebroso del } \\
\text { Real Felipe: } \\
\text { Cuando José Ramón Rodil, } \\
\text { Comandante Militar de las } \\
\text { fuerzas del Callao, se rehúsa } \\
\text { a aceptar la independencia } \\
\text { del Perú (1824), este se } \\
\text { encierra en la Fortaleza del } \\
\text { Real Felipe con } 13 \text { mil } \\
\text { personas entre militares y } \\
\text { civiles, casi dos años } \\
\text { después este se rinde y de la } \\
\text { Fortaleza solo salen } 400 \\
\text { personas. } \\
\text { Las otras } 12.600 \text { aún siguen } \\
\text { ahí. Esperándote. } \\
31 \text { de octubre, recorrido } \\
\text { nocturno. }\end{array}$} & Comentarios & Positivo & $\square$ & \multirow[t]{2}{*}{672} \\
\hline & & Likes & & 15 & \\
\hline \multirow{2}{*}{$\begin{array}{l}15 \mathrm{de} \\
\text { noviembre } 2016\end{array}$} & \multirow{2}{*}{$\begin{array}{l}\text { Evento Tour de noche } \\
\text { (compartido del Facebook } \\
\text { de "Los misterios del Real } \\
\text { Felipe") }\end{array}$} & Comentarios & Positivo & 4 & \multirow[t]{2}{*}{345} \\
\hline & & Likes & & 1 & \\
\hline \multirow{2}{*}{$\begin{array}{l}15 \mathrm{de} \\
\text { noviembre } 2016\end{array}$} & \multirow{2}{*}{$\begin{array}{l}\text { Video Tour de noche } \\
\text { Texto: Este viernes } 18 \text { de } \\
\text { noviembre. }\end{array}$} & Likes & & 1 & \multirow[t]{2}{*}{670} \\
\hline & & Reproducciones & & 2.376 & \\
\hline $26 \mathrm{de}$ & Post en el cual se comparte & Likes & & 1 & 315 \\
\hline
\end{tabular}




\begin{tabular}{|c|c|c|c|c|c|}
\hline noviembre 2016 & $\begin{array}{l}\text { la página de "Los misterios } \\
\text { del Real Felipe" } \\
\text { Texto: Hoy sábado } 26 \text { de } \\
\text { noviembre - Recorrido } \\
\text { nocturno }\end{array}$ & & & & \\
\hline \multirow{2}{*}{$\begin{array}{l}1 \text { de diciembre } \\
2016\end{array}$} & \multirow{2}{*}{$\begin{array}{l}\text { Foto Tour de noche } \\
\text { (compartido del Facebook } \\
\text { de "Los misterios del Real } \\
\text { Felipe") } \\
\text { Texto: No te lo pierdas. }\end{array}$} & Comentarios & Neutro & 4 & \multirow[t]{2}{*}{400} \\
\hline & & Likes & & 8 & \\
\hline $\begin{array}{l}13 \text { de enero } \\
2017\end{array}$ & $\begin{array}{l}\text { Evento Tour de noche } \\
\text { Primer tour del } 2017 \\
\text { (compartido del Facebook } \\
\text { de "Los misterios del Real } \\
\text { Felipe") }\end{array}$ & Likes & & 26 & 415 \\
\hline \multirow{4}{*}{$\begin{array}{l}27 \text { de enero } \\
2017\end{array}$} & \multirow{4}{*}{$\begin{array}{l}\text { Video Tour de noche } \\
\text { Texto: Mañana } 28 \text { de enero, } \\
\text { recorrido nocturno. No te lo } \\
\text { pierdas. } \\
\text { Los misterios del Real } \\
\text { Felipe }\end{array}$} & Comentarios & Positivo & 1 & \multirow[t]{4}{*}{319} \\
\hline & & & Neutro & 2 & \\
\hline & & Likes & & 17 & \\
\hline & & Reproducciones & & 2,376 & \\
\hline $\begin{array}{l}31 \text { de enero } \\
2017\end{array}$ & $\begin{array}{l}\text { Evento Tour de noche } \\
\text { (compartido del Facebook } \\
\text { de "Los misterios del Real } \\
\text { Felipe") }\end{array}$ & $r=2$ & & 24 & 613 \\
\hline \multirow{4}{*}{$\begin{array}{l}16 \text { de febrero } \\
2017\end{array}$} & \multirow{4}{*}{$\begin{array}{l}\text { Video Tour de noche } \\
\text { Texto: Mañana viernes } 17 \mathrm{de} \\
\text { febrero y el sábado } 4 \text { de } \\
\text { marzo RECORRIDO } \\
\text { NOCTURNO. } \\
\text { Los misterios del Real } \\
\text { Felipe }\end{array}$} & \multirow{2}{*}{ Comentarios } & Positivo & 2 & \multirow[t]{4}{*}{241} \\
\hline & & & Neutro & 2 & \\
\hline & & Likes & & 13 & \\
\hline & & Reproducciones & & 2,376 & \\
\hline \multirow{2}{*}{$\begin{array}{l}26 \text { de febrero } \\
2017\end{array}$} & Post de Tour de noche & Comentarios & Neutro & 3 & \multirow[t]{2}{*}{170} \\
\hline & $\begin{array}{l}\text { Texto: Mañana tour } \\
\text { nocturno. }\end{array}$ & Likes & & 5 & \\
\hline \multirow{4}{*}{$\begin{array}{l}22 \text { de marzo } \\
2017\end{array}$} & \multirow{4}{*}{$\begin{array}{l}\text { Texto: Siga a su guía, no se } \\
\text { separe, fíjese por dónde } \\
\text { camina, no haga caso a las } \\
\text { voces, identifique a los } \\
\text { vivos, no se desespere, } \\
\text { ubique las salidas. }\end{array}$} & Comentarios & Neutro & 3 & \multirow[t]{4}{*}{696} \\
\hline & & Likes & & 29 & \\
\hline & & & & $3 \mathrm{c}$ & \\
\hline & & & & & \\
\hline $\begin{array}{l}25 \text { de marzo } \\
2017\end{array}$ & $\begin{array}{l}\text { Post de Tour de noche } \\
\text { Texto: Hoy tour nocturno. } \\
\text { 7pm. }\end{array}$ & Likes & & 4 & 151 \\
\hline \multirow{2}{*}{$\begin{array}{l}31 \text { de marzo } \\
2017\end{array}$} & \multirow[b]{2}{*}{$\begin{array}{l}\text { Post y foto de Tour de noche } \\
\text { Texto: Hoy 07:00 pm tour } \\
\text { nocturno en el Real Felipe. } \\
\text { Solo para mayores de } 18 \\
\text { años si ve alguna persona } \\
\text { menor ignórela y aléjese. }\end{array}$} & Comentarios & Positivo & 1 & \multirow[t]{2}{*}{1,100} \\
\hline & & Likes & & 12 & \\
\hline 7 de abril 2017 & Evento Tour de noche & Comentarios & Neutro & 7 & 792 \\
\hline
\end{tabular}




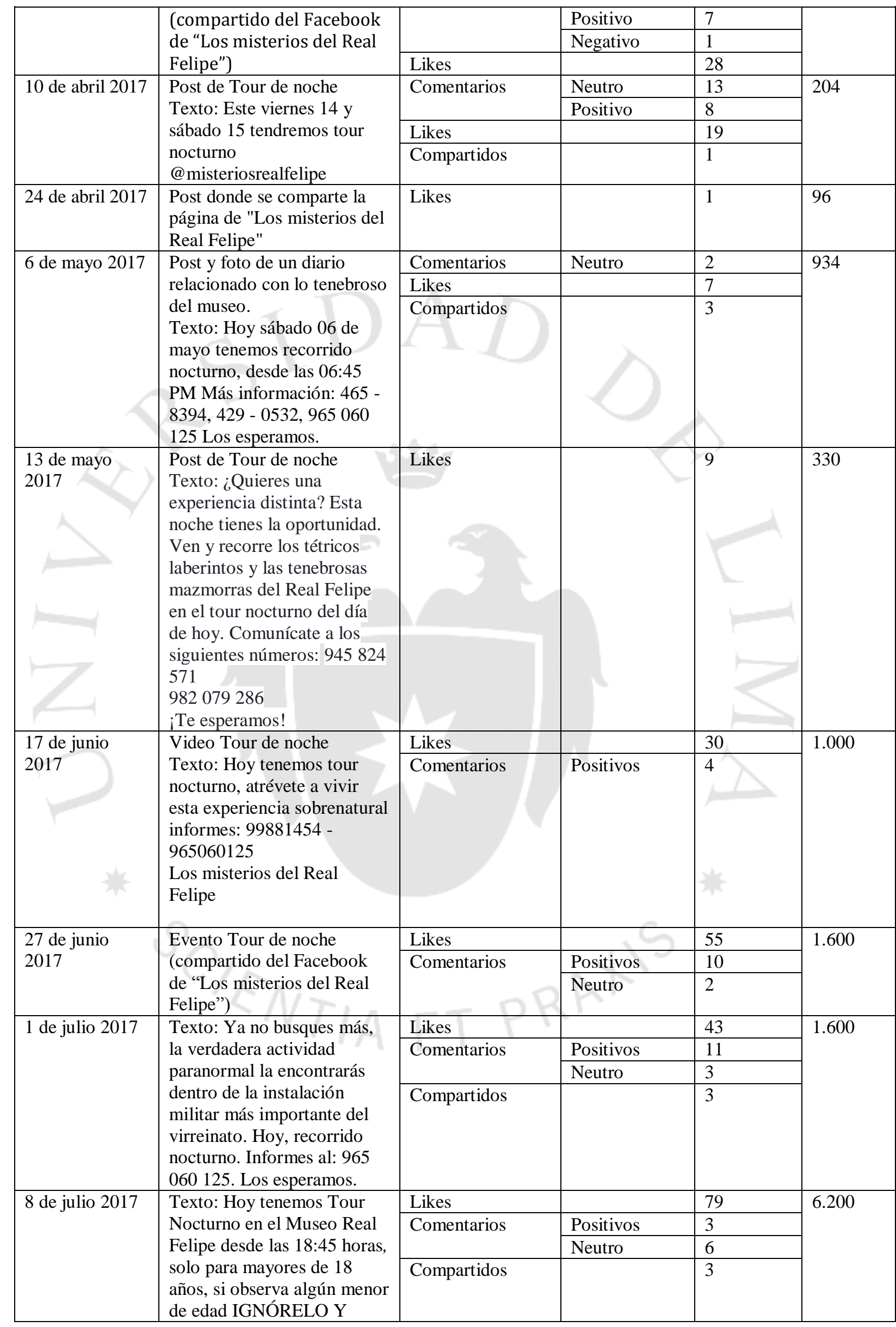




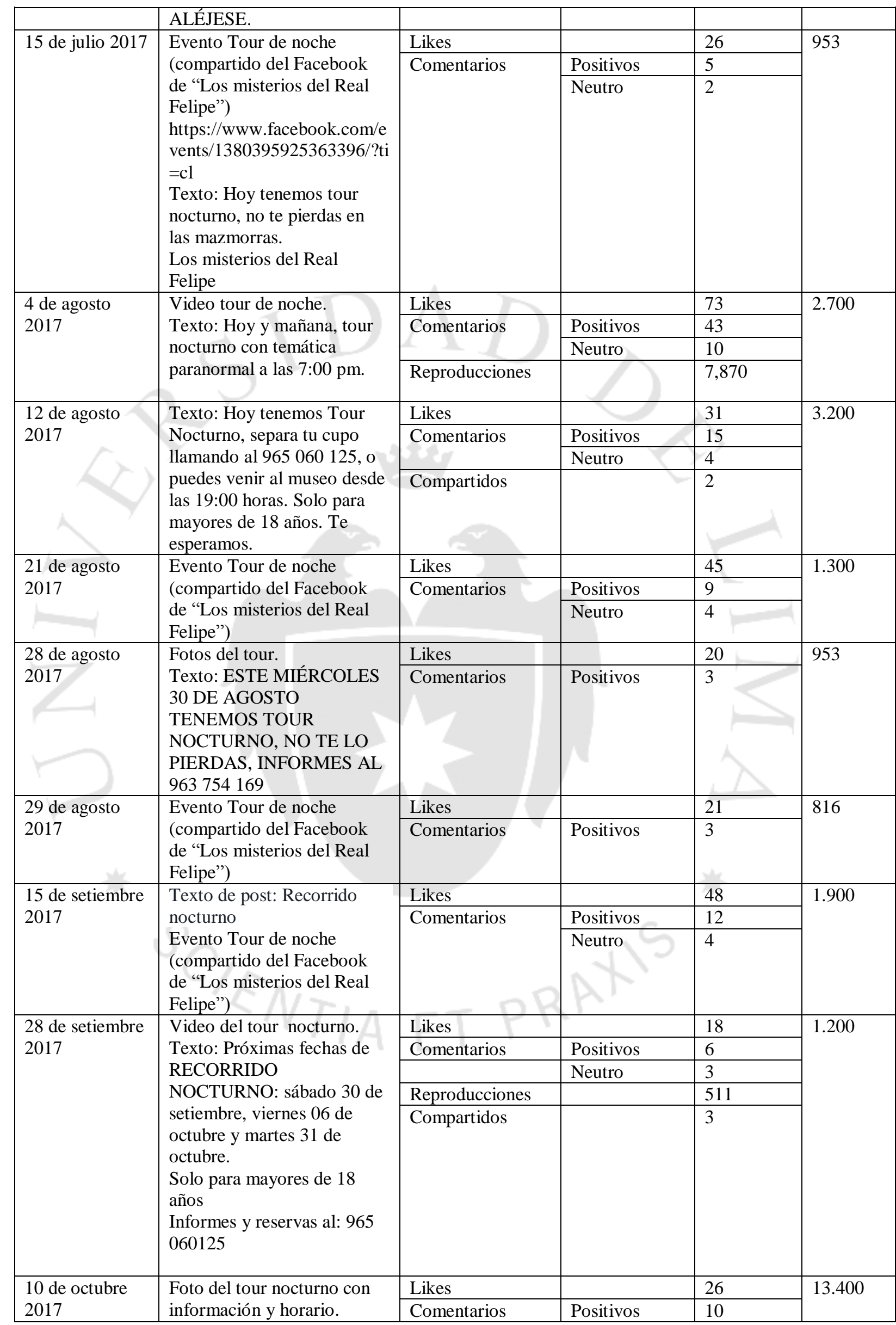




\begin{tabular}{|c|c|c|c|c|c|}
\hline & & Compartidos & & 7 & \\
\hline \multirow{3}{*}{$\begin{array}{l}25 \text { de octubre } \\
2017\end{array}$} & \multirow{3}{*}{$\begin{array}{l}\text { Foto del tour nocturno con } \\
\text { información y horario. }\end{array}$} & Likes & & 22 & \multirow[t]{3}{*}{18.600} \\
\hline & & Comentarios & Positivos & 5 & \\
\hline & & Compartidos & & 7 & \\
\hline \multirow{2}{*}{$\begin{array}{l}27 \text { de octubre } \\
2017\end{array}$} & \multirow{2}{*}{$\begin{array}{l}\text { Evento Tour de noche } \\
\text { Halloween (compartido del } \\
\text { Facebook de "Los misterios } \\
\text { del Real Felipe") }\end{array}$} & Likes & & 16 & \multirow[t]{2}{*}{21.300} \\
\hline & & Comentarios & Positivos & 1 & \\
\hline \multirow{3}{*}{$\begin{array}{l}3 \text { de noviembre } \\
2017\end{array}$} & \multirow{3}{*}{$\begin{array}{l}\text { Texto: Mañana sábado } 04 \text { de } \\
\text { noviembre, informes al } 963 \\
754169 \text {. }\end{array}$} & Likes & & 19 & \multirow[t]{3}{*}{1.300} \\
\hline & & Comentarios & Positivos & 4 & \\
\hline & & Compartidos & & 4 & \\
\hline \multirow{4}{*}{$\begin{array}{l}14 \mathrm{de} \\
\text { noviembre } 2017\end{array}$} & \multirow{4}{*}{$\begin{array}{l}\text { Foto del tour nocturno con } \\
\text { información y horario. }\end{array}$} & Likes & & 78 & \multirow[t]{4}{*}{19.300} \\
\hline & & Comentarios & Positivos & 13 & \\
\hline & & & Neutros & 5 & \\
\hline & & Compartidos & & 7 & \\
\hline \multirow{4}{*}{$\begin{array}{l}20 \text { de } \\
\text { noviembre } 2017\end{array}$} & \multirow{4}{*}{$\begin{array}{l}\text { Foto del tour nocturno con } \\
\text { información y horario. }\end{array}$} & Likes & Pre & 52 & \multirow[t]{4}{*}{4.000} \\
\hline & & Comentarios & Positivos & 25 & \\
\hline & & & Neutros & 7 & \\
\hline & & Compartidos & & 4 & \\
\hline \multirow{3}{*}{$\begin{array}{l}22 \text { de marzo } \\
2018\end{array}$} & \multirow[b]{3}{*}{$\begin{array}{l}\text { Evento Tour de noche } \\
\text { (compartido del Facebook } \\
\text { de "Los misterios del Real } \\
\text { Felipe") } \\
\text { Texto: Este sábado } 24 \text { de } \\
\text { marzo ven y conoce el lado } \\
\text { tenebroso de nuestra } \\
\text { Fortaleza recorriendo sus } \\
\text { laberintos y mazmorras en } \\
\text { donde se suscitaron } \\
\text { diferentes torturas. } \\
\text { Para mayor información y } \\
\text { reservas llamar a los } \\
\text { números: } 996256648 \text { // } \\
\text { (01) } 4658394 \\
\text { ¡Los esperamos! }\end{array}$} & Likes & & 100 & \multirow[t]{3}{*}{1.200} \\
\hline & & Comentarios & Positivos & 28 & \\
\hline & & & Neutros & 8 & \\
\hline \multirow[t]{3}{*}{12 de abril 2018} & \multirow[b]{3}{*}{$\begin{array}{l}\text { Evento Tour de noche } \\
\text { (compartido del Facebook } \\
\text { de "Los misterios del Real } \\
\text { Felipe") } \\
\text { Texto: Una vez más nuestras } \\
\text { puertas se abren de noche } \\
\text { para conocer los relatos más } \\
\text { aterradores y crueles de } \\
\text { nuestra historia. Siendo la } \\
\text { Fortaleza Real Felipe testigo } \\
\text { de múltiples torturas por la } \\
\text { corona española a quienes } \\
\text { iban en su contra. } \\
\text { ¡Ven! Y conoce los } \\
\text { calabozos y mazmorras en } \\
\text { donde se suscitaron todos } \\
\text { estos acontecimientos. } \\
\text { Te esperamos. } \\
\text { Para mayor información y } \\
\text { reservas llamar a los } \\
\text { números: } 996256648 \text { o al } \\
\text { (01) } 4658394\end{array}$} & Likes & & 115 & \multirow[t]{3}{*}{1.700} \\
\hline & & Comentarios & Positivos & 54 & \\
\hline & & & Neutros & 10 & \\
\hline
\end{tabular}




\section{Anexo 9: Imágenes de las publicaciones}

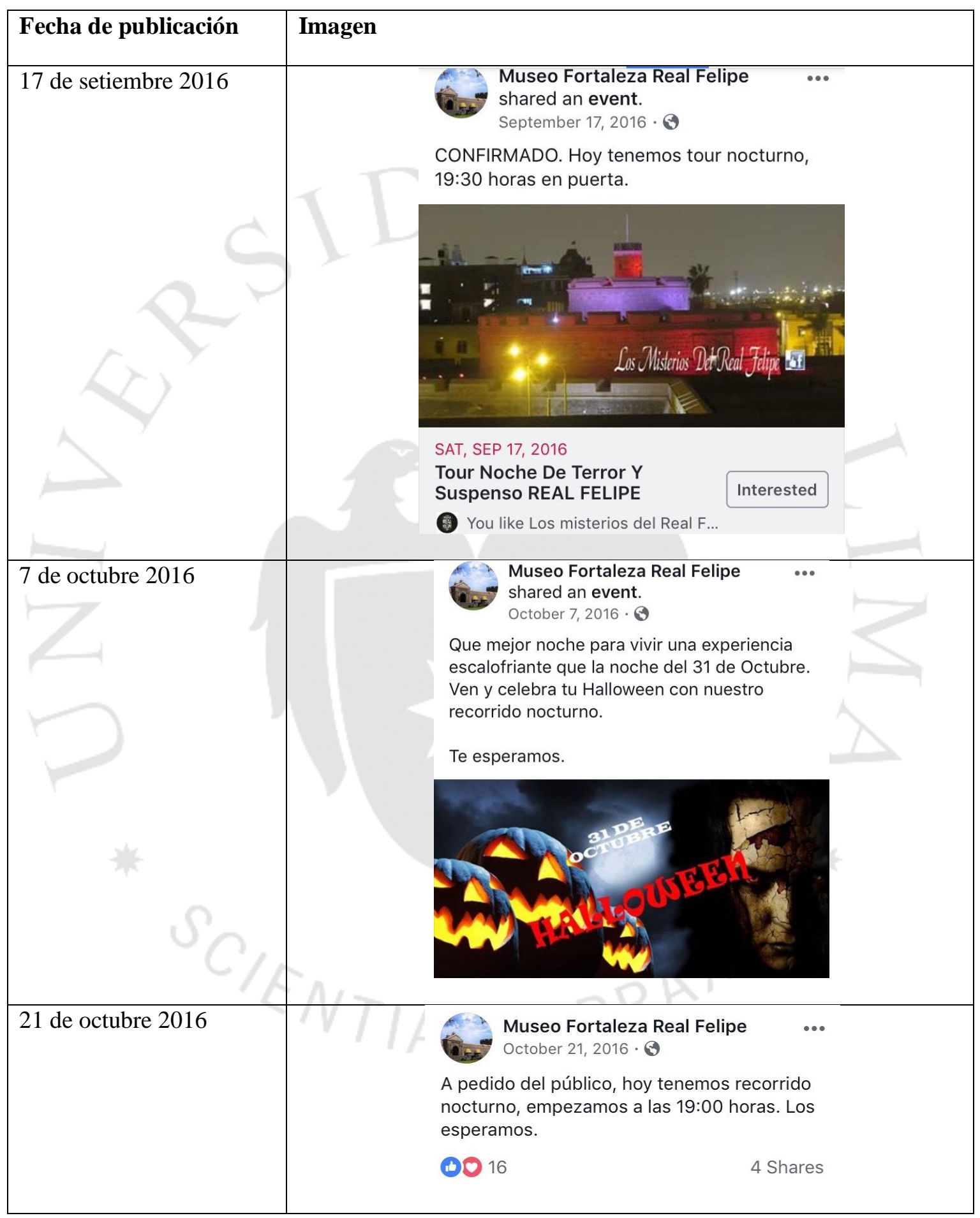




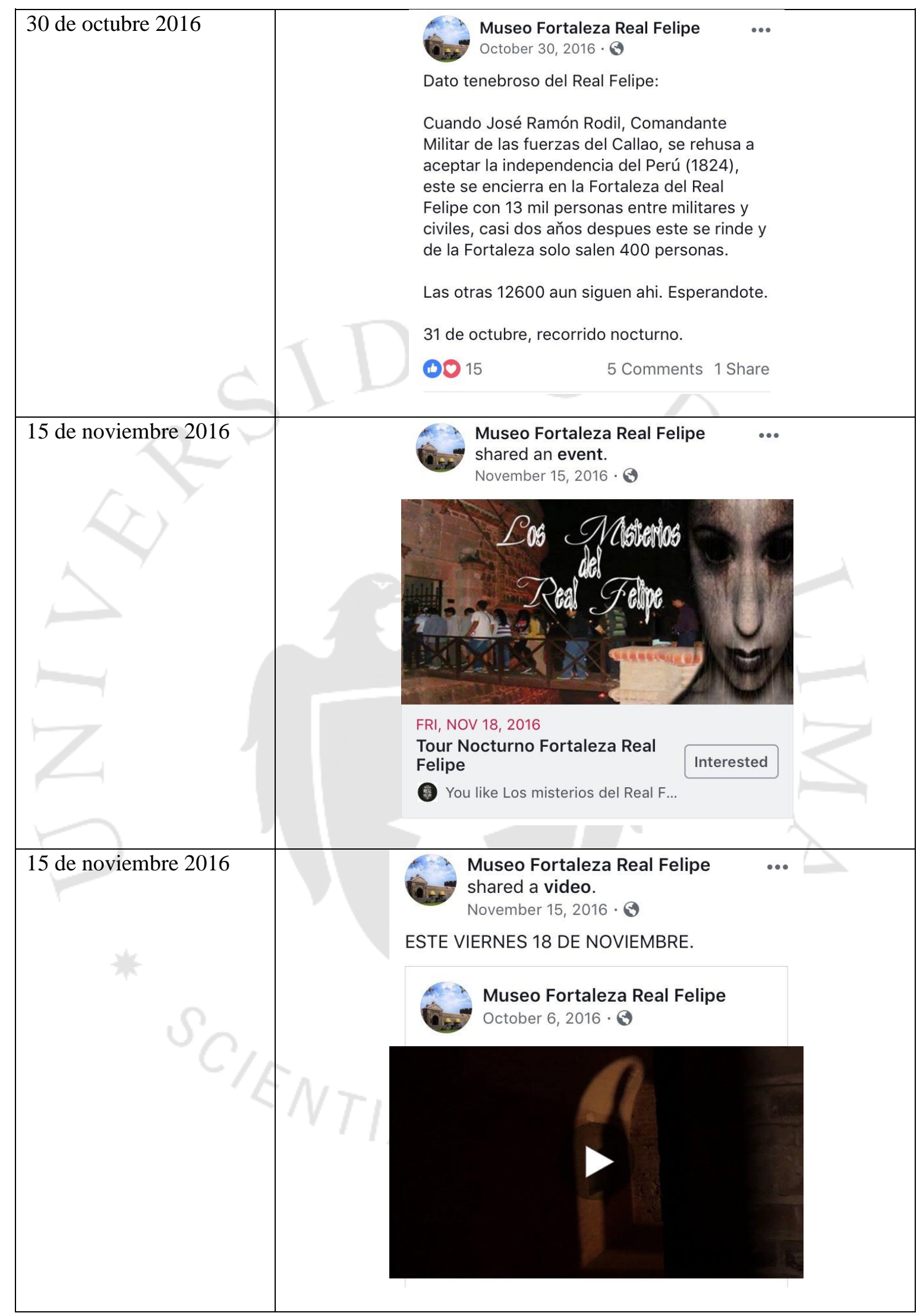




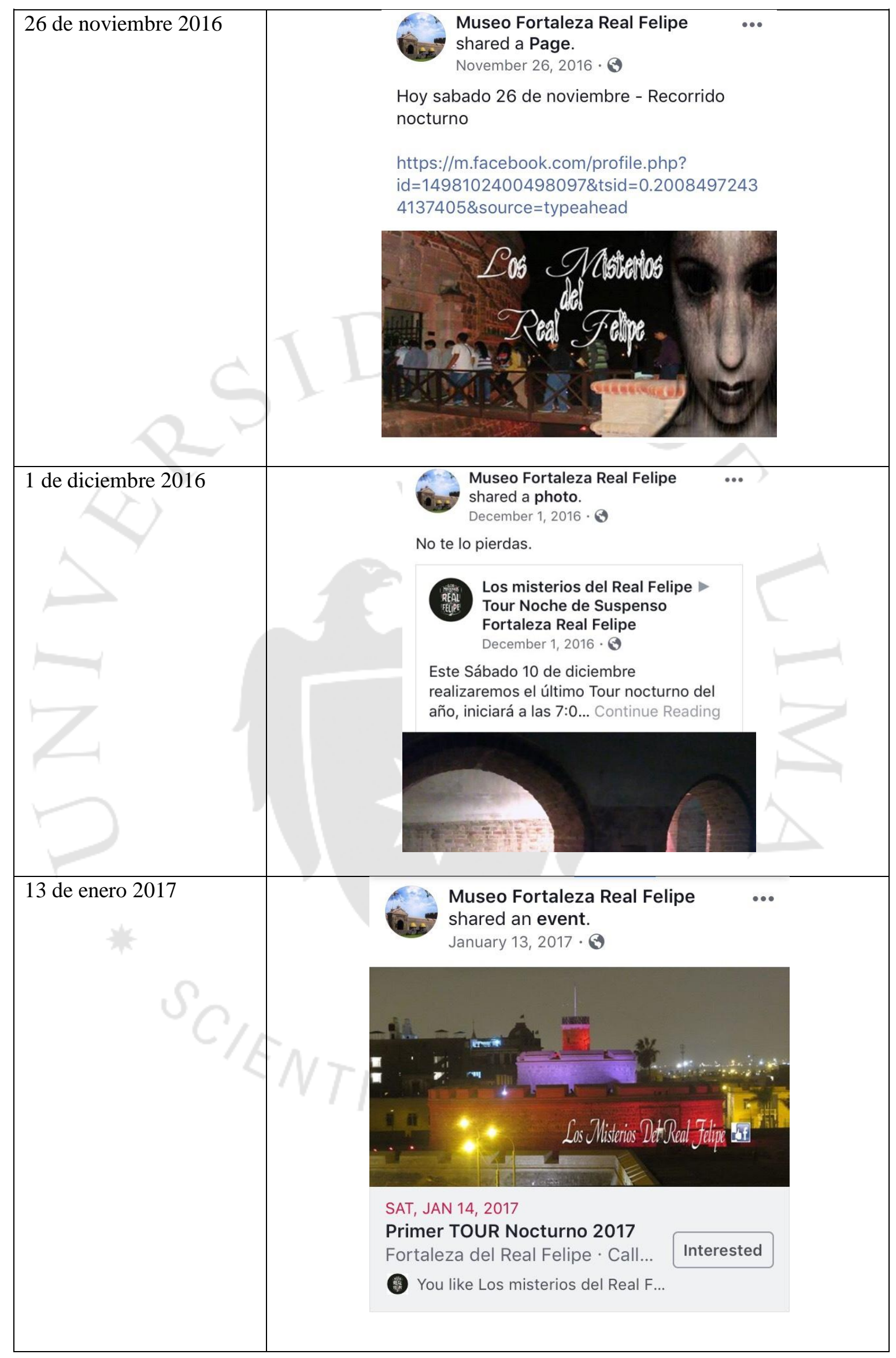




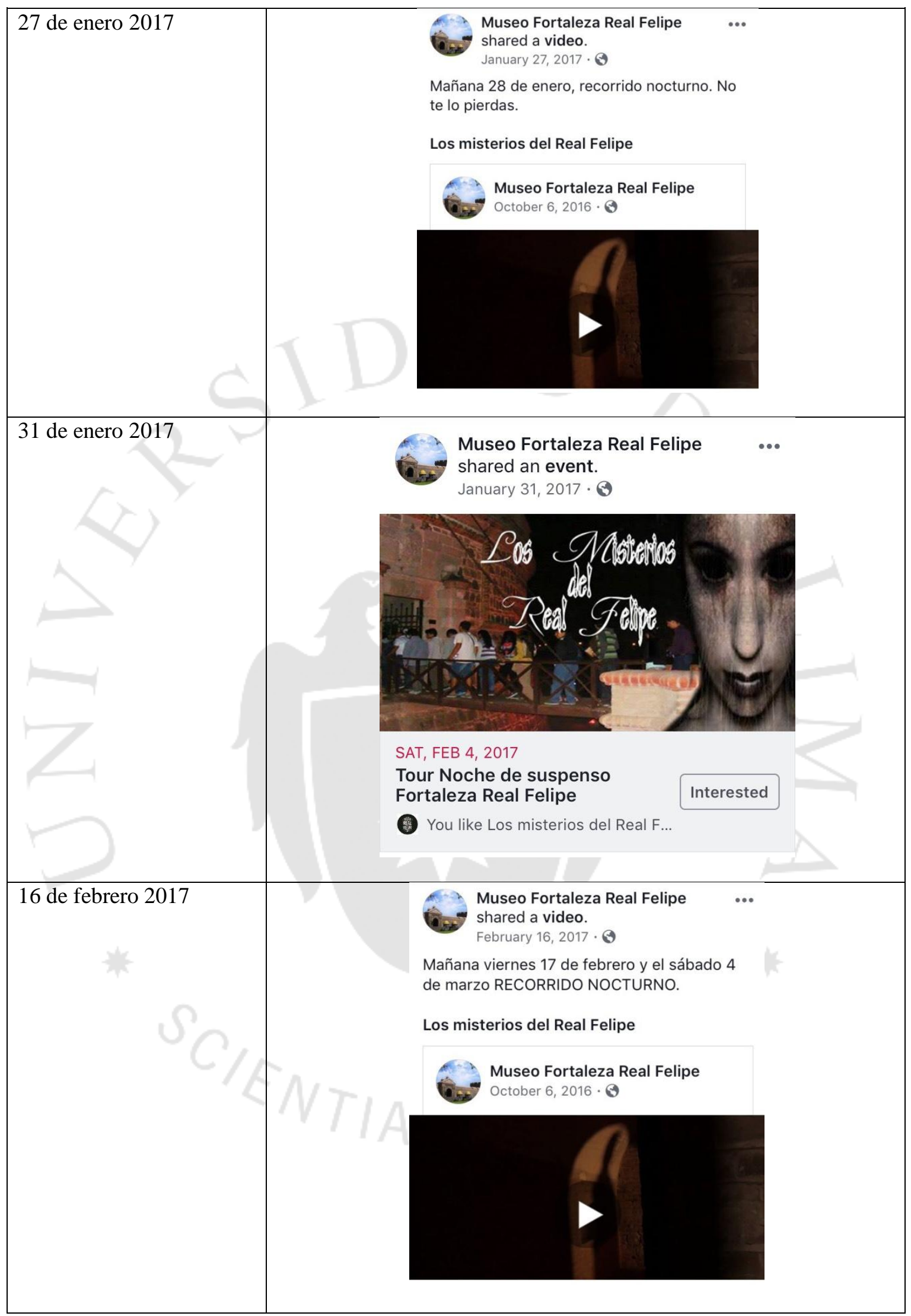




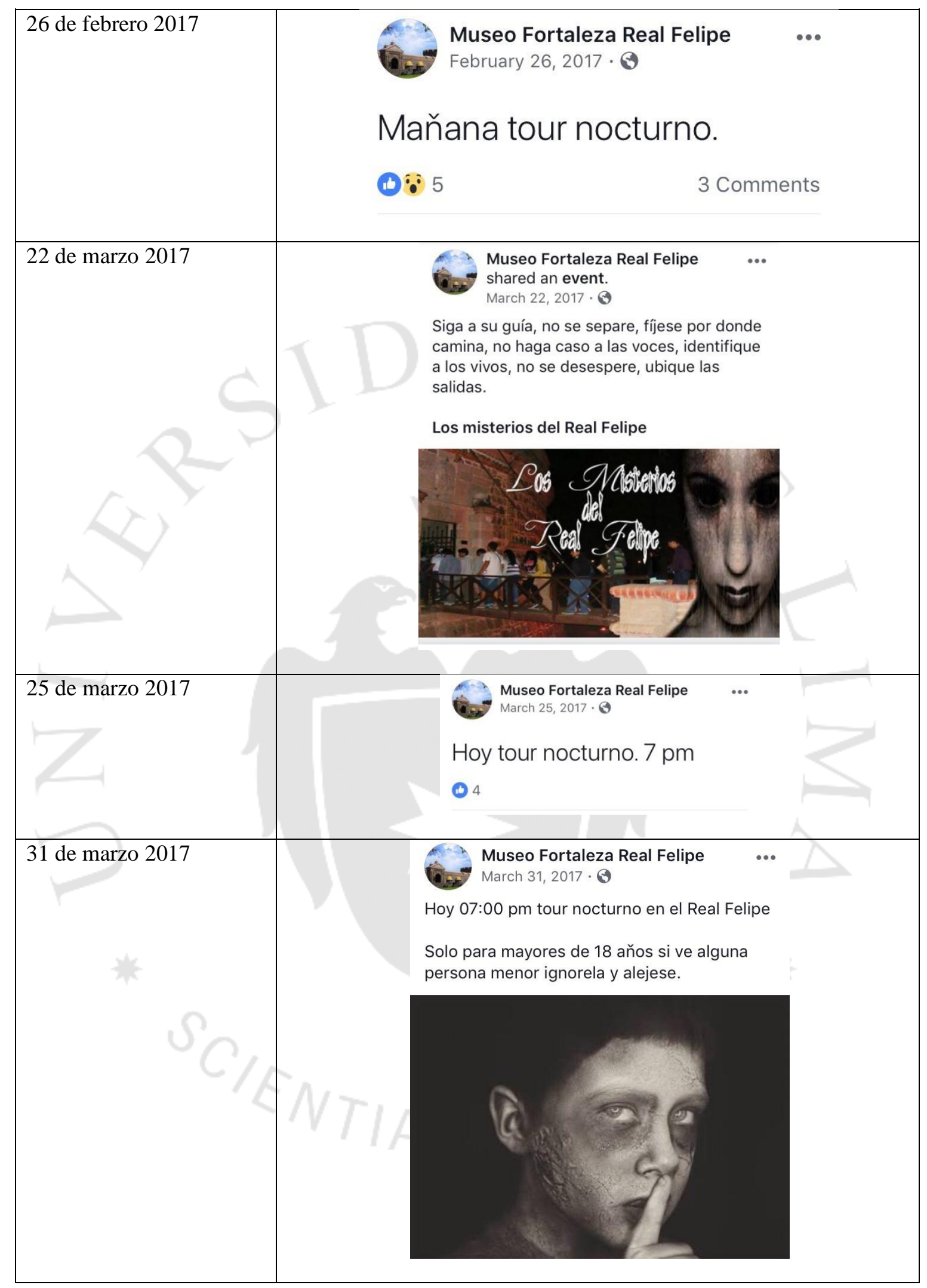




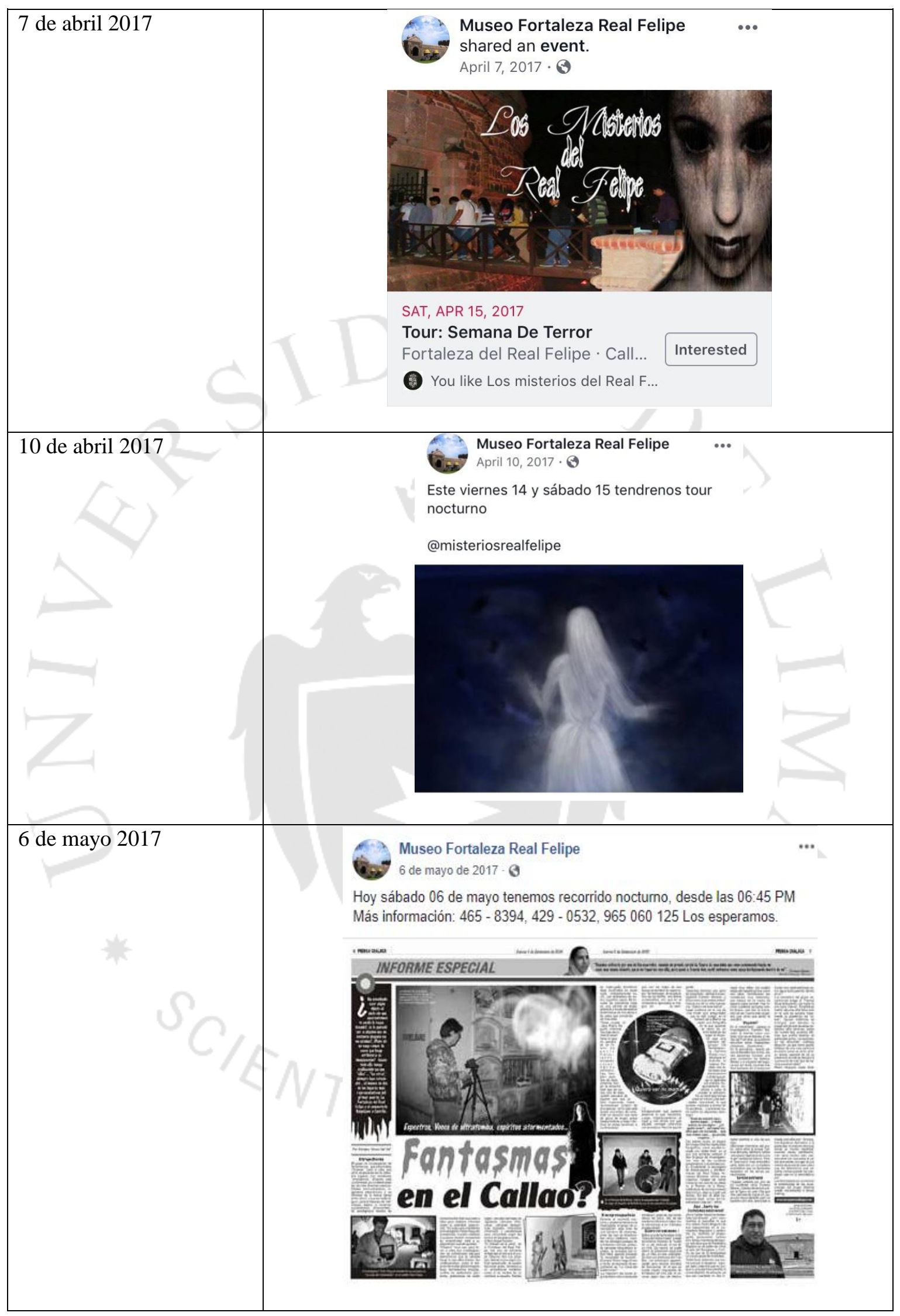




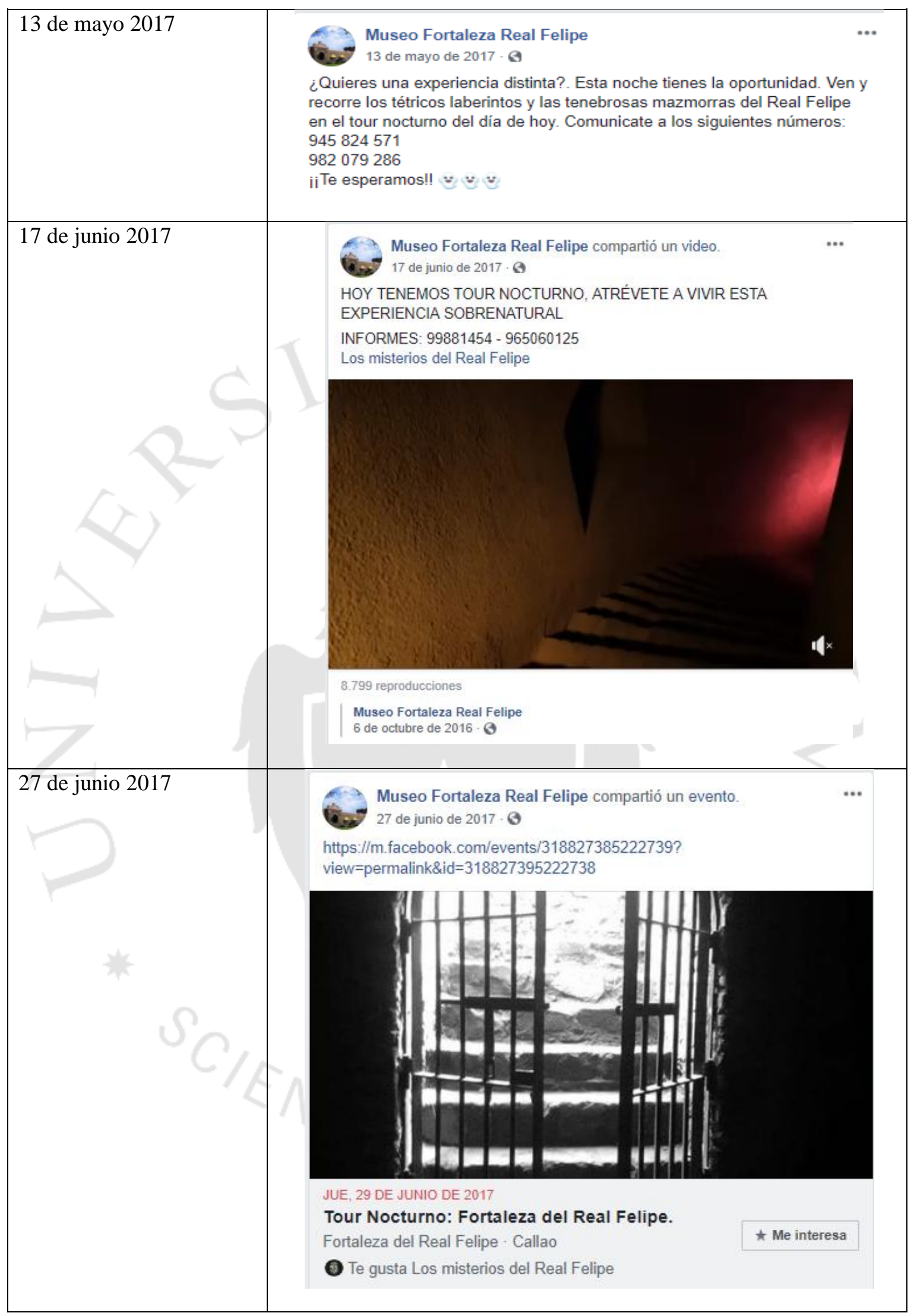




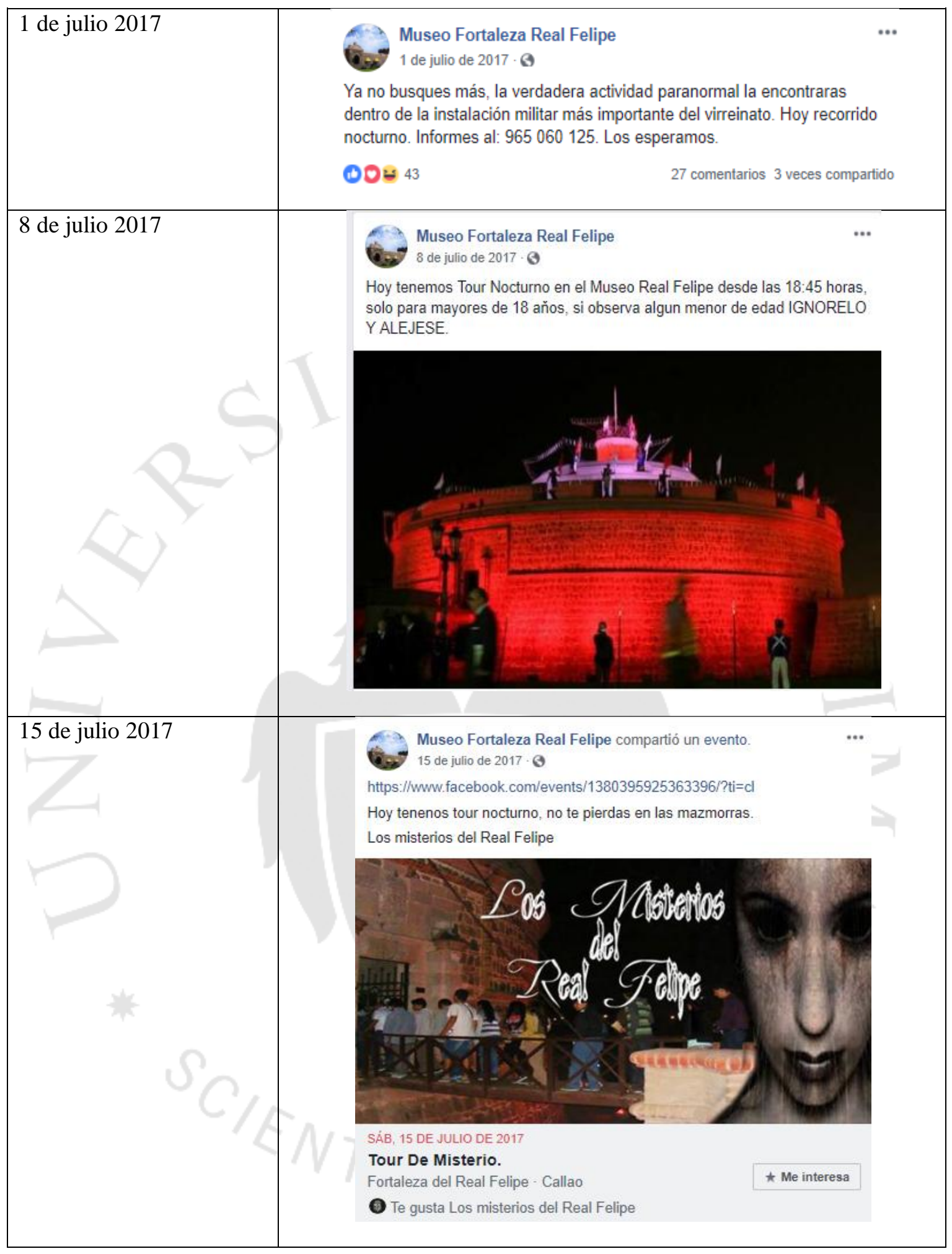




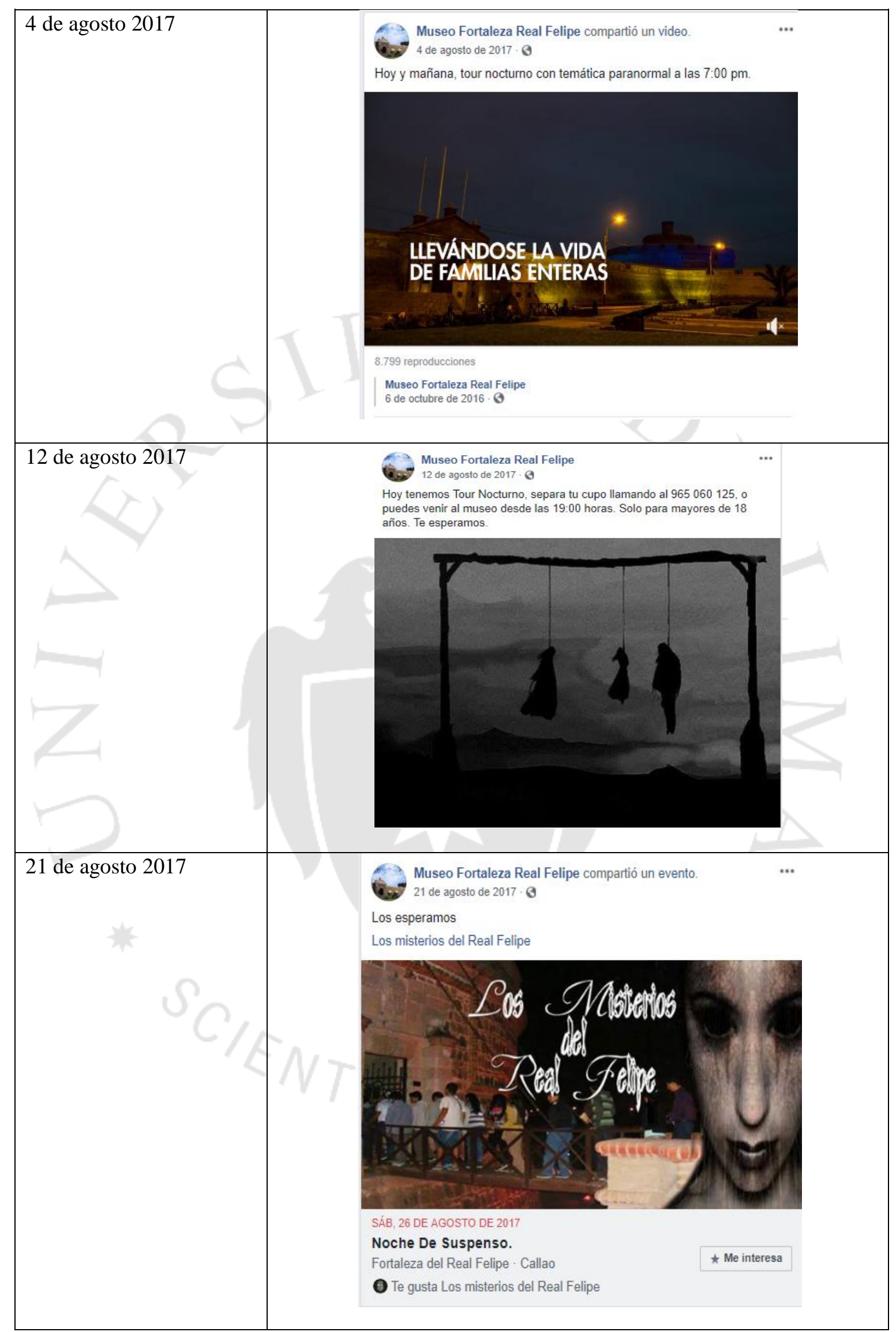




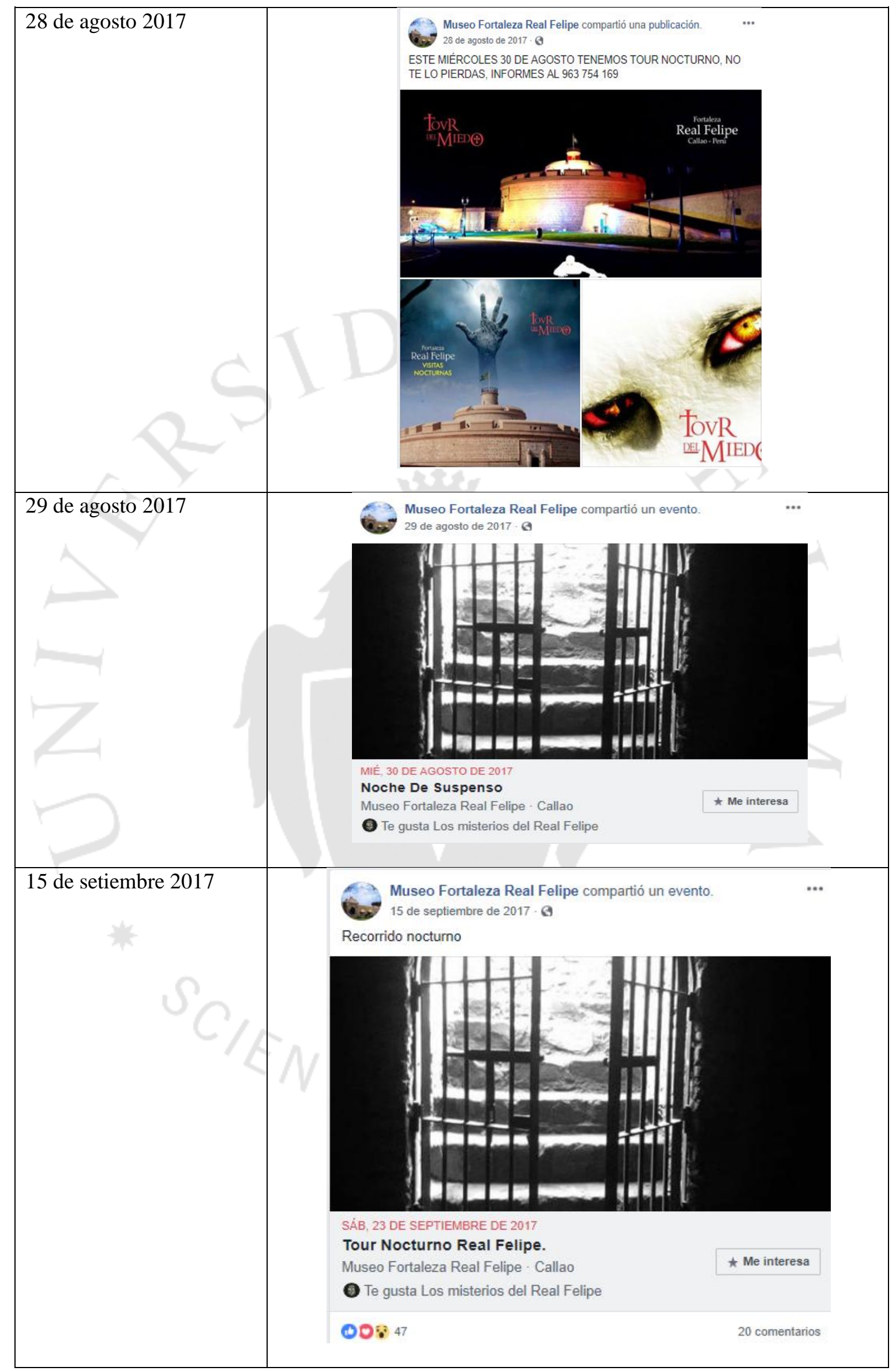




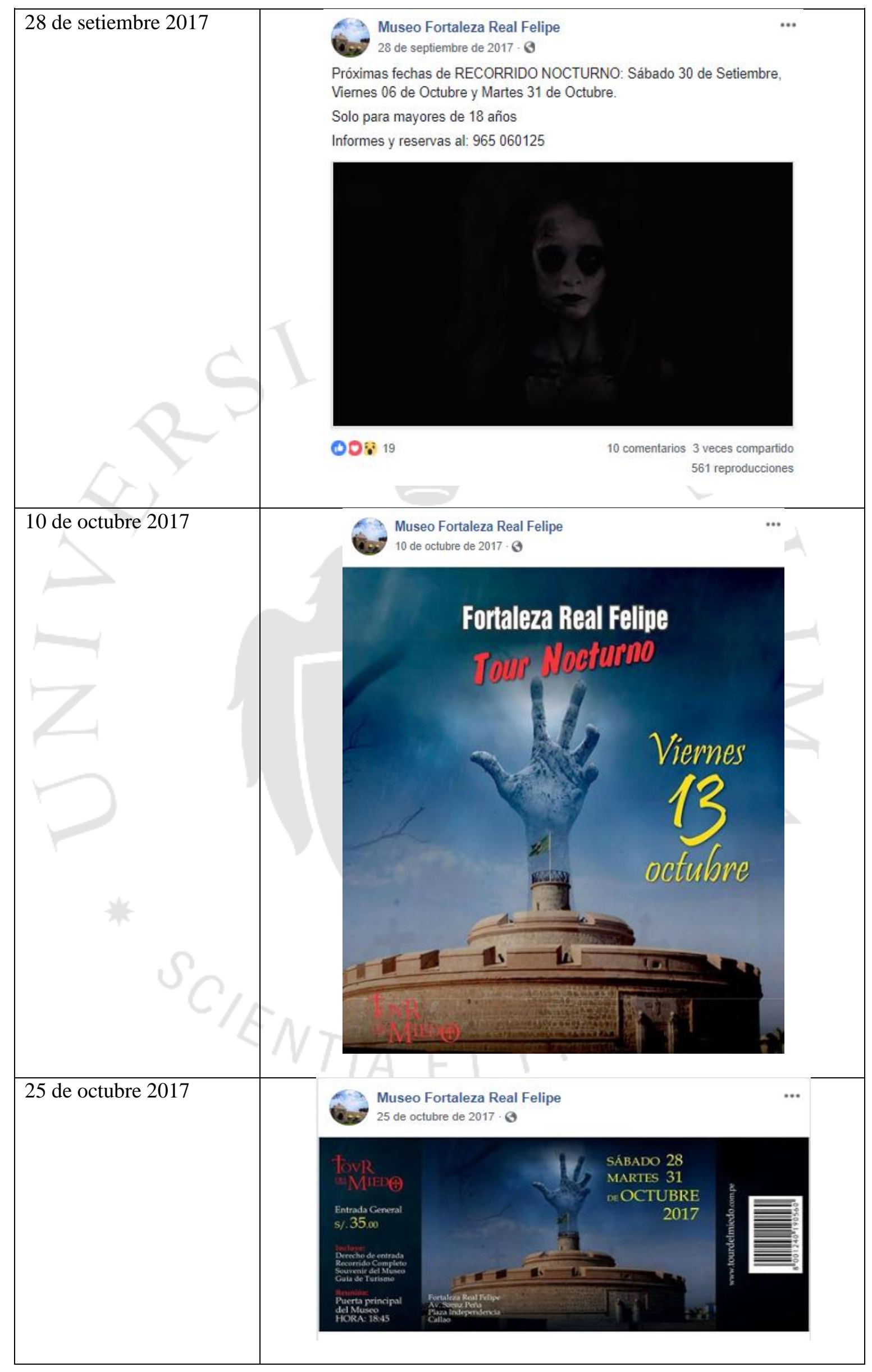




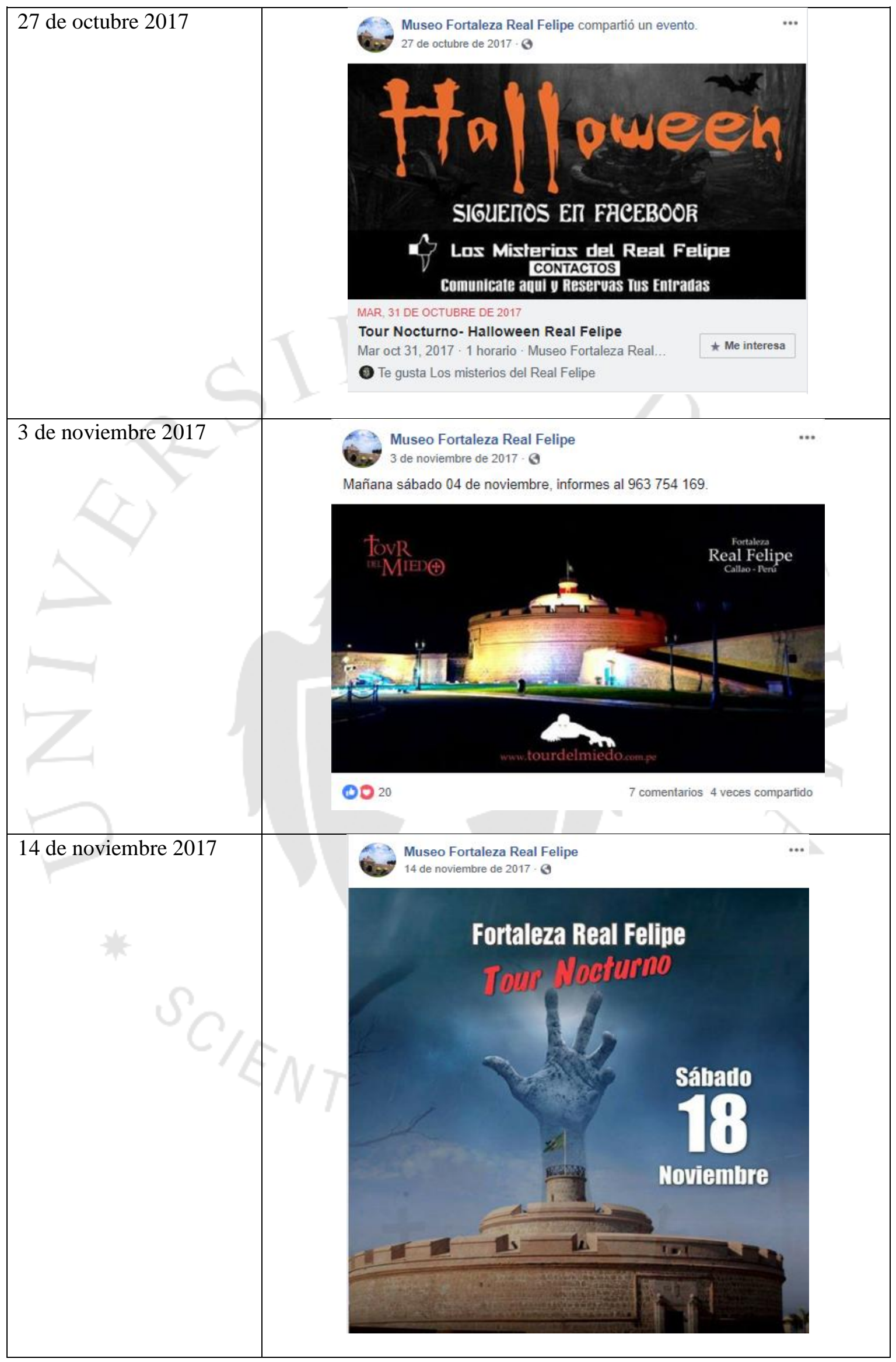




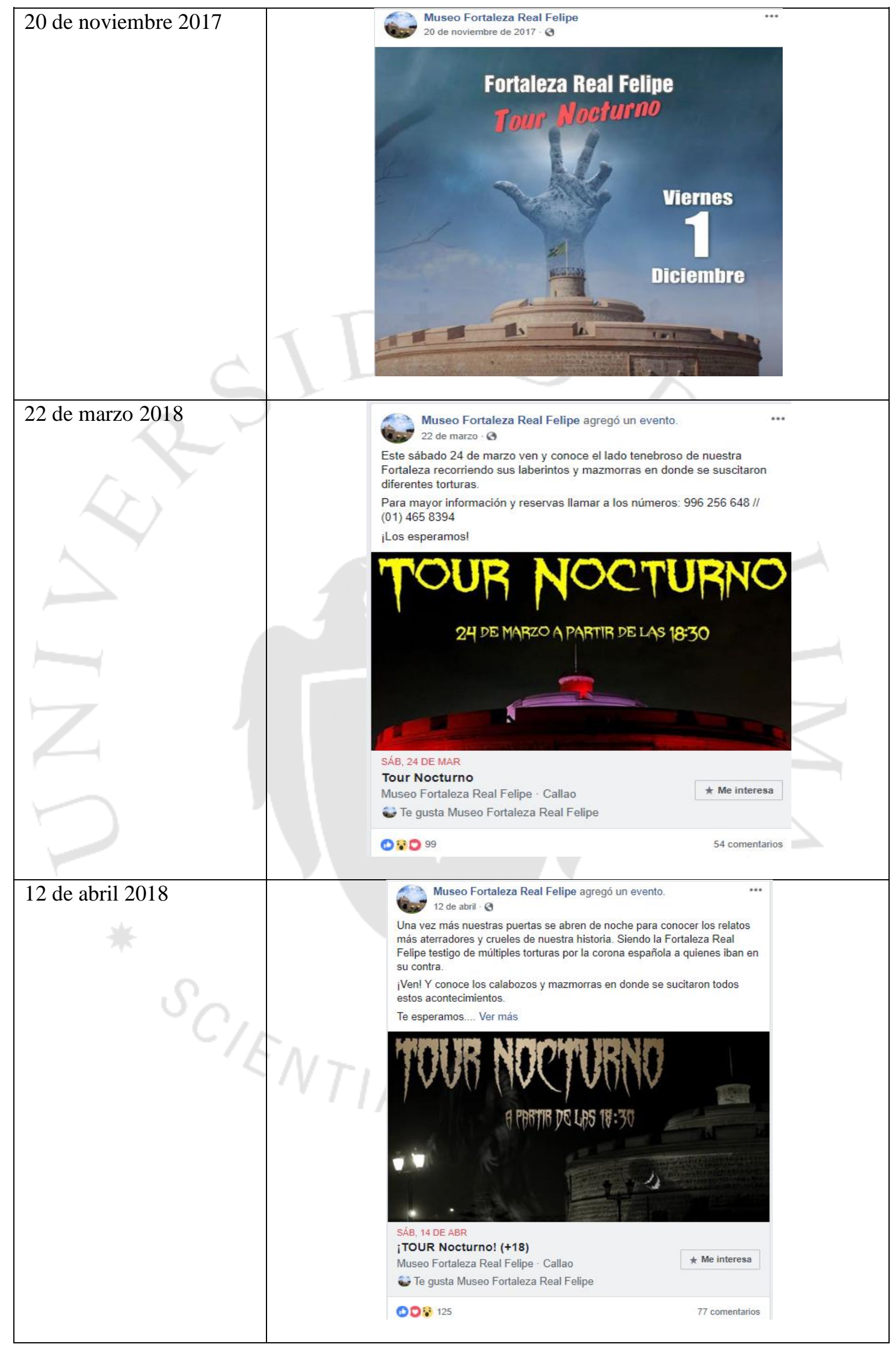

